\title{
WestVirginiaUniversity
}

THE RESEARCH REPOSITORY @ WVU

Graduate Theses, Dissertations, and Problem Reports

2008

\section{Effects of alternative -food sources on operant behavior}

\author{
Raquel Moreira Alo \\ West Virginia University
}

Follow this and additional works at: https://researchrepository.wvu.edu/etd

\section{Recommended Citation}

Alo, Raquel Moreira, "Effects of alternative -food sources on operant behavior" (2008). Graduate Theses, Dissertations, and Problem Reports. 2685.

https://researchrepository.wvu.edu/etd/2685

This Dissertation is protected by copyright and/or related rights. It has been brought to you by the The Research Repository @ WVU with permission from the rights-holder(s). You are free to use this Dissertation in any way that is permitted by the copyright and related rights legislation that applies to your use. For other uses you must obtain permission from the rights-holder(s) directly, unless additional rights are indicated by a Creative Commons license in the record and/ or on the work itself. This Dissertation has been accepted for inclusion in WVU Graduate Theses, Dissertations, and Problem Reports collection by an authorized administrator of The Research Repository @ WVU.

For more information, please contact researchrepository@mail.wvu.edu. 


\title{
Effects of Alternative-Food Sources on Operant Behavior
}

\author{
Raquel Moreira Aló
}

\begin{abstract}
Dissertation submitted to the
College of Arts and Sciences

At West Virginia University in partial fulfillment of the requirements for the degree of Doctor of Philosophy

in Psychology
\end{abstract}

\author{
Kennon A. Lattal, Ph.D., Chair \\ Michael Perone, Ph.D. \\ Claire St. Peter Pipkin, Ph.D. \\ Constance Toffle, Ph.D \\ Oliver Wirth, Ph.D.
}

\author{
Department of Psychology \\ Morgantown, West Virginia \\ 2008
}

Keywords: Pigeon, alternative-food source, VI schedule, FI schedule, VT schedule, FT schedule, response rates, response patterns 


\section{ABSTRACT \\ Effects of Alternative-Food Sources on Operant Behavior}

Raquel Moreira Aló

To investigate how operant and alternative food arranged by different schedules interact to determine response rates and patterns when the sources of food are the same or different, six experiments were delineated. The effects of the number of food sources were investigated in Experiments 1-4. In Experiments 1 and 2, a variable-interval (VI) schedule was used to program the operant food, while the fixed-time (FT - Experiment 1) or the variable-time (VT - Experiment 2) alternative food was delivered from the same or a different source than that of the operant food. Experiments 3 and 4 were identical to Experiments 1 and 2, except that the operant food was arranged by a differentialreinforcement-of-low-rates (DRL) schedule. The effects of the schedule delivering the alternative food were investigated in Experiments 5 and 6. In Experiment 5, food arranged according to a FT or a VT schedule was superimposed to another source of that delivering the VI-scheduled food. In Experiment 6, the baseline schedule was DRL. Response rates were lower when the operant and alternative food were delivered from different sources, but did not differ systematically depending on the schedule delivering the alternative food. Response patterns were most commonly negatively accelerated when the alternative-food schedule was FT. Peaks during the first tenth of the alternativefood interval were also observed, and were more pronounced when the DRL was used to arrange the operant food. The results are discussed in terms the discriminative properties of the alternative-food presentations, determined by the temporal arrangement of this food, the schedule arranging the operant food, and the separation of alternative- and operant-food sources. 


\section{Acknowledgements}

I would like to thank Andy Lattal, for his support, patience, dedication, and his heavy use of positive reinforcement. His advising and friendship were invaluable, and made my graduate school experience (as was the case with all of his other students) extremely enriching and exciting. I feel very lucky and honored to have had Andy as my advisor.

I would also like to thank my committee members: Mike Perone, Claire St. Peter Pipkin, Constance Toffle, and Oliver Wirth, for their valuable feedback to improve this document, and the professors that provided me with such high-quality education in Behavior Analysis: Andy Lattal, Mike Perone, Claire St. Peter Pipkin, and Karen Anderson. I thank my friends and colleagues in graduate school for all I learned from them, and for being so cooperative and supportive: Megan Maxwell, Mirari Elkoro, Jessica Long, Harold Lobo, and Chata Dickson.

Agradeço também a minha família, principalmente meus pais, Tita e Mingo, e irmãos, Daniel, Clarisse e Mariana, pelo apoio incondicional e amor, e por sempre me estimularem a tentar ser uma pessoa melhor. Megan e Toquinho Maxwell, minha família Americana, também me ofereceram apoio ao qual nunca poderei agradecer o suficiente, e mudaram a minha vida imensamente. Amo vocês. Finalmente, agradeço ao Carlos por sua doçura, lealdade, dedicação e amor. Você é um presente na minha vida, bonito. 
Table of Contents

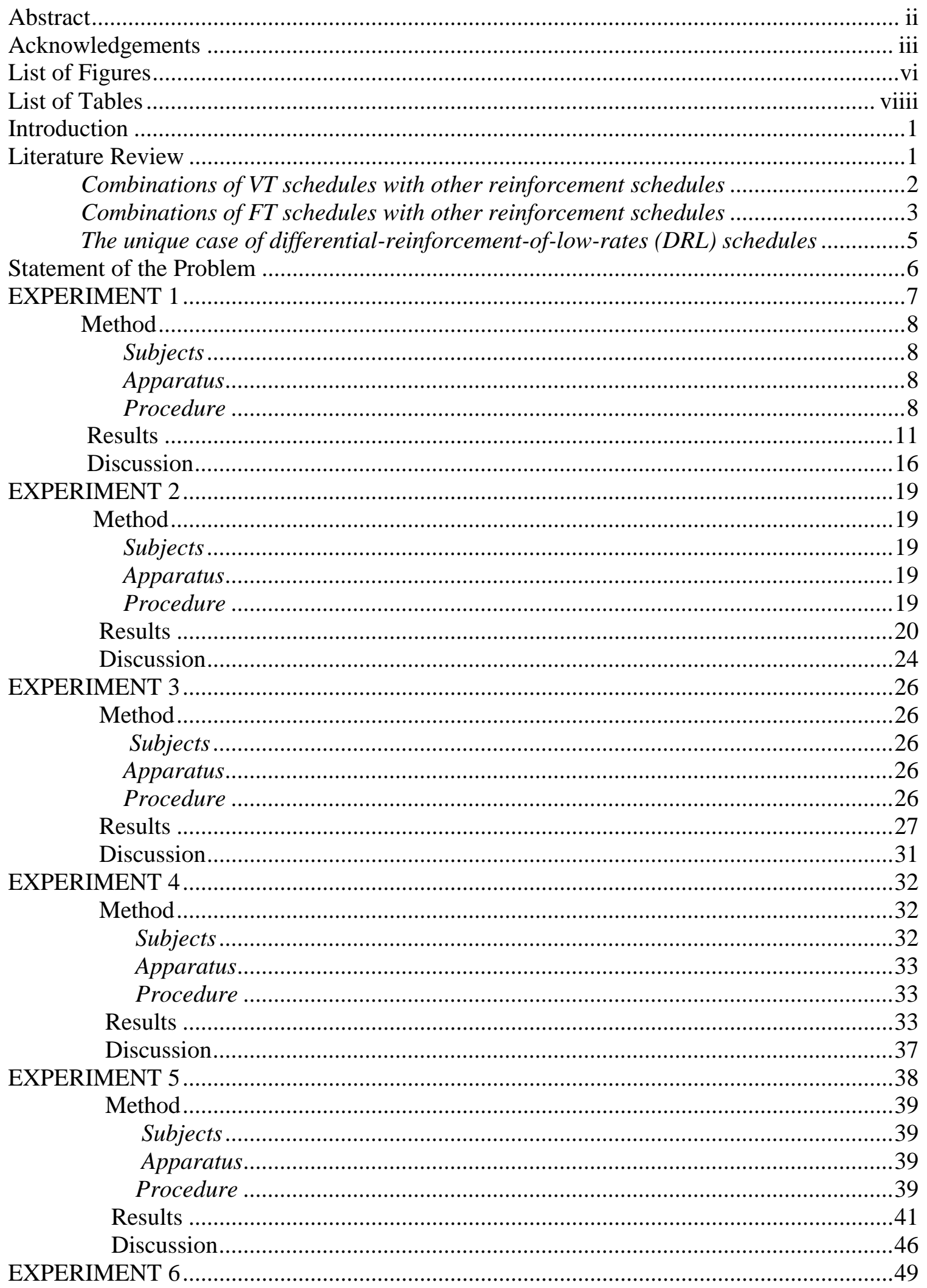




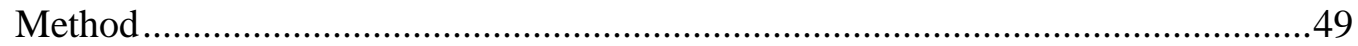

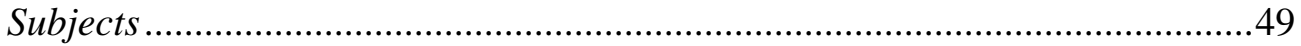

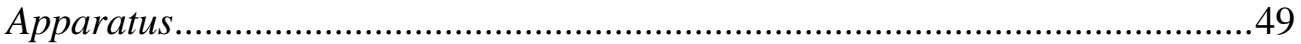

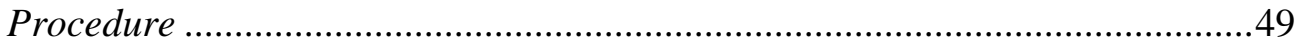

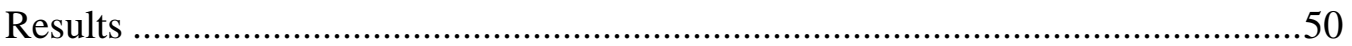

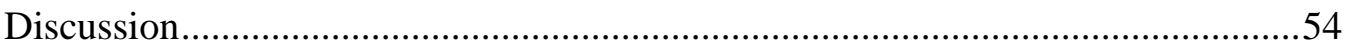

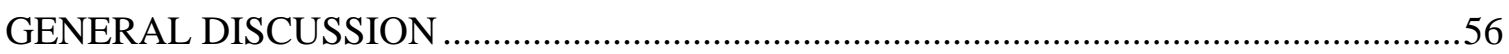

Effects of the Schedules And The Number Of Sources Delivering The Operant And

Alternative Food ............................................................................................56

Combinations Of Operant- And Alternative-Food Delivery In The Basic Extant

Operant Behavior Literature ..................................................................................59

On the Effects of Concomitant Schedules of Reinforcement............................60

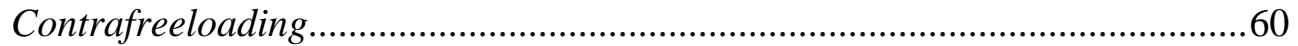

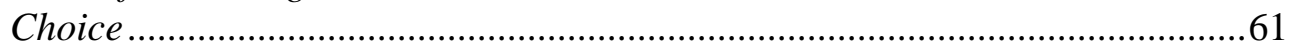

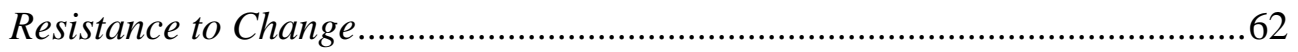

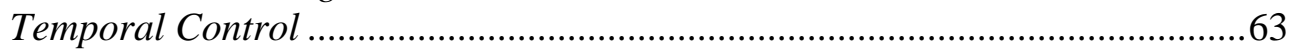

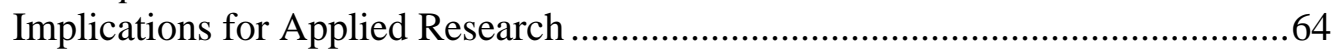

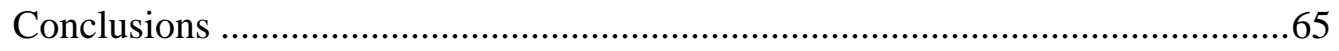

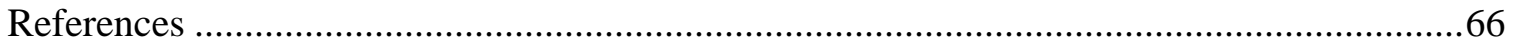




\section{List of Figures}

Figure 1. Response rates during the last six sessions of each condition, for each pigeon in Experiment 1 .

Figure 2. Average number of responses emitted in each tenth of the alternative-food intervals during the last six session of each condition, for each pigeon in Experiment 1 ....

Figure 3. Average proportion of responses emitted in each tenth of the alternative-food intervals during the last six sessions of each condition, for each pigeon in

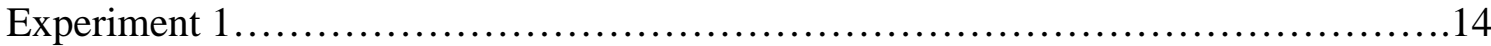

Figure 4. Response rates during the last six sessions of each condition, for each pigeon in

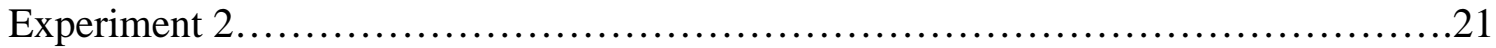

Figure 5. Average number of responses emitted in each tenth of the alternative-food intervals during the last six session of each condition, for each pigeon in Experiment 2.

Figure 6. Average proportion of responses emitted in each tenth of the alternative-food intervals during the last six sessions of each condition, for each pigeon in Experiment 2 .

Figure 7. Response rates during the last six sessions of each condition, for each pigeon in

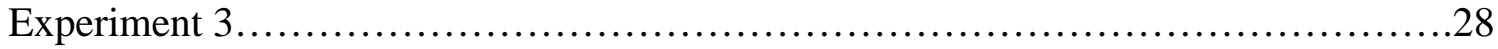

Figure 8. Average number of responses emitted in each tenth of the alternative-food intervals during the last six session of each condition, for each pigeon in Experiment 3.

Figure 9. Average proportion of responses emitted in each tenth of the alternative-food intervals during the last six sessions of each condition, for each pigeon in

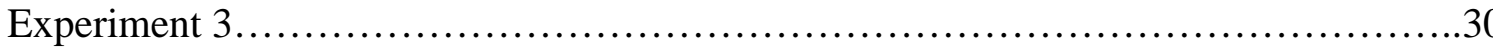

Figure 10. Response rates during the last six sessions of each condition, for each pigeon in Experiment 4

Figure 11. Average number of responses emitted in each tenth of the alternative-food intervals during the last six session of each condition, for each pigeon in Experiment 4 .

Figure 12. Average proportion of responses emitted in each tenth of the alternative-food intervals during the last six sessions of each condition, for each pigeon in Experiment 4. 
Figure 13. Response rates during the last six sessions of each condition, for each pigeon

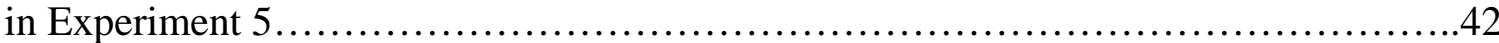

Figure 14. Average number of responses emitted in each tenth of the alternative-food intervals during the last six session of each condition, for each pigeon in Experiment 5

Figure 15. Average proportion of responses emitted in each tenth of the alternative-food intervals during the last six sessions of each condition, for each pigeon in Experiment 5.

Figure 16. Response rates during the last six sessions of each condition, for each pigeon in Experiment 6

Figure 17. Average number of responses emitted in each tenth of the alternative-food intervals during the last six session of each condition, for each pigeon in Experiment 6

Figure 18. Average proportion of responses emitted in each tenth of the alternative-food intervals during the last six sessions of each condition, for each pigeon in Experiment 6 .53 


\section{List of Tables}

Table 1. Schedules in effect in each condition, number of sources delivering these food types, the final distance between the sources, the number of sessions per condition, and the average number of alternative-food deliveries in which the photocell was broken (“Alt food consumed" - with ranges in the parenthesis) during Experiments 1-4.......9

Table 2. Average quarter-life of the last six sessions of each condition (ranges in parenthesis), for each pigeon, in Experiments 1-4................................15

Table 3. Average obtained delays between the last response before the alternative-food deliveries and alternative-food deliveries during the last six sessions of the conditions with alternative food, for each pigeon in Experiments 1-4. Numbers in parenthesis are standard deviations

Table 4. Schedules in effect in each condition, number of sources delivering these food types, the final distance between the sources, the number of sessions per condition, and the average number of alternative-food deliveries in which the photocell was broken ("Alt food consumed" - with ranges in the parenthesis) during

Table 5. Average quarter-life of the last six sessions of each condition (ranges in parenthesis), for each pigeon, in Experiments 5 and 6.

Table 6. Average obtained delays between the last response before the alternative-food deliveries and alternative-food deliveries during the last six sessions of the conditions with alternative food, for each pigeon in Experiments 5 and 6. Numbers in parenthesis are standard deviations. 


\section{Introduction}

Behavior maintained by reinforcement contingencies is disrupted frequently by events that are not dependent on such behavior. For example, the study behavior of a child in the classroom may be disrupted by the behavior of the teacher or that of other children; the working behavior of an employee may be disrupted by a malfunction of the equipment or by the behavior of other people around him; an increase in more appropriate behavior resulting from a treatment for depression may be disrupted by an event such as being left by a spouse; and the behavior of an animal chasing a prey may be disrupted by the sight or smell of another animal. In fact, the adaptive nature of operant behavior almost dictates that it often be sensitive not only to the maintaining contingencies, but also to other concurrently occurring events in the environment. Yet, as Lattal and Abreu-Rodrigues (1997) observed, many intruded events do not have a systematic effect on behavior. This is certainly adaptive too, because the disruption of behavior by the occurrence of any random event would make the behavior capricious and possibly would reduce the sensitivity to the consequences of the organism's own behavior. It follows that, to understand adaptive behavior, it would be useful to investigate the variables that determine under what conditions and the manner in which behavior can be disrupted by intruded events.

A case of disruption by intruded events that has been investigated in the operant laboratory is one in which schedule-maintained behavior is disrupted by the presentation of a stimulus, for example, food, that is similar in form to the reinforcer maintaining the operant response. This involves making response-independent (hereafter, alternative) food available after either fixed or variable time periods while still arranging the response-dependent (hereafter, operant) food according to a schedule of food reinforcement. Investigations of this sort have varied the schedule of reinforcement used to maintain the operant behavior, the schedule determining the delivery of the alternative food, and the manner in which the component schedules are combined in relation to one another. The results are that 1 ) the overall response rates typically decrease with the intrusion of the alternative food; however, such decreases are not always proportional to the proportion of alternative food delivered; 2) the patterns of responding may or may not change from the baseline with operant food only, to the test with the alternative food arranged concomitantly with the operant food, and 3) such changes in the response patterns and the specific patterns of responding obtained depend on the specific schedules in effect, the manner in which they are combined, and on the presence of stimuli correlated with each schedule.

The literature review that follows examines a number of experiments designed to assess the effects of alternative food imposed during schedule-maintained responding. This literature review provides the framework for a series of six experiments examining the effects of alternative food delivery schedules and locations on schedule-maintained responding.

\section{Literature Review}

Research investigating the effects of adding alternative food to a baseline of operant behavior can be classified according to the schedules used to arrange each food 
type. Both fixed- and variable-ratio and interval schedules have been used to arrange the operant food, and both fixed- and variable-time schedules have been used to deliver the alternative food. In an attempt to systematize the results obtained with different combinations of schedules arranging each food type, the next two sections of this review will present studies that used variable-time (VT) and fixed-time (FT) schedules separately.

\section{Combinations of VT schedules with other reinforcement schedules}

Most commonly, studies in which the alternative food was delivered according to a VT schedule involved the arrangement of operant food according to either fixed interval (FI) schedules (e.g., Cohen, Riley, \& Weigle, 1993; Lattal \& Bryan, 1976, Experiment 1) or variable-interval (VI) schedules (e.g., Boakes, Halliday, \& Poli, 1975; Cohen et al., 1993; Lattal, 1974; Nevin, 1984; Nevin, Tota, Torquato, \& Shull, 1990; Shull, Gaynor, \& Grimes, 2002). Less commonly, these studies have used fixed-ratio (FR) schedules (e.g., Cohen et al., 1993), and variable-ratio (VR) schedules (e.g., Cohen et al., 1993) to arrange the operant food.

In some studies where VT schedules are superimposed on other reinforcement schedules, there has been a more-or-less direct relation between response rates and the proportion of alternative food delivered. For example, Lattal (1974) exposed pigeons to a VI schedule during the baseline, followed by a VT schedule in which the temporal distribution of food delivery was identical to the one obtained during the baseline. After this condition, the subjects were exposed to a schedule in which food was arranged according to both a VI and a VT schedule (i.e., concomitant [conct] VIVT; Imam \& Lattal, 1992). Under this conct VI VT condition, the proportion of operant food was increased and then decreased across successive conditions by making every third, every tenth, or all food deliveries in a session response-dependent. Response rates were approximately proportional to the proportion of food arranged by either one of the two schedules. Specifically, increases (or decreases) in the number of operant food deliveries per session were accompanied by an increase (or a decrease) in the response rates for all subjects. Superimposing the VT schedule did not change the linear pattern of responding produced by the exposure to the VI schedule.

Another study in which a direct relation was found between response rates and proportion of operant food deliveries was that of Cohen et al. (1993). Among the manipulations performed in different experiments, these authors combined schedules arranging food delivered according to FR or VR schedules with alternative food arranged according to VT schedules. During the baseline of Experiment 1, for example, rats in one group were exposed to FR schedules, and rats in another group were exposed to VR schedules. During the test, which took place after stable responding was achieved under a specific schedule value, a VT schedule was superimposed on the schedules in effect for both groups. During subsequent baseline and test conditions, the values of both the ratio and VT schedules were varied systematically. Increases (or decreases) in the proportion of food deliveries arranged by the ratio schedule were accompanied by increases (or decreases) in response rates across the different ratio values. The absence of data 
depicting the distribution of responses in time in Cohen et al.'s (1993) study prevents determining whether and how adding the VT schedule affected the patterns of responding engendered by the FR and VR schedules.

Contrary to the findings of Lattal (1974) and Cohen et al. (1993), there is not always a direct relation between the proportion of operant food delivered and overall response rates. Such findings, however, are not surprising given the nature of the schedules comprising the combinations. For example, when exposing pigeons to a conct FI VT schedule, Lattal and Bryan (1976, Experiment 1) found that, up to a certain VT value, overall response rates increased. Further increases in the VT food rate, however, proportionally decreased the overall response rates. The initial increase in response rates appeared to be the result of changes in the temporal patterns of responding that occurred when food delivered according to the VT schedule was intruded in the baseline of behavior maintained by the FI schedule. Specifically, intruding the VT food changed the positively accelerated pattern of responding maintained by the FI schedule to a linear one. This occurred because local response rates at the beginning and in the middle of the FI increased, while response rates toward the end of the interval decreased. The net effect was an overall response rate increase when the VT schedule was in place. Further increases in the rate of VT-food delivery did not change the linear pattern of responding, but did decrease response rates throughout the FI interreinforcement interval. As a result, the overall response rates also decreased with these increases in VT-food delivery rates.

Lattal and Bryan's (1976, Experiment 1) results indicate that the change in response rates engendered by superimposing the schedule delivering alternative food may be related to changes in the distribution of responses in time as a function of the addition of alternative food. In fact, changes in overall response rates found in several other studies combining operant and alternative food can be interpreted similarly. Some of those studies are described below.

\section{Combinations of FT schedules with other reinforcement schedules}

The majority of the studies that have used FT schedules of alternative food delivery used either FI schedules (e.g., Lattal \& Bryan, 1976, Experiment 3) or VI schedules (e.g., Lattal \& Abreu-Rodrigues, 1997; Zeiler, 1977) to arrange the delivery of operant food. Fewer studies have used VR schedules (e.g., Zeiler, 1977) to arrange the operant food. A literature search revealed no studies that have investigated the effects of adding alternative food delivered according to an FT schedule on behavior maintained by FR schedules.

As with the results of combinations of VT schedules with other schedules, some studies using FT schedules reported a direct relation between overall response rates and the proportion of operant food delivered. For example, Zeiler (1977) found that adding FT schedules to a baseline of behavior maintained by VR schedules produced decreases in response rates that were proportional to the frequency of alternative-food deliveries. The absence of data depicting the distribution of responses in Zeiler's study prevents 
determining the effects of the FT food on response patterns, and how such changes might be related to the changes observed in the overall response rates.

Also, as with the results of studies superimposing VT schedules to other reinforcement schedules, the results of some studies using FT schedules did not yield a systematic relation between overall response rates and proportion of operant food delivered. These results provide further evidence that changes in the overall response rates may reflect changes in the patterns of responding produced by the addition of alternative food. One such experiment was conducted by Lattal and Bryan (1976, Experiment 3). Pigeons were exposed to a conct FI FT schedule in which, across different conditions, the FT schedule delivered food at the same rates or at rates higher than those associated with the FI schedule. Superimposing the FT schedule to the FI baseline produced a positively accelerated pattern within each FT interfood interval and, as a result, the overall response rates were not an orderly function of the proportion of operant food presentations.

Other authors have studied the changes in response patterns produced by adding FT-arranged food to a baseline in which operant food was delivered. Lattal and AbreuRodrigues (1997), for example, conducted a series of experiments to investigate the variables that determine whether the pattern of responding will change with the addition of an alternative source of food, and the characteristics of such a change. In Experiment 1, alternative food delivered according to an FT schedule was added to a baseline of behavior maintained by a VI schedule. For each subject, intruding the FT food affected both the overall response rates and the distribution of responses throughout the interfood intervals. Specifically, overall response rates were reduced with the addition of the FT schedule; however, changes in the proportion of operant food presentations did not systematically alter overall response rates. Additionally, in most conditions involving concomitant schedules, the linear pattern of responding produced by the VI baseline schedule was changed to a negatively accelerated pattern of responding between the alternative-food deliveries. This pattern was characterized by an increase in the local response rates after the FT food delivery, followed by either a relatively linear pattern or progressively lower local response rates across the FT interfood interval.

In the subsequent experiments, Lattal and Abreu-Rodrigues (1997) attempted to replicate the negatively accelerated pattern of responding found in the first experiment, to isolate some of the controlling variables responsible for such a pattern. In Experiments 2 through 4, both a negatively accelerated pattern of responding and linear responding throughout the FT interfood intervals occurred. In Experiment 5, pigeons were exposed to a concurrent (conc) VI FT schedule requiring a single peck on a change over response key to switch between the schedules (Findley, 1958). That is, there were different discriminative stimuli (the key colors) correlated with each schedule, and the delivery of food programmed by each schedule occurred only in the presence of the specific discriminative stimulus. The schedules operated independently, in that the interval of each schedule continued to time when either schedule was in effect. Although food occurred independently of responding in the presence of the FT discriminative stimulus, food delivery did depend on a response on the changeover key. This procedure was used 
to investigate the effects of the temporal separation of the schedules on the pattern of responding throughout the FT interfood intervals. The negatively accelerated pattern of keypecking under the VI schedule occurred in several of the experimental conditions, and it was most marked during the FT schedule arranging the most frequent food delivery. The authors thus concluded that variables that increase the temporal separation between the schedules arranging the operant and the alternative food (such as the temporal separation of such food arrangements) increase the likelihood of finding the negatively accelerated pattern of responding when FT schedules are superimposed to VI schedules of reinforcement.

In summary, the results of several studies indicate that changes in the overall response rates when an alternative source of food is added to the schedule arranging the operant food can be related to changes in the patterns of responding (e.g., Lattal \& Bryan, 1976, Experiment 3). Moreover, such changes in response patterns are more likely when temporal separation of the food sources is implemented (Lattal \& Abreu-Rodrigues, 1997). The specific changes in the patterns of responding will depend on both schedules arranging the operant and the alternative food.

\section{The unique case of differential-reinforcement-of-low-rates (DRL) schedules}

As noted previously in this review, research on the effects of intruded events typically has used interval schedules to arrange the delivery of operant food. A DRL schedule has in common with interval schedules the fact that the contingencies in effect involve a passage of time requirement for the delivery of reinforcers. These DRL schedules differ from interval schedules, however, in that an additional requirement is present: responses have to be temporally separated by a minimum interval to be reinforced. That is, DRL schedules constraint response rates in a manner not present in interval schedules. The manner in which such an additional constraint may interact with the contingencies determining the delivery of alternative food independently of responding has not yet been determined.

Lattal (personal communication, October $25^{\text {th }}, 2006$ ) investigated the effects of adding an alternative source of food to a baseline of behavior maintained by a DRL 30-s schedule. When an FT schedule was superimposed to the DRL schedule, response rates and patterns typically did not change systematically from those observed with the DRL schedule alone. Furthermore, changing the rate of FT food delivery also did not systematically affect response rates or response patterns. In a few cases, perhaps 10 percent, superimposing the alternative-food source substantially increased response rates. In addition, in those cases, the linear pattern of responding observed during the exposure to the DRL schedule changed to a positively accelerated response pattern, similar to that typical of FI schedules.

The increase in response rates found by Lattal (personal communication, October $25^{\text {th }}, 2006$ ) is the opposite of the typical effect observed when an alternative-food source is added to behavior maintained by interval schedules. One explanation for this finding is that DRL responding was accidentally reinforced by the delivery of the FT food. That is, 
adventitious temporal pairings between key pecks and FT food deliveries may have resulted in these higher DRL response rates. Accidental reinforcement of responses by alternative-food deliveries, however, can happen when any reinforcement schedule produces responding that may be contiguous with such food. What makes the case of the DRL schedule unique is the way that accidental reinforcement may interact with the additional constraint that DRL schedules impose on responding. Specifically, because accidental reinforcement increases response rates and because DRL schedules involve a low response rate requirement, accidental reinforcement may decrease the DRL reinforcement rates. Furthermore, if accidental reinforcement increases response rates, the likelihood that a response will be closely followed by an FT-food delivery also increases, creating a "self perpetuating" process. The combination of low DRL reinforcement rates and accidental reinforcement of key pecking by FT-food deliveries may be responsible for Lattal's finding of a positively accelerated response pattern. In fact, if DRL reinforcement rates decrease to zero and responses are systematically and closely followed by FT-food deliveries, the conct DRL FT schedule would be functionally equivalent to an FI schedule. The inconsistency of Lattal's finding of a positively accelerated response pattern across subjects may be due to the fact that it depends on accidental reinforcement of DRL responding by FT food deliveries, which will not necessarily be the case. In fact, it seems just as likely that responses other than keypecking would be followed by alternative-food deliveries, and thus increase in frequency. In this case, the positively accelerated pattern of responding would likely not be produced, and if keypecking is incompatible with the response that is accidentally reinforced by the alternative-food deliveries, decreases in response rates should be observed.

\section{Statement of the Problem}

A considerable number of operant studies have examined the effects of delivering operant and alternative events on response rates and patterns. In the study conducted by Zeiler (1968), for example, response rates and patterns changed when reinforcement schedules were replaced by other schedules delivering the same nominal reinforcer. Specifically, the rates of responding were higher with schedules arranging only operant food, but the specific patterns of responding varied as a function of the schedule of food delivery: FT schedules produced positively accelerated responding and VT schedules produced either linear, variable, or negatively accelerated responding. These results led Zeiler to suggest that response rates and response patterns are independently controlled by the response-reinforcer dependency and by the temporal distribution of food presentations, respectively.

Zeiler's (1968) findings were limited to situations in which all food deliveries were either operant or alternative. As noted in the review above, however, behavior frequently occurs in situations in which different schedules simultaneously arrange the delivery of operant and alternative food. The literature on the effects of combinations of schedules that simultaneously arrange these types of food is limited when compared to the literature on the effects of simple reinforcement schedules. In contrast to Zeiler's argument, the results that comprise the operant/alternative food delivery schedule 
combinations literature suggest that response rates sometimes are not directly proportional to the proportion of operant food deliveries. Instead, these rates varied as a function of the temporal distribution of food arranged by the component schedules. For example, Lattal \& Bryan (1976, Experiment 3) found that combining FI and FT schedules produced a positively accelerated pattern within each FT interfood interval and, as a result, the overall response rates were not an orderly function of the proportion of food delivered response dependently.

Lattal and Abreu-Rodrigues (1997, Experiment 5) found that the temporal arrangement of the operant- and alternative-food deliveries interacts with the temporal separation of the food sources to determine response rates and patterns under schedule combinations. Specifically, these authors obtained negatively accelerated response patterns during the FT interfood intervals when temporal separation of the food arranged by the VI and the FT was effected. This separation was obtained by requiring a changeover response to access the food arranged by each schedule. By using this procedure, however, the temporal distribution of food presentations likely was modified as well. That is, if the changeover key was not pecked before the FT interval elapsed, the FT food would not be delivered at precisely fixed intervals.

In addition to temporally separating the two sources of food under these combination schedules, another way to separate operant- and alternative-food schedules is to deliver these food types from different sources. By doing so, the temporal arrangement of food dictated by each schedule remains intact. To this date, the only study in which the operant and alternative food occurred at different locations was conducted by Williams (1989). The effects of the separation of the food sources were confounded in his study, however, by the fact that the events delivered according to each schedule were different (either food pellets or cooking oil was response dependent and the other was delivered independently of responding).

In the present experiments, response rates and patterns were investigated in situations in which 1) the alternative food was delivered from a source that was relatively distant from the one delivering the operant food, and 2) both operant and alternative food were delivered from the same source. In addition, the effects of the number of sources delivering the operant and the alternative food were investigated using a variety of schedules to arrange the delivery of both food types. These manipulations were conducted to further examine the interactive effects of the location and the temporal arrangement of both the operant and the alternative food on response rates and patterns.

\section{EXPERIMENT 1}

Lattal and Abreu-Rodrigues (1997, Experiments 1 and 2) found that VI response rates decreased and patterns of responding remained linear or became positively or negatively accelerated as a function of the FT delivery of alternative food from the same source as the reinforcer. The present experiment also examined VI-maintained responding as a function of the delivery of alternative food according to an FT schedule. 
The effect of interest here, however, was the changes in VI responding as a function of the source/location of the alternative food.

\section{Method}

\section{Subjects}

Three White Carneau pigeons were used, each with a prior history of responding on a variety of schedules of reinforcement. They were maintained at approximately $85 \%$ of their free-feeding weights, and had free access to water and health grit in their individual home cages. These cages were kept in a vivarium maintained at a constant temperature and on a 12:12 hr light:dark cycle.

\section{Apparatus}

A plywood chamber measuring $32 \mathrm{~cm}$ wide by $310 \mathrm{~cm}$ long by $38 \mathrm{~cm}$ high was used. The chamber contained an aluminum work panel at either end. The front panel, located at the left end of the chamber, contained a Gerbrands response key, located $26 \mathrm{~cm}$ above the floor and centered on the midline of the panel. The key operated with a force of about $0.10 \mathrm{~N}$. The key was transilluminated red at all times, except during food presentation from the food hopper located behind this panel. The food hopper was a Gerbrands model G5610, which, when operated, could be accessed through a $5.5 \mathrm{~cm}$ by $4.5 \mathrm{~cm}$ aperture located on the midline of the work panel, $14 \mathrm{~cm}$ below the center of the response key. The aperture was illuminated by a $28 \mathrm{~V}$ light bulb during food presentation. The back panel was located on the right side of the chamber and could be moved, in 30.5 $\mathrm{cm}$ increments, between a distance of $30.5 \mathrm{~cm}$ and $122 \mathrm{~cm}$ from the front panel. The back panel contained a food hopper that could be accessed through a $5.5 \mathrm{~cm}$ by $4.5 \mathrm{~cm}$ aperture located on the midline of the panel. This aperture also was illuminated when the hopper was activated. Photocells placed across both apertures recorded when the pigeon's head crossed the aperture, providing an index of food consumption during food delivery cycles. A fan and white noise masked extraneous sounds outside the chamber. Experimental events were controlled and the data were recorded with a microcomputer running MED-PC ${ }^{\mathrm{TM}}$ software and located in an adjacent room.

\section{Procedure}

Because the pigeons were experienced, training began immediately in the Baseline condition, during which a VI 30-s schedule was in effect on the front panel, with the back panel located $30.5 \mathrm{~cm}$ away. The VI schedule was generated using the constant probability distribution described by Fleshler and Hoffman (1962). The schedule consisted of 15 intervals. The mean VI value was increased over several sessions in increments of $30 \mathrm{~s}$, with at least two sessions at each value, to a mean interreinforcement interval (IRI) of $300 \mathrm{~s}$.

Table 1 shows the schedule(s) in effect, the number of food sources ( 1 or 2 hoppers) delivering the operant and the alternative food, and the final distance between 
Table 1

Schedules in Effect in Each Condition, Number of Sources Delivering These Food Types, the Final Distance Between the Sources, the Number of Sessions per Condition, and the Average Number of Alternative-Food Deliveries in Which the Photocell was Broken ("Alt Food Consumed" - With Ranges in the Parenthesis) During Experiments 1-4.

\begin{tabular}{|c|c|c|c|c|c|c|c|c|c|}
\hline Exp. 1 & Condition & $\begin{array}{l}\text { Sessions } \\
\text { VI } \\
\text { Baseline } \\
\end{array}$ & \multicolumn{2}{|c|}{$\begin{array}{cc}\text { Sessions } & \begin{array}{c}\text { Alt food } \\
\text { consumed }\end{array} \\
\text { VI FT } \\
\text { 1-Source }\end{array}$} & \multicolumn{2}{|c|}{$\begin{array}{cc}\text { Sessions } & \begin{array}{c}\text { Alt food } \\
\text { consumed }\end{array} \\
& \\
\text { VI FT } \\
\text { 2-source }\end{array}$} & \multicolumn{2}{|c|}{$\begin{array}{cc}\text { Sessions } & \begin{array}{c}\text { Alt food } \\
\text { consumed }\end{array} \\
\text { VI FT } \\
\text { 1-source }\end{array}$} & \multirow{2}{*}{$\begin{array}{c}\begin{array}{c}\text { Final distance } \\
\text { between } 2 \\
\text { sources }(\mathrm{cm})\end{array} \\
122\end{array}$} \\
\hline & 681 & 20 & 27 & $35(35-35)$ & 36 & $32(29-34)$ & 21 & 34.8 (34-35) & \\
\hline & 191 & 35 & 21 & 30.2 (13-35) & 61 & 31.5 (30-32) & 22 & 35 (35-35) & 122 \\
\hline & 481 & 20 & 66 & $34.8(34-35)$ & 44 & $24.5(20-27)$ & 16 & $35(35-35)$ & 122 \\
\hline \multirow{5}{*}{ Exp. 2} & & VI & \multicolumn{2}{|c|}{ VI VT } & \multicolumn{2}{|c|}{ VI VT } & \multicolumn{2}{|c|}{ VI VT } & \\
\hline & & Baseline & \multicolumn{2}{|c|}{ 1-source } & & purce & \multicolumn{2}{|c|}{ 1-source } & \\
\hline & 536 & 45 & 17 & 33.8 (33-35) & 38 & $32.3(29-34)$ & 15 & 33.7 (31-35) & 61 \\
\hline & 979 & 29 & 24 & $34.2(32-35)$ & 67 & 32.7 (32-33) & 15 & $34.3(33-35)$ & 30.5 \\
\hline & 830 & 14 & 30 & 33.7 (32-35) & 16 & $23.3(15-30)$ & 15 & 33.7 (33-34) & 30.5 \\
\hline \multirow[t]{5}{*}{ Exp. 3} & & DRL & \multicolumn{2}{|c|}{ DRL FT } & \multicolumn{2}{|c|}{ DRL FT } & \multicolumn{2}{|c|}{ DRL FT } & \\
\hline & & Baseline & \multicolumn{2}{|c|}{ 1-source } & \multicolumn{2}{|c|}{ 2-source } & \multicolumn{2}{|c|}{ 1-source } & \\
\hline & 946 & 24 & 36 & 35 (35-35) & 26 & $26.5(20-31)$ & 20 & 35 (35-35) & 122 \\
\hline & 617 & 72 & 19 & $34.8(34-35)$ & 33 & 26.7 (28-32) & 15 & 33.2 (31-35) & 122 \\
\hline & 955 & 21 & 35 & $35(35-35)$ & 30 & 31.5 (31-33) & 26 & $35(35-35)$ & 122 \\
\hline \multirow[t]{5}{*}{ Exp. 4} & & DRL & \multicolumn{2}{|c|}{ DRL VT } & \multicolumn{2}{|c|}{ DRL VT } & \multicolumn{2}{|c|}{ DRL VT } & \\
\hline & & Baseline & \multicolumn{2}{|c|}{ 1-source } & \multicolumn{2}{|c|}{ 2-source } & \multicolumn{2}{|c|}{ 1-source } & \\
\hline & 791 & 47 & 29 & 35 (35-35) & 35 & $21.7(15-30)$ & 15 & $35(35-35)$ & 122 \\
\hline & 960 & 21 & 33 & 33.8 (32-35) & 49 & 31.8 (29-35) & 54 & 35 (35-35) & 61 \\
\hline & 545 & 18 & 19 & 31.7 (29-35) & 60 & 26.7 (20-27) & 15 & 31.8 (29-34) & 30.5 \\
\hline
\end{tabular}


these sources during the 2-source condition, for each pigeon and in each condition. Following stable performance on the VI 300-s (baseline) schedule, a conct VI FT schedule was in effect. Under this schedule, the VI 300-s schedule remained in effect but at the same time food was delivered independently of responding according to an FT 100s schedule. The food arranged by both the VI and the FT schedule was delivered from the hopper located on the front panel, with the back panel $30.5 \mathrm{~cm}$ away. This condition hereafter will be described as VI FT 1-source. In the third condition the same conct VI FT schedule was in effect, but in this condition the distance between the sources of operant and alternative food was increased as described in the paragraph below. Other than the distance between the sources of operant and alternative food this condition, hereafter identified as the VI FT 2-source condition, was identical to the previous condition. The fourth condition was a return to the VI FT 1-source condition, with the front panel 30.5 $\mathrm{cm}$ away from the back panel. The remaining of this section describes procedures that were common to the other experiments comprising this study.

The procedure for increasing the distance between the operant- and alternativefood sources during the 2-source condition was as follows. The distance between the panels was increased in $30.5 \mathrm{~cm}$ steps to $122 \mathrm{~cm}$, with the qualification that a minimum of 25 alternative-food deliveries had been consumed (as suggested by a photocell break during the 3-s alternative-food delivery cycles) during each one of three consecutive sessions with the same distance between the panels. If, after ten sessions at a certain distance, the criterion to increase the distance was not met, the final distance was established as the current one.

During all conditions, in the unlikely event that the alternative-food delivery was programmed to occur during operant-food delivery resulting from key pecking under the schedule arranging the operant food, the hopper was deactivated at the completion of the reinforcement cycle, and then immediately reactivated to deliver the food programmed by the alternative schedule. The response key light was on during the alternative-schedule food delivery. If a response that met the operant schedule requirement occurred during the alternative-schedule food delivery, another response was required after the deactivation of the hopper to activate the operant schedule-programmed reinforcer.

Sessions were conducted at least 6 days per week, at approximately the same time of the day during the light phase of the vivarium light:dark cycle, for each pigeon. Each session started with a 30-s blackout in the chamber to reduce the effects of handling the pigeon. During baseline, sessions ended after what would be the equivalent to 35 alternative-food deliveries (i.e., these food deliveries were sham). During the remaining conditions, sessions ended after 35 alternative-food deliveries.

Conditions were changed only when response rates and quarter lives were stable. Stability was assessed after the $13^{\text {th }}$ session during Condition 1 , after the $15^{\text {th }}$ session during Conditions 2 and 4, and after the $15^{\text {th }}$ session with the final distance between the operant- and alternative-food sources during Condition 3. The quarter lives were measured as the proportion of the sham or actual alternative-food interval required to emit .25 of the responses. If 1 ) response rates during the last six sessions were considered 
stable by visual inspection, and 2) the average quarter lives of the last six sessions did not differ more than 3\% from the average quarter lives from the last two blocks of three sessions, the next condition was implemented.

\section{Results}

Table 1 shows the average number of alternative-food deliveries in which the photocell was broken (indicating food consumption) by each pigeon during the last six sessions of each condition of Experiment 1. These averages ranged from 35 (Pigeon 681 during the first 1-source condition, and Pigeons 191 and 481 during the last 1-source condition) to 24.5 (Pigeon 481, during the 2-source condition). With the exception of Pigeon 191, the average number of alternative-food deliveries in which the photocell was broken was always smaller in the 2-source, as compared to the 1-source, conditions. Table 1 also shows the final distance between the operant- and alternative-food sources. This distance was $122 \mathrm{~cm}$ for each pigeon.

Figure 1 shows the response rates (total responses/total time - food delivery time [both sources]) of each pigeon during the last six sessions of each condition of Experiment 1. These rates under the VI 300-s schedule ranged from 18 responses per minute (rpm) (Pigeon 191) to $88.8 \mathrm{rpm}$ (Pigeon 481). During the second condition (VI FT 1-source), adding the FT 100-s schedule delivering food from the same source as the operant food decreased the response rates of only Pigeon 481 (although, considering the range of response rates during the first condition, this decrease was not of a great magnitude). When, in the third condition (VI FT 2-source), the alternative food was delivered from the back hopper, response rates of each pigeon decreased from the previous conditions. In the fourth condition, where the operant and alternative food again were delivered from the same hopper, response rates increased from the preceding condition and returned to the levels observed in the second condition.

The average number of responses in successive tenths of the fixed interfood interval during the last six sessions of each condition is shown for each pigeon in Figure 2. These same data are shown as proportion of total responses in Figure 3. These measures provide a direct index of local responding and of the pattern of responding during the alternative-food intervals. Table 2 shows the average quarter life values, which are a summative and indirect index of the patterns of responding, during the last six sessions of each condition, for each pigeon. During the VI 300-s baseline, responses were recorded in the same way as during conditions with concomitant schedules but, as noted in the procedure section above, alternative-food deliveries were sham. In summary, adding alternative food delivered according to the FT schedule to the VI baseline always changed the distribution of responses (hereafter, pattern of responding) from linear to something else. Furthermore, across pigeons, the negatively accelerated pattern of responding was obtained in two of the three conditions involving two food sources, and in only two out of six conditions with one food source. Finally, the specific pattern of responses was always more extreme (i.e., characterized by a greater range) when the alternative and operant food were arranged in two, rather than one source. 

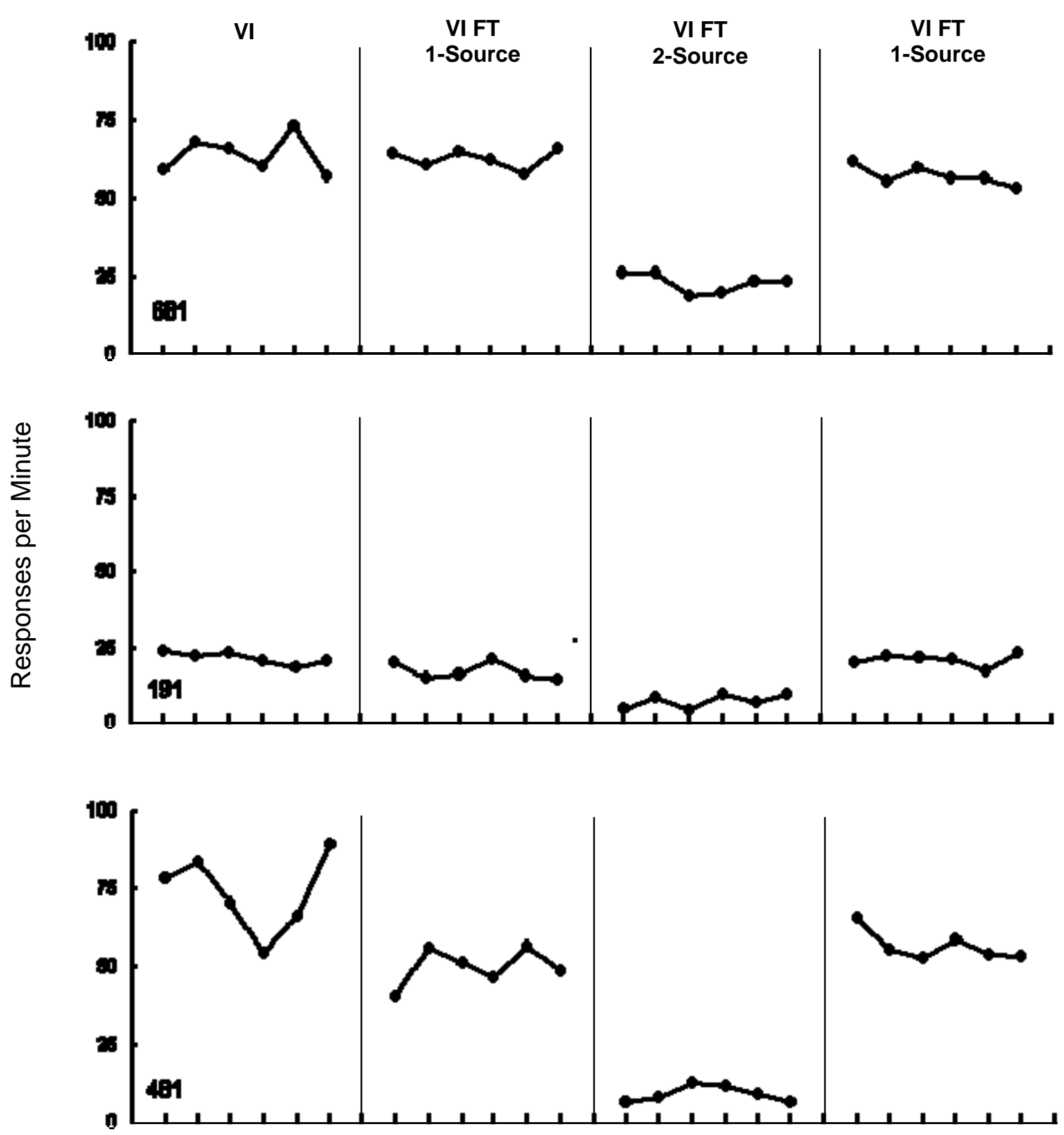

Sessions

Figure 1. Response rates during the last six sessions of each condition, for each pigeon in Experiment 1. 

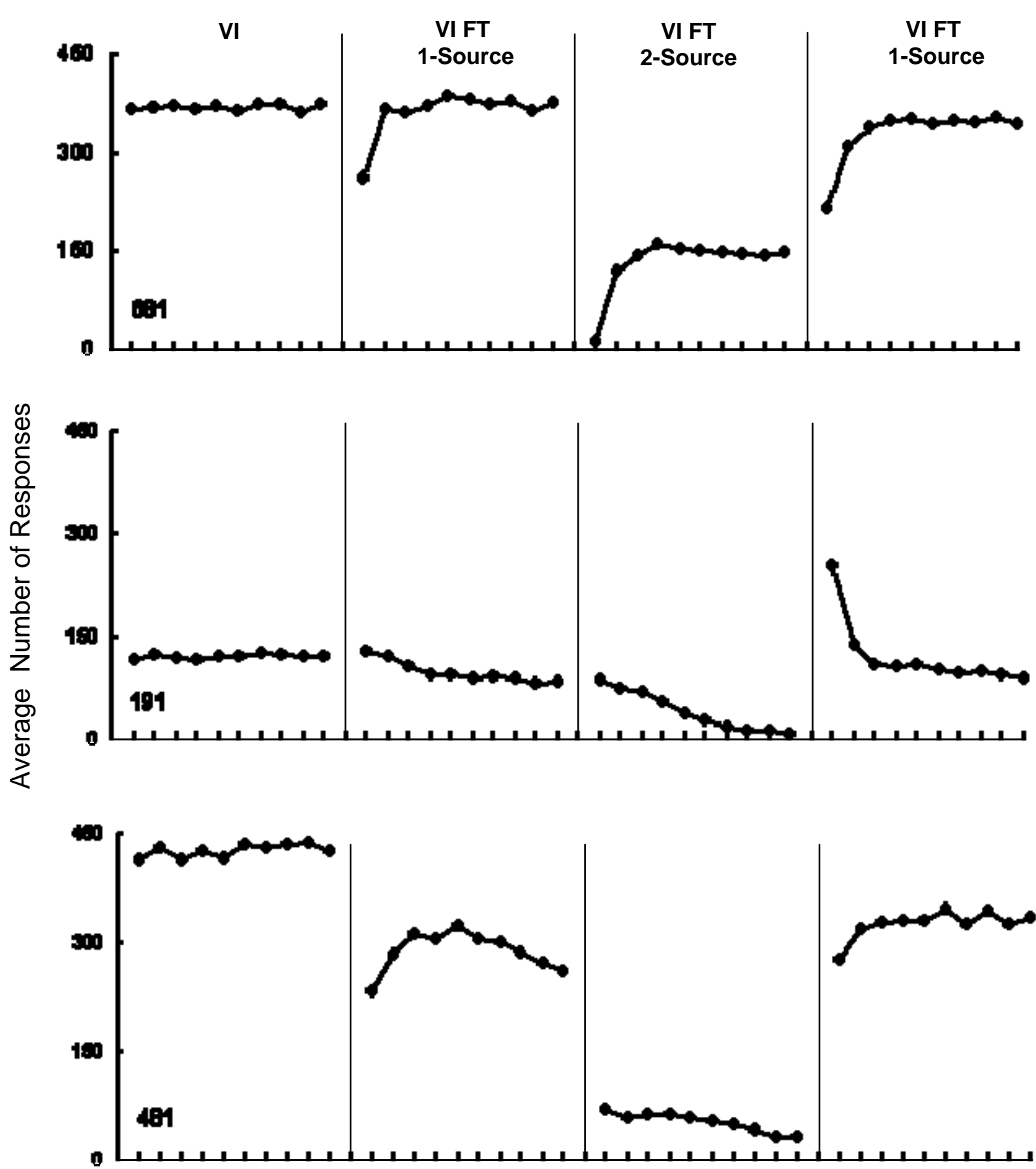

Tenths of the Alternative Interfood Interval

Figure 2. Average number of responses emitted in each tenth of the alternative-food intervals during the last six session of each condition, for each pigeon in Experiment 1. 

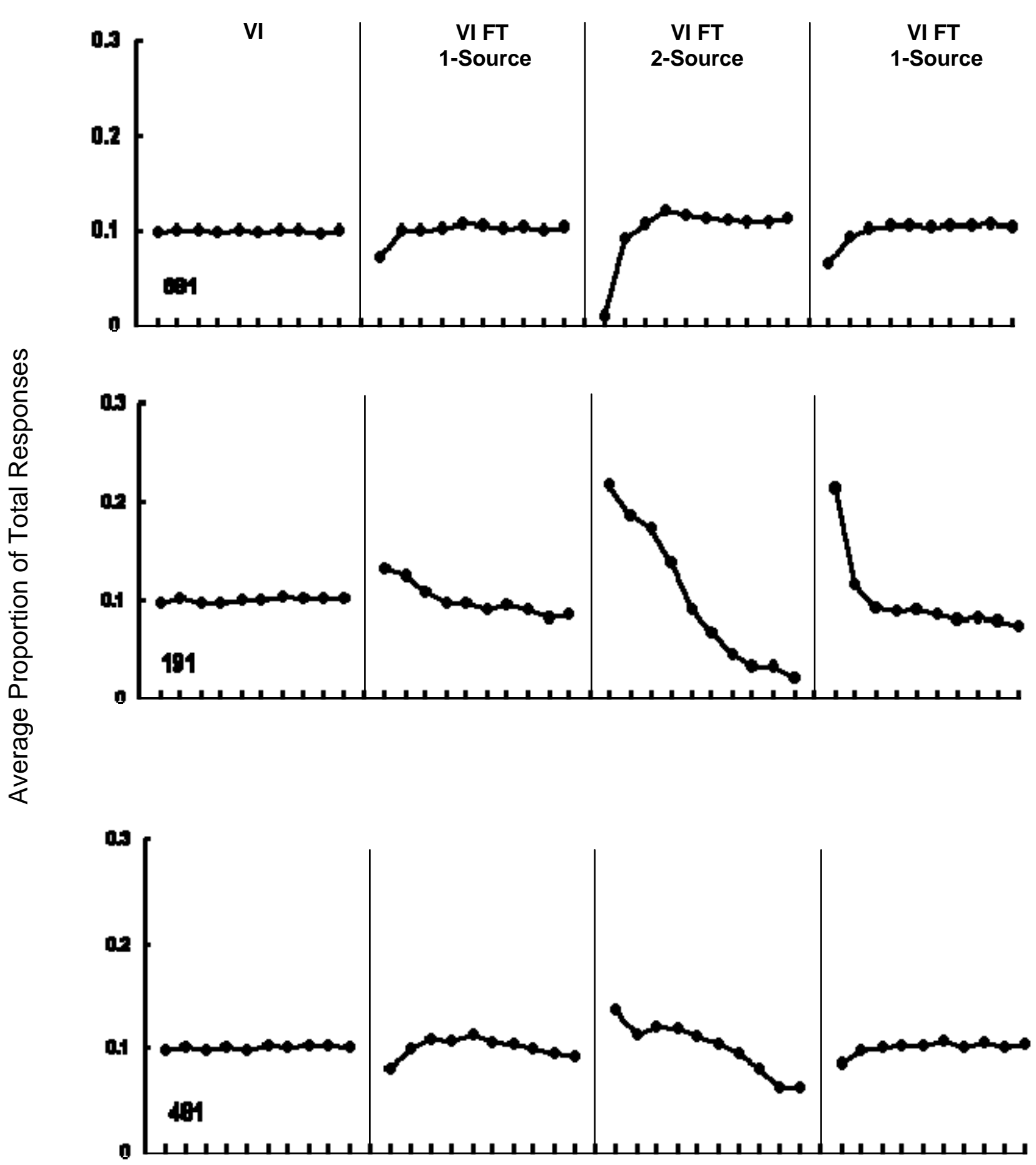

Tenths of the Alternative Interfood Interval

Figure 3. Average Proportion of responses emitted in each tenth of the alternative-food intervals during the last six sessions of each condition, for each pigeon in Experiment 1. 
Table 2

Average Quarter-Life of the Last Six Sessions of Each Condition (Ranges in Parenthesis), for Each Pigeon, in Experiments 1-4.

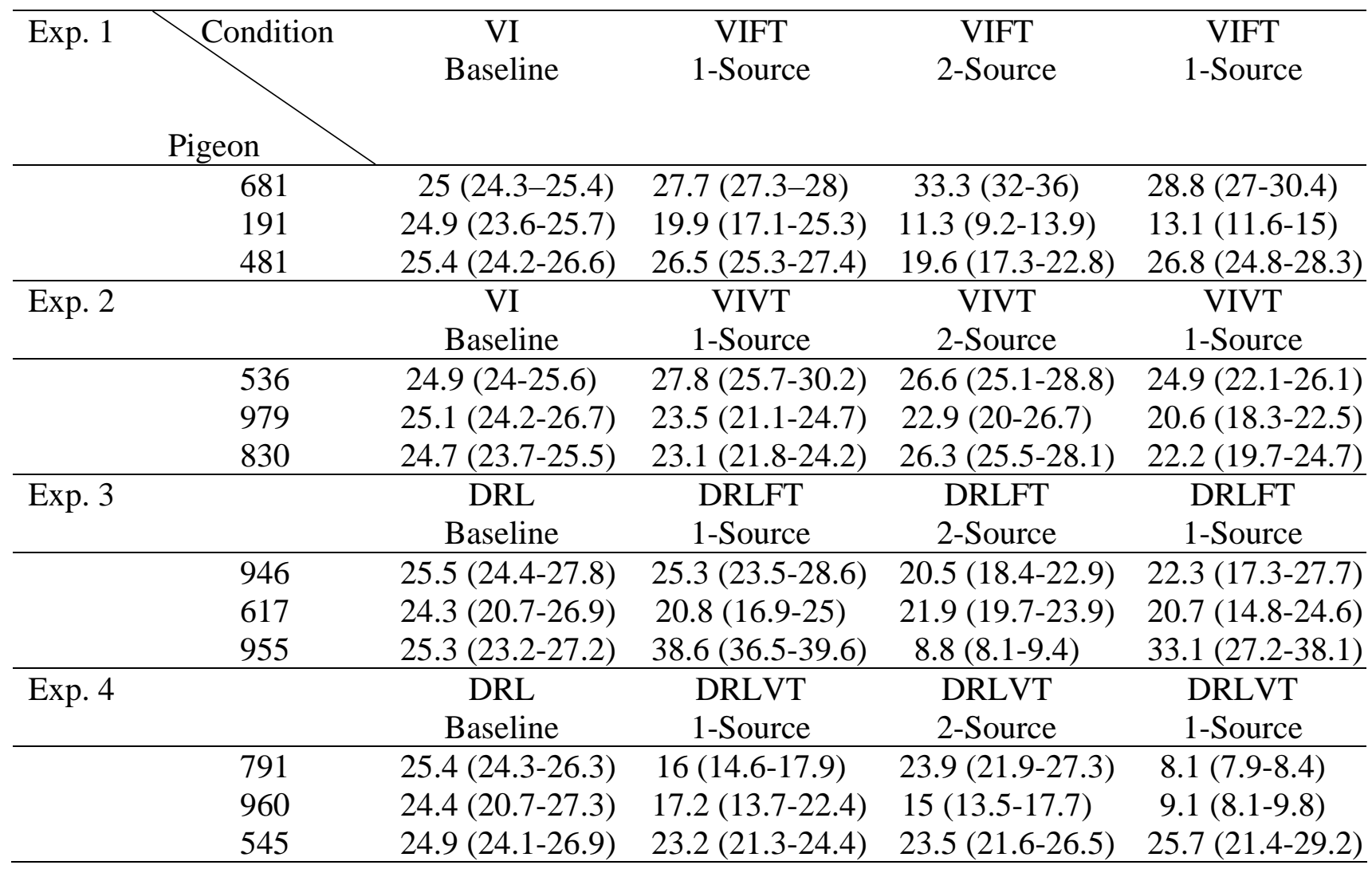


During baseline, the average number of responses of each pigeon was equal across successive tenths of the alternative-food interval. Delivering alternative food from the same source as the operant food produced variable results. For Pigeon 681, the average number of responses was lower during the first tenth of the alternative-food interval. For Pigeon 191, the average number of responses decreased across successive tenths, reflecting a negatively accelerated response pattern across the FT. Finally, for Pigeon 481, there was a small decrease in the average number of responses emitted during the first and last tenths of the FT interfood interval. When the alternative-food source was moved to the back panel, in the next condition, the patterns observed for Pigeons 681 and 191 during the previous condition were magnified, whereas for Pigeon 481 the proportion of responses became negatively accelerated across the FT interfood interval. When the location of the alternative-food source was reversed and returned to the front panel, during the fourth condition, the response pattern across the FT returned to that observed in the identical second condition for Pigeon 681. For Pigeon 191, this location reversal decreased the negatively accelerated pattern from the previous condition, but not to the same levels observed during the first exposure to the 1-source condition. The pattern of a lower average number of responses during the first tenth followed by more-or-less similar response rates across the remaining tenths of the FT occurred for Pigeon 481 during the return to the VI FT 1-source condition.

The average obtained delays between the last response before the alternative-food deliveries and the food deliveries for the last six sessions of each condition with concomitant schedules are shown in Table 3. If no responses were emitted during a given alternative-food interval, the delay was set as the duration of this interval. All variability measures are standard deviations. For each pigeon, the delays were systematically longer when the alternative food was delivered from a source other than that of the operant food.

\section{Discussion}

Adding alternative FT food from the same source that delivered the VI food did not systematically change response rates, but delivering the alternative food from another source decreased rates relative to those obtained from the 1-source conditions. Response patterns were more commonly negatively accelerated when the alternative and operant food were delivered from different sources than when they were delivered from the same source. Average obtained delays between the last response before the alternative-food deliveries and the alternative-food deliveries were longer during the 2-source, as compared to the 1-source, condition.

The findings of response rates and average obtained delays between the last response before alternative-food deliveries and alternative-food deliveries were consistent both within and across pigeons. Patterns of responding, however, were not. Although negatively accelerated responding was more common in the 2-source conditions, it was obtained in all conditions with concomitant schedules for Pigeon 191, but it was never obtained for Pigeon 681. 
Table 3

Average Obtained Delays Between the Last Response Before the Alternative-Food Deliveries and Alternative-Food Deliveries During the Last Six Sessions of the Conditions With Alternative Food, for Each Pigeon in Experiments 1-4. Numbers in Parenthesis are Standard Deviations.

\begin{tabular}{|c|c|c|c|c|}
\hline \multirow[t]{5}{*}{ Exp. 1} & Condition & $\begin{array}{c}\text { VIFT } \\
\text { 1-Source }\end{array}$ & $\begin{array}{c}\text { VIFT } \\
\text { 2-Source }\end{array}$ & $\begin{array}{c}\text { VIFT } \\
\text { 1-Source }\end{array}$ \\
\hline & & & & \\
\hline & 681 & $2.2(10.76)$ & $10.98(26.77)$ & 3.04 (13.94) \\
\hline & 191 & 3.64 (3.67) & $46.97(28.11)$ & $2.56(2.10)$ \\
\hline & 481 & $2.41(2.05)$ & $33.23(27.52)$ & $2.03(2.21)$ \\
\hline \multirow[t]{5}{*}{ Exp. 2} & & VIVT & VIVT & VIVT \\
\hline & & 1-Source & 2-Source & 1-Source \\
\hline & 536 & $3.82(4.11)$ & $4.38(3.68)$ & 5.07 (5.34) \\
\hline & 979 & 2.05 (2.37) & 7.39 (7.89) & 3.14 (2.96) \\
\hline & 830 & $1.92(1.84)$ & $3.57(4.11)$ & 3.84 (8.93) \\
\hline \multirow[t]{5}{*}{ Exp. 3} & & DRLFT & DRLFT & DRLFT \\
\hline & & 1-Source & 2-Source & 1-Source \\
\hline & 946 & $5.04(4.99)$ & $12.83(11.56)$ & $6.2(5.94)$ \\
\hline & 617 & $6.32(6.87)$ & $12.58(8.12)$ & $6.43(5.28)$ \\
\hline & 955 & $2.24(2.55)$ & $17.53(11.14)$ & $6.24(6.55)$ \\
\hline \multirow[t]{5}{*}{ Exp. 4} & & DRLVT & DRLVT & DRLVT \\
\hline & & 1-Source & 2-Source & 1-Source \\
\hline & 791 & $6.65(7.22)$ & $9.12(6.46)$ & $7.21(6.44)$ \\
\hline & 960 & $9.33(11.41)$ & 8.12 (8.51) & 7.09 (7.15) \\
\hline & 545 & $6.39(6.72)$ & $8.43(6.48)$ & $9.19(9.22)$ \\
\hline
\end{tabular}


Unlike the finding of Lattal and Abreu-Rodrigues (1997), response rates in the present Experiment did not reliably decrease when the alternative food was made available from the same source as that delivering the operant food. The difference in the results of these two Experiments may be understood when local responding is analyzed. Figure 2 shows that, under 1-source conditions, the average local number of responses significantly decreased across all tenths of the FT only for Pigeon 481. As a result, decreases in overall response rates as compared to the baseline were observed only for this pigeon.

That negatively accelerated responding was more common under 2-source conditions is consistent with the extant literature showing that separating the food sources when combining VI and FT schedules produces this pattern more reliably then when the sources are not separated (Lattal and Abreu-Rodrigues, 1997). The fact that negatively accelerated responding was found for Pigeon 191 also during 1-source conditions is consistent with previous experiments that sometimes found this pattern using conct VI FT schedules delivering food from a single source (Lattal and Abreu-Rodrigues, 1997, Experiments 1-3).

As previously noted, the negatively accelerated response pattern was never observed for Pigeon 681. It is possible that, when the FT hopper was activated during the 2-source condition, this pigeon could arrive at this source rapidly enough to consume the food before this hopper was deactivated. This possibility is supported by the data provided in Table 1 showing that, of the 35 FT-food deliveries during each of the last six sessions of the 2-source condition, the photocell was broken (indicating food consumption) 32 times, on average. Thus, the absence of control of keypecking by the temporal arrangement of the FT-food deliveries would not have prevented its consumption.

The pattern of decreases during the first tenth of the alternative-food intervals for Pigeon 681 is consistent with the results found for some subjects in Lattal and AbreuRodrigues' (1997) Experiment 5, using the same schedules. These authors argued that pausing or changing over from the alternative- to the operant-food schedule may account for this result. The more pronounced pauses after the alternative food in the 2-source condition as compared to the 1-source conditions for this pigeon is not surprising, because pauses in the 2-source condition included the travel time back to the front panel.

The average obtained delays between the last response before the FT-food delivery and this food delivery cannot be compared to the extant literature, because no other studies have used one or two sources of operant and alternative food, and compared obtained delays between responses and food deliveries in each case. It is not surprising that such delays were longer during the 2-source conditions, however, because the average number of responses emitted at the end of the alternative-food interval was lower in this condition, as compared to the 1-source condition, for each pigeon. That is, when less responses occur, the chances that they will be closely followed by food delivery decreases. 


\section{EXPERIMENT 2}

When alternative food delivered at varying times is added while responding is being maintained by a VI schedule, response rates decrease as a function of the rate of alternative-food delivery, but response patterns do not change systematically (Lattal, 1974). This has been observed, however, only when a single food source was used to deliver both operant and alternative food. Experiment 2 therefore was designed to complement this earlier finding by investigating how VI responding changes under the same schedules used by Lattal as a function of the location of the operant and alternative food.

Method

\section{Subjects}

Three pigeons, each with a prior history of responding under different reinforcement schedules, were maintained under conditions identical to those described in Experiment 1.

\section{Apparatus}

The apparatus was the same as described in Experiment 1.

\section{Procedure}

Because of the pigeons' prior history, they were exposed immediately to the same initial training described for Experiment 1 until responding was stabilized on a VI 300-s schedule in effect on the front panel, with the back panel located $30.5 \mathrm{~cm}$ away.

Table 1 shows the schedule(s) in effect, the number of food sources ( 1 or 2 hoppers) delivering the operant and the alternative food, and the final distance between these sources during the 2-source condition, for each pigeon and in each condition. The conditions in effect, their procedural details, and the order in which they were implemented during Experiment 2 were identical to Experiment 1, except that a VT 100-s schedule replaced the FT 100-s schedule used in Experiment 1 to arrange the alternativefood deliveries. The VT schedule included 16 intervals, 15 of which were derived from the constant probability distribution described by Fleshler and Hoffman (1962), and one of which was equal to $100 \mathrm{~s}$. These two 100-s values were added to the distribution to allow determining the effects of the variables manipulated with identical interval values (for further details of this analysis, see results section below). The condition labels were changed accordingly (i.e., VI VT 1-source and VI VT 2-source). All other procedural details were as described during the last four paragraphs of the procedure section of Experiment 1. 
Results

Table 1 shows the average number of alternative-food deliveries in which the photocell was broken (indicating food consumption) by each pigeon during the last six sessions of each condition of Experiment 2. These averages ranged from 34.3 (Pigeon 979, during the last 1-source condition) to 23.3 (Pigeon 830, during the 2-source condition). The average number of alternative-food deliveries in which the photocell was broken was always smaller in the 2-source, as compared to the 1-source, conditions. Table 1 also shows the final distance between the operant- and alternative-food sources. This distance was equal to $61 \mathrm{~cm}$ for Pigeon 536, and $30.5 \mathrm{~cm}$ for Pigeons 979 and 830.

Figure 4 shows response rates for each pigeon during each of the last six sessions of each condition of Experiment 2. These response rates were calculated as in Experiment 1. During the VI 300-s schedule baseline, response rates ranged from $24.2 \mathrm{rpm}$ (Pigeon 536) to $49.3 \mathrm{rpm}$ (Pigeon 830). In comparison to the VI baseline, adding VT food to the same source delivering the VI food during the first VI VT 1-source condition decreased response rates for Pigeons 536 and 830, but did not change the response rates for Pigeon 979. When the VT food source was moved to the back panel (VI VT 2-source condition), the response rates of each pigeon decreased from the previous conditions. During the next condition, moving the alternative-food delivery back to the same source as the operant food (VI VT-1 source condition) did not change the response rates for Pigeons 536 and 830, but increased the response rates of Pigeon 979. This increase, however, did not represent a complete return to the levels observed for this pigeon during the first exposure to this condition.

To provide an index of changes in local responding and of the pattern of responding during the alternative-food intervals, two different analyses were conducted. The first one was similar to that used in constructing Figures 2 and 3 of Experiment 1. Because a VT schedule delivered the alternative food in Experiment 2, however, the intervals that were divided into tenths of the alternative-food intervals were not equal in duration to one another. The number of responses per tenth on a given session was calculated by dividing each VT-interval value by ten, and determining the number of responses emitted in each tenth. The number of responses per tenth was accumulated throughout the session, and the average number of responses per tenth during the last six sessions of the condition was calculated. As in Experiment 1, during the VI 300-s baseline, responses were recorded in the same way as during conditions with concomitant schedules, but alternative-food deliveries were sham. The second analysis was identical to the previous one, but included only the VT intervals that were equal to 100-s. Because both analyses yielded similar results, but the second one was characterized by greater variability, only the first analysis is presented herein. Figures 5 and 6 show the average number of responses and the average proportion of responses throughout successive tenths of the VT intervals, respectively, during the last six sessions of all conditions of Experiment 2, for each pigeon. Table 2 shows the average quarter-life values of the last six sessions of each condition, calculated using all the VT intervals, for each pigeon. During 1-source conditions, patterns of responding were most commonly characterized 
by a peak in the first tenth of the VT interval followed by more-or-less linear responding. Patterns were most commonly linear during the 2-source conditions.
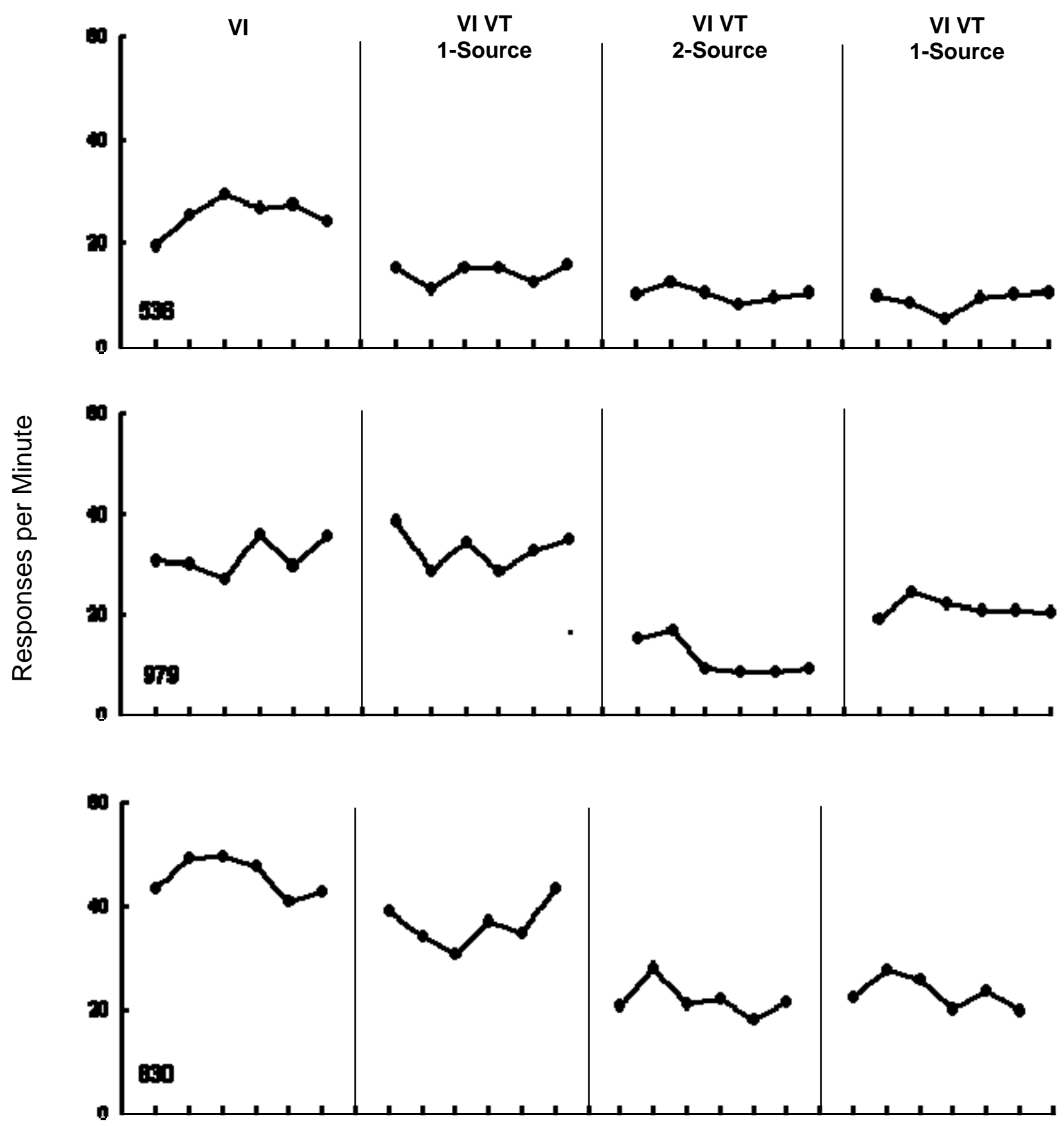

Sessions

Figure 4. Response rates during the last six sessions of each condition, for each pigeon in Experiment 2. 

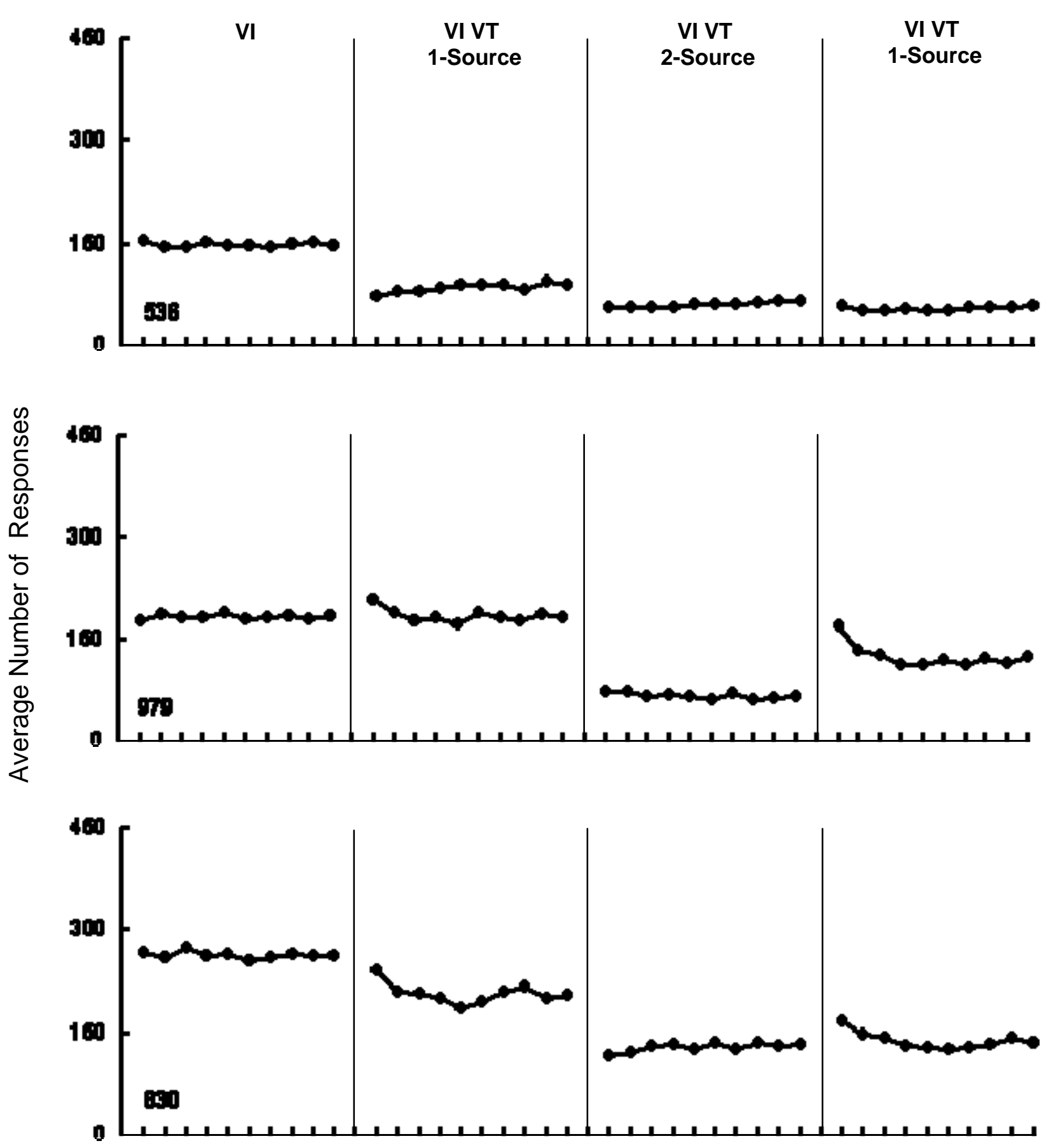

Tenths of the Alternative Interfood Interval

Figure 5. Average number of responses emitted in each tenth of the alternative-food intervals during the last six session of each condition, for each pigeon in Experiment 2. 


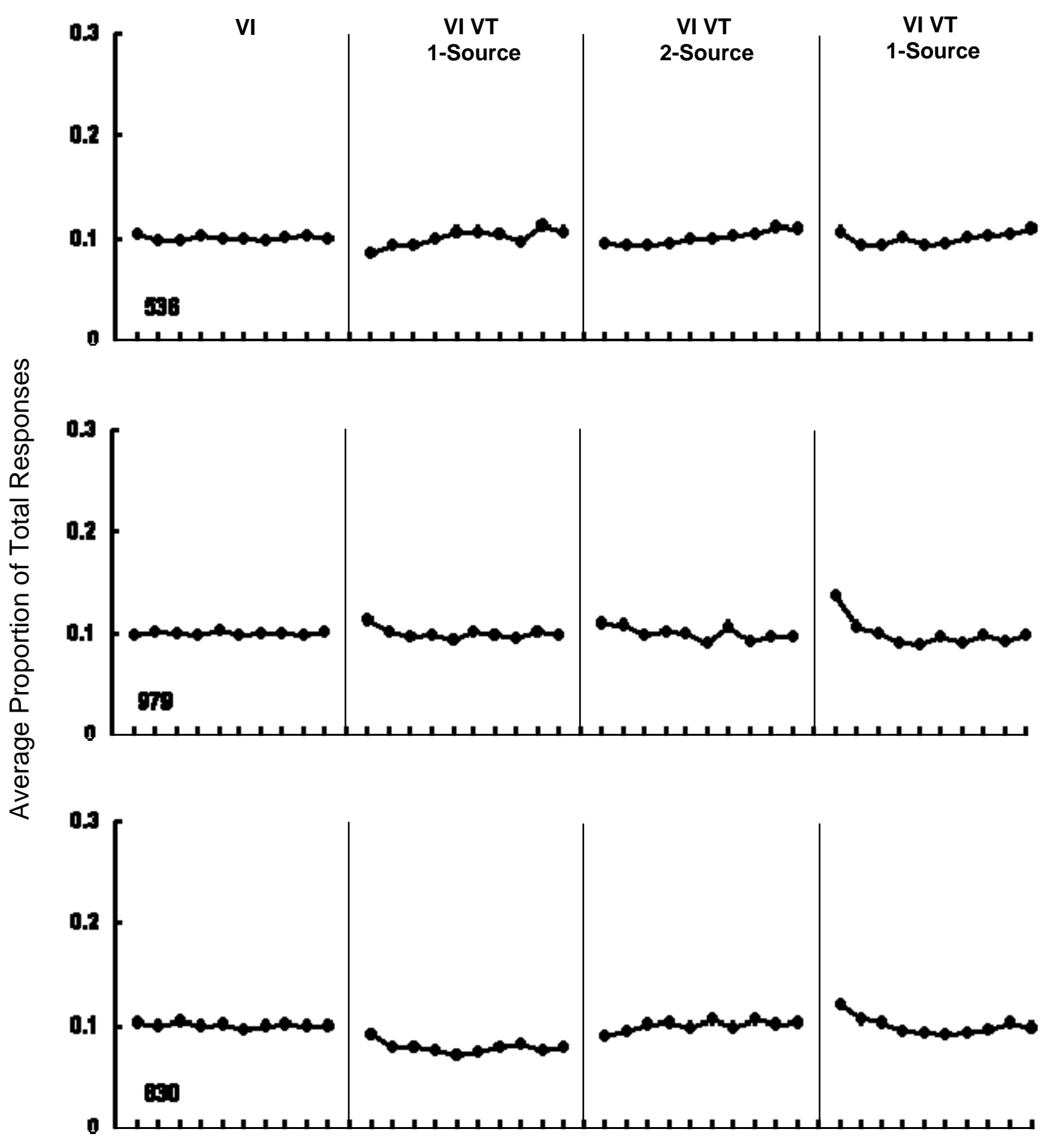

Tenths of the Alternative Interfood Interval

Figure 6. Average Proportion of responses emitted in each tenth of the alternative-food intervals during the last six sessions of each condition, for each pigeon in Experiment 2. 
A linear pattern of responding throughout the sham VT intervals occurred for each pigeon during the VI baseline. For Pigeons 979 and 830, in the first VI VT 1-source conditions, the pattern of responses was characterized by a small peak during the first tenth of the alternative-food interval followed by more-or-less linear responding throughout this interval. For Pigeon 536, a fairly positively accelerated pattern of responses was observed. Superimposing the alternative food to a source other than that delivering the operant food (i.e., VI VT 2-source conditions) resulted in a slightly positively accelerated pattern of responses for Pigeon 536, and linearly distributed responding for Pigeons 979 and 830 during the VT intervals. When the VI VT 1-source condition was reinstated, patterns of responding of all pigeons became similar to those obtained during the first exposure to this condition.

Average delays between the last response before the alternative-food deliveries and alternative-food deliveries during the last six session of each concomitant-schedule condition are presented in Table 3. These average delays were calculated as in Experiment 1. For Pigeons 536 and 830, the delays increased slightly across conditions. Only for Pigeon 536 there was a systematic relation between the number of sources delivering the alternative and the operant food and the obtained response-alternative food delay, in that the condition with two food sources was characterized by longer delays than conditions with one food source.

\section{Discussion}

In Experiment 2, response rates only decreased systematically from the previous conditions when the operant and the alternative food were delivered from different sources. Furthermore, during the 1-source conditions, patterns of responding were most commonly characterized by a small peak in the first tenth of the VT interval followed by more-or-less linear responding. During the 2-source conditions, responding was most commonly linear. Finally, average obtained delays between the last response before the alternative-food deliveries and the alternative-food deliveries were unsystematic across pigeons.

The finding of decreases in response rates from the previous conditions only with 2 food sources was systematic both within and across pigeons. The finding of a peak followed by linear responding in 1-source conditions and linear responding during 2source conditions, however, was not. Specifically, responding was moderately positively accelerated across both the conditions with 1 and 2 sources, for Pigeon 536. The average obtained delays between the last response before the VT-food deliveries and the VT-food deliveries were also unsystematic across pigeons: while these delays increased across conditions for two of the pigeons, they were longer with two (rather than one) food sources, for one pigeon.

Although the temporal arrangement of the operant- and alternative-food deliveries and the number of sources delivering each food type was identical across pigeons, the final distance between the sources of food was not. This distance was equal to $61 \mathrm{~cm}$ for Pigeon 536, and $30.5 \mathrm{~cm}$ for Pigeons 979 and 830. The difference across pigeons in the 
distance between the food sources seems not to have influenced the results, however, in terms of response rates. That is, although the final distance between the sources was shorter in Experiment 2 than in Experiment 1, the results of both experiments were systematic in that response rates only decreased reliably during the 2-source condition, in comparison to the 1-source conditions. As in Experiment 1, the absence of a decrease in response rates when the alternative food was added to the same source delivering the operant food is not consistent with the results of other studies using a similar proportion of operant- to alternative-food deliveries (e.g., Lattal, 1974). Also as in Experiment 1, however, changes or maintenance of overall response rates may be explained by changes or maintenance of the local number of responses following changes in the conditions. For example, for Pigeon 979, when the VT food was added during the first 1-source condition, the linear pattern of responding and the local number of responses per tenth of the VT interval obtained during the baseline remained intact (except for the small peak observed during the first tenth of the alternative-food interval). As a net result, overall response rates were similar during baseline and the next 1-source condition.

The peak in responding during the first tenth of the alternative-food intervals during the 1-source conditions is consistent with previous findings. For example, Deluty (1976) found local increases in responding after the alternative-food deliveries, when using a conct random-interval (RI) random-time (RT) schedule with only one food source, a schedule similar to that in effect during the 1-source conditions in the present experiment. According to Uhl and Garcia (1969), it is possible that food deliveries function as discriminative stimuli, because in their presence, further responses produce additional reinforcers. Although food is delivered in the absence of keypecking in the concomitant schedules of the present experiment, food deliveries may maintain their evocative effects if food follows keypecking more systematically than it follows other responses that the pigeons may be engaging in at the time of the alternative-food delivery.

During the 2-source conditions, the peaks in responding during the first tenth of the alternative-food interval did not occur. Probably, the final distance between the sources was long enough that the travel time back to the front panel was sufficient to eliminate this peak.

The linear pattern of responding that occurred either from the second tenth of the alternative-food intervals on in the 1-source conditions, and during all tenths in the 2source conditions, is consistent with the findings of other authors that combined the same schedules in a concomitant manner (e.g., Lattal, 1974). That a positively accelerated pattern of responding was found in one case, however, is not consistent with previous studies. The reason why this pattern occurred is not clear. It is possible that the fact that intervals that were equal to or approximated $100 \mathrm{~s}$ were more common than the other VT intervals (because of the way that the VT was programmed, as described in the procedure section above) is related to the finding of positively accelerated responding for one pigeon (cf. Lund, 1976). 
Finally, the fact that average delays between the last response before the VT food deliveries and the VT food deliveries were unsystematic across pigeons is different from the systematic finding of longer average delays during 2-source conditions in Experiment 1. In any case, as in Experiment 1, there was an inverse relation between the average number of responses emitted during the last tenth of the alternative-food interval and the average obtained delays between the last response before the alternative-food delivery and this food delivery. This inverse relation is clearest in the results of Pigeon 979. For this pigeon, average delays were longer and the average number of responses during the last tenth was lower with two, rather than one, food sources.

\section{EXPERIMENT 3}

In previously published experimental analyses of combinations of operant and alternative food delivery, responding has been maintained by interval or ratio schedules (e.g., Lattal \& Bryan, 1976; Zeiler, 1977), but never by DRL schedules (cf. Lattal \& Maxey, 1971). Given the unique combination of pausing and responding required by DRL schedules, it was of interest in the third experiment to examine the effects on DRL responding of adding alternative food delivered according to FT schedules to the same or a different source than that delivering the DRL food.

Method

\section{Subjects}

Three pigeons, each with a prior history of responding under different reinforcement schedules, were maintained under conditions identical to those described in Experiment 1.

\section{Apparatus}

Both the microcomputer used to control the experimental events and record the data, and the chamber used in Experiment 3 were identical to those used in Experiment 1, except that the chamber had two keys located at the same height as the key of the chamber used for Experiment 1. These keys were located $13 \mathrm{~cm}$ from each other and only the left key was used. The food hopper aperture was located midway between the keys, with its center $10.5 \mathrm{~cm}$ from the chamber floor.

\section{Procedure}

Because of the pigeons' prior history, each was exposed from the experiment outset to the baseline consisting of a DRL 30-s schedule that was in effect on the front panel, with the back panel located $30.5 \mathrm{~cm}$ away, until responding was stabilized. At the beginning of the session, a counter started timing the interresponse times (IRT). Only IRTs equal to or greater than $30 \mathrm{~s}$ were reinforced. Interresponse times of less than $30 \mathrm{~s}$ reset the timer and an additional $30 \mathrm{~s}$ were required for the next response to be reinforced. The counter also restarted immediately after the reinforcement cycle. 
Table 1 shows the schedule(s) in effect, the number of sources (1 or 2 hoppers) delivering the operant and the alternative food, and the final distance between these sources during the 2-source condition, for each pigeon and in each condition. The conditions in effect, their procedural details, and the order in which they were implemented during Experiment 3 were identical to Experiment 1, except that the DRL 30-s schedule (programmed as described above) replaced the VI 300-s schedule used in Experiment 1 to arrange the operant food deliveries. The condition labels were changed accordingly (i.e., DRL FT 1-source and DRL FT 2-source). All other procedural details were as described during the last four paragraphs of the procedure section of Experiment 1.

Results

Table 1 shows the average number of alternative-food deliveries in which the photocell was broken (indicating food consumption) by each pigeon during the last six sessions of each condition of Experiment 3. These averages ranged from 35 (Pigeons 946 and 955, during each 1-source condition) to 26.5 (Pigeon 946, during the 2-source condition). The average number of alternative-food deliveries in which the photocell was broken was always fewer in the 2-source, as compared to the 1-source, conditions. Table 1 also shows the final distance between the operant and alternative food sources. This distance was $122 \mathrm{~cm}$ for each pigeon.

Figure 7 shows response rates for each pigeon during the last six sessions of each condition of Experiment 3. These rates were calculated as in Experiment 1, and varied from $8.6 \mathrm{rpm}$ (Pigeon 946) to $23.2 \mathrm{rpm}$ (Pigeon 955) during the DRL 30-s baseline. During the next condition (DRL FT 1-source), superimposing the alternative-FT food to the same source delivering the DRL food did not change the response rates for Pigeon 946, but increased the response rates of Pigeons 617 and 955. When the alternative food was delivered from the back panel during the next condition (DRL FT 2-source), response rates of each pigeon decreased from the previous conditions. When the alternative food was reinstated on the front panel (DRL FT 1-source), the response rates of each pigeon increased from the preceding condition. Only for Pigeon 946, however, did the response rates return to the levels observed during the first exposure the DRL FT 1-source Condition.

The average number of responses and the average proportion of responses during the alternative interfood intervals of the last six sessions of each condition are respectively shown in Figures 8 and 9. These averages were as calculated in Experiment 1. Table 2 shows the average quarter-life values of the last six sessions of each condition for each pigeon, calculated as in Experiment 1. Linear response rates occurred during the DRL baseline for each pigeon. In summary, during all conditions involving the FT schedule, a peak in the pattern of responses in the first tenth of the alternative-food intervals occurred for each pigeon. Also, for each pigeon, this peak was more pronounced during the conditions in which the alternative and the operant food were delivered from two different sources (i.e., DRL FT 2-source conditions). In all 

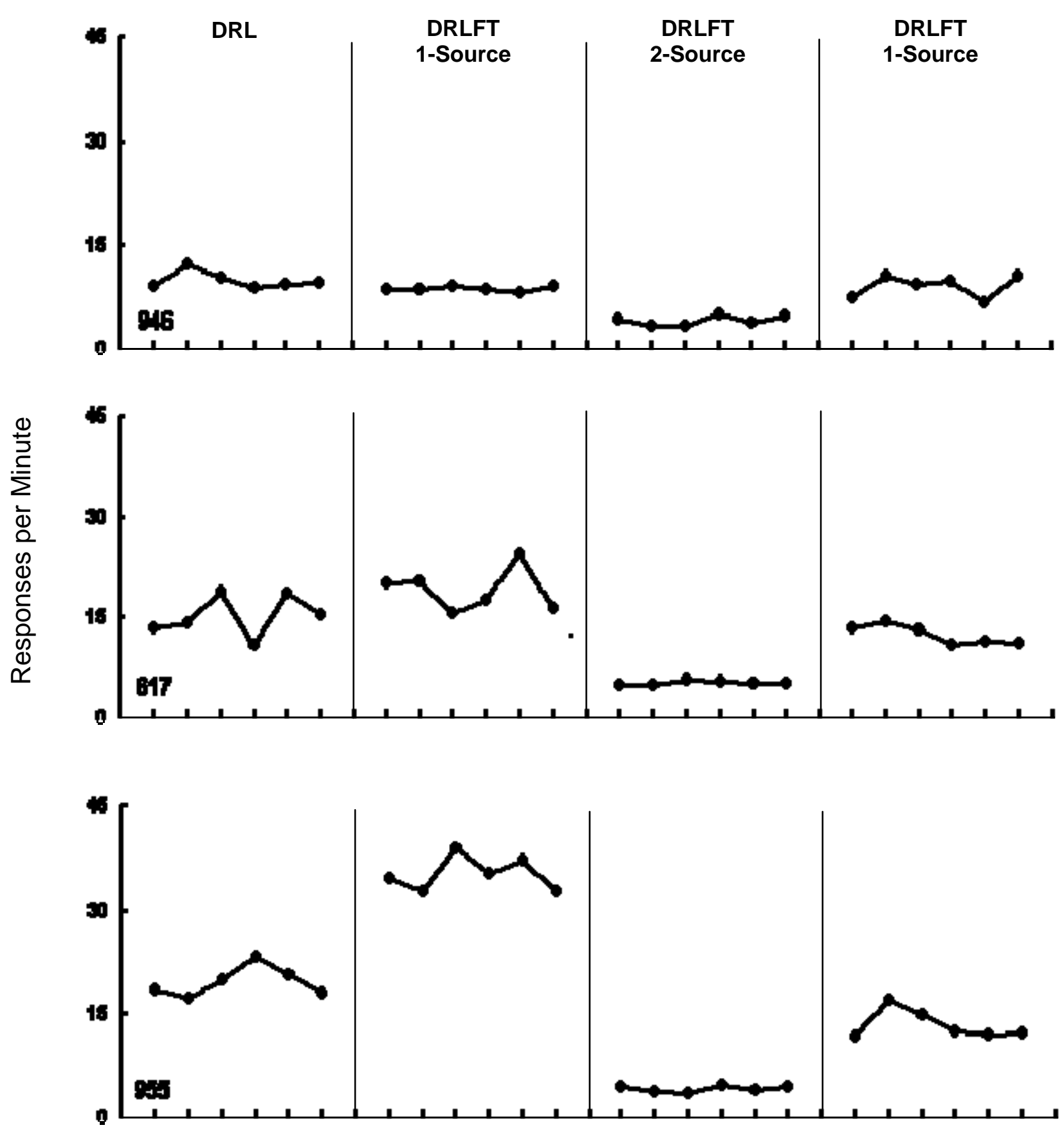

Sessions

Figure 7. Response rates during the last six sessions of each condition, for each pigeon in Experiment 3. 

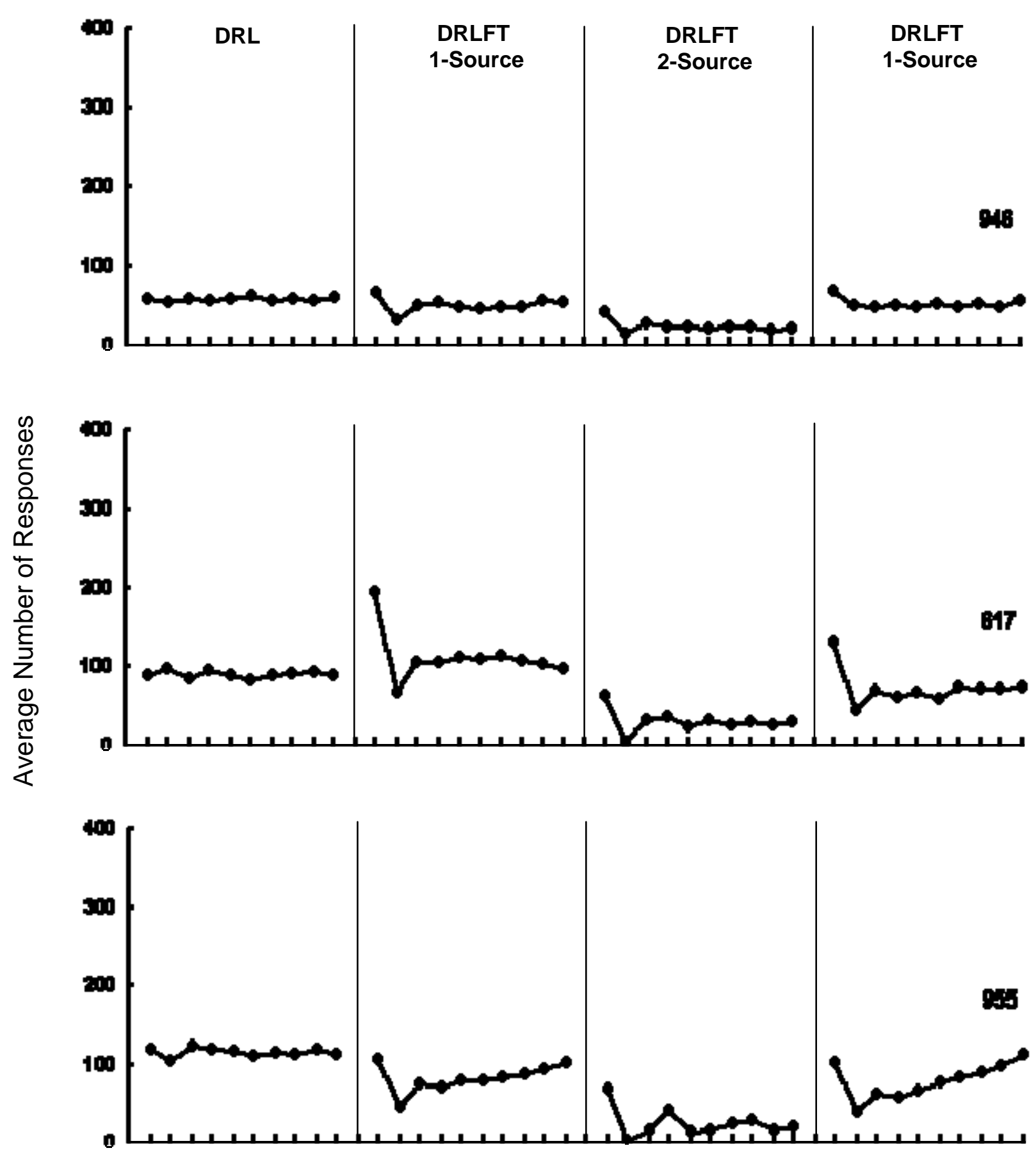

Tenths of the Alternative Interfood Interval

Figure 8. Average number of responses emitted in each tenth of the alternative-food intervals during the last six session of each condition, for each pigeon in Experiment 3. 


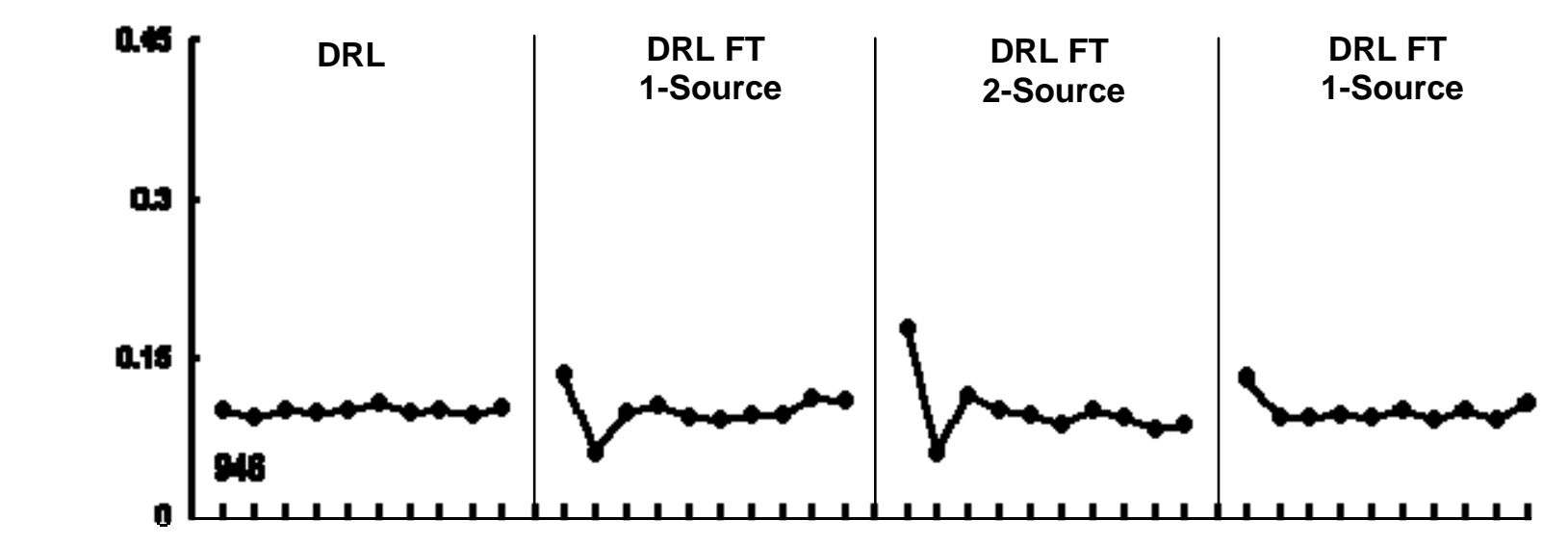

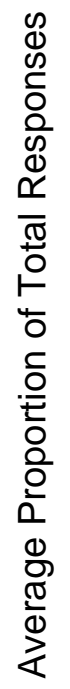
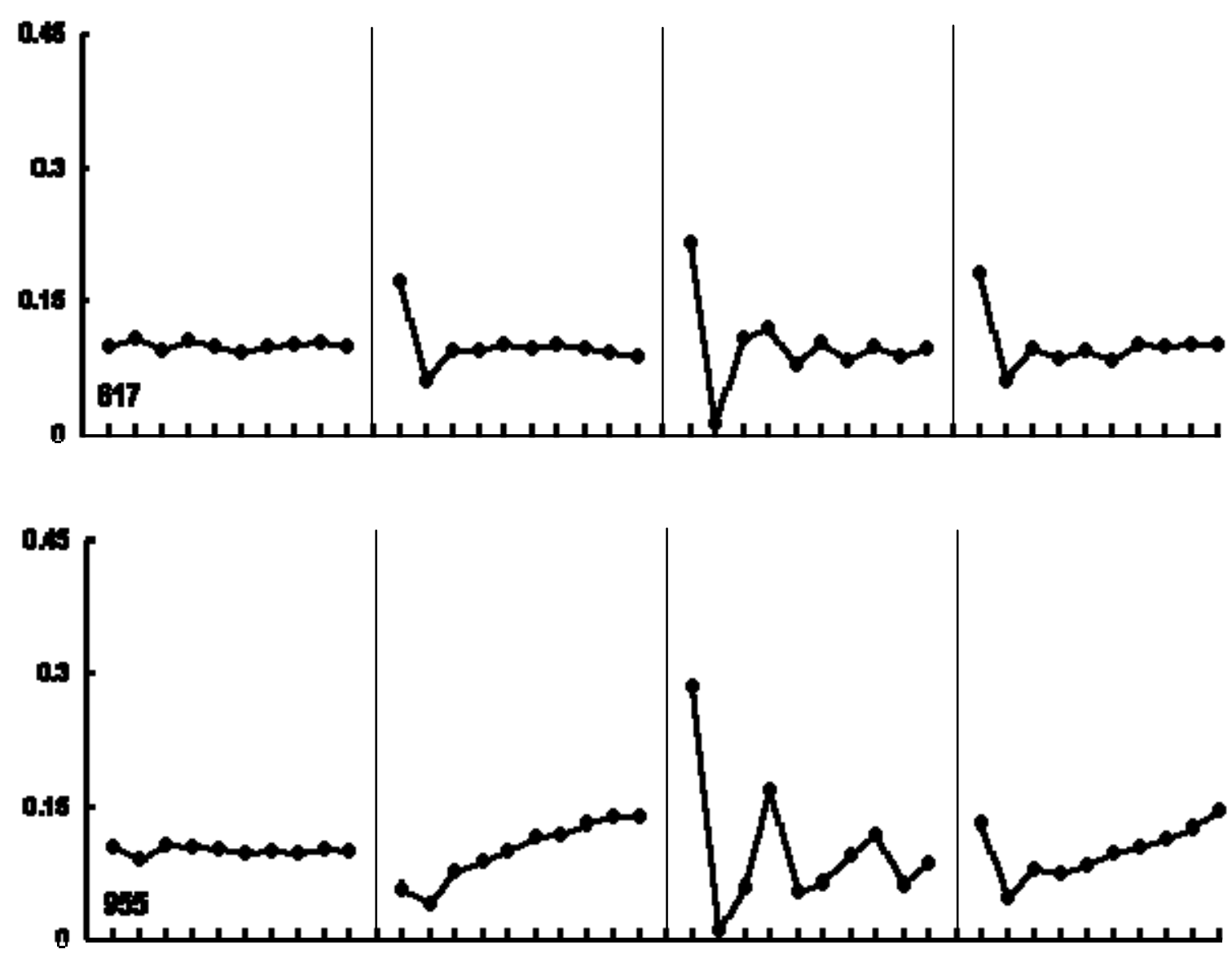

Tenths of the Alternative Interfood Interval

Figure 9. Average Proportion of responses emitted in each tenth of the alternative-food intervals during the last six sessions of each condition, for each pigeon in Experiment 3. 
conditions involving concomitant schedules, following the peak in the first tenth, responding during the second tenth was lower than during the remaining tenths (with the exception of Pigeon 946, during the second exposure to the DRL FT 1-source condition). From the third tenth of the alternative-food interval on, responding was linear (Pigeon 946 during the DRL FT 1-source conditions, Pigeon 617 during all conditions, and Pigeon 955 during the DRL FT 2-source condition), positively accelerated (Pigeon 955, during the DRL FT 1-source conditions), or negatively accelerated (Pigeon 946, during the DRL FT 2-source condition). In conclusion, the patterns that occurred from the third tenth of the alternative-food interval on were not consistent across pigeons.

Table 3 shows the average obtained delays between the last response before the alternative-food deliveries and the alternative-food deliveries, during the last six sessions of each concomitant-schedule condition. These delays were calculated as in Experiment 1. For each pigeon, longer delays were obtained during concomitant schedules with two food sources than with concomitant schedules with only one food source.

\section{Discussion}

In comparison to baseline, response rates only decreased systematically during the 2-source conditions. In all conditions with alternative-food deliveries, a peak in the proportion of responses during the first tenth of the alternative-food interval occurred and it was followed by a decrease in responding during the second tenth, as compared to the remaining tenths of the interval. From the third tenth on, however, responding was variable. These response peaks were more pronounced in the 2-source conditions. The average delays between the last response before the alternative-food deliveries and the alternative-food deliveries were longer with two food sources, as opposed to one. These results were consistent both within and across pigeons.

The occurrence of systematic decreases in response rates as compared to baseline only with 2 food sources is consistent with the results of both Experiments 1 and 2. Also as in these earlier experiments, the absence of decreases in response rates during the 1source conditions may reflect changes in the local patterns of responding across the alternative-food intervals. For example, for Pigeon 617, superimposing the alternative food from the same source delivering the operant food in the first 1-source condition sharply increased the number of responses during the first tenth of the alternative-food interval and, as a net result, overall response rates increased during this condition.

The presence of peaks in responding after the alternative-food deliveries also is consistent with the results of Experiment 2 and, like that experiment, may reflect the evocative effects of food deliveries. The fact that the peaks observed in Experiment 3, using a DRL schedule, were more pronounced than that of Experiment 2, in which a VI schedule was used, may be related to the higher response rates during VI schedules than during DRL schedules. That is, because fewer responses occur under DRL schedules, local increases in responding are proportionally greater with this schedule than with VI schedules. That overall response rates were even lower during the 2-source condition may explain why peaks in responding at the beginning of the alternative-food interval 
were more pronounced when there were two food sources. Finally, the decrease in responding during the second tenth of the alternative-food interval may be a function of the extinction of the higher response rates observed during the first tenth, because high rates are not reinforced under the DRL 30-s schedule.

The positively accelerated pattern of responding after the peak during the first tenth found for Pigeon 955 is consistent with the results of Lattal (personal communication, October $25^{\text {th }}, 2006$ ) and, as discussed in the literature review, may be a function of accidental temporal contiguity between keypecking and the alternative-FT food deliveries. This possibility is supported by the short average obtained delays between the last response before the alternative-food deliveries and these food deliveries for Pigeon 955, especially during the first 1-source condition. During the 2-source condition, when the positively accelerated pattern was less pronounced, average obtained delays were also longer. These delays decreased during the next 1-source condition, when the positively accelerated pattern again became more pronounced.

Finally, longer average delays between the last response before the FT food delivery and that food delivery during the 2-source condition is consistent with the results of Experiment 1, in which an FT also scheduled the alternative food. As in the previous experiments, there was an inverse relation between the average obtained delays and the average number of responses during the last tenth of the alternative-food intervals.

\section{EXPERIMENT 4}

During Experiment 3, superimposing alternative food arranged by an FT schedule to a baseline of DRL-maintained responding produced peaks in the proportion of responses emitted during the first tenth of the alternative-food interval. These peaks were more pronounced when the operant and alternative food were delivered from different sources. In one case, the peak during the first tenth of the alternative-food interval was followed by positively accelerated responding. Experiment 4 was conducted to investigate whether the peaks in responding and the positively accelerated pattern observed in Experiment 3 were a function of the fixed temporal arrangement of the alternative-food deliveries, or if similar results would be obtained when the temporal arrangement of the alternative food is variable.

\section{Method}

\section{Subjects}

Three pigeons, each with a prior history of responding under different reinforcement schedules, were maintained under conditions identical to those described in Experiment 1. 


\section{Apparatus}

The apparatus was the same as described in Experiment 3.

\section{Procedure}

Because of the pigeons' prior history, each was exposed from the experiment outset to the baseline consisting of a DRL 30-s schedule that was programmed as in Experiment 3 and in effect on the front panel, with the back panel located $30.5 \mathrm{~cm}$ away, until responding was stabilized.

Table 1 shows the schedule(s) in effect, the number of sources ( 1 or 2 hoppers) delivering the operant and the alternative food, and the final distance between these sources during the 2-source condition, for each pigeon and in each condition. The conditions in effect, their procedural details, and the order in which they were implemented during Experiment 4 were identical to Experiment 1, except that a DRL 30s schedule replaced the VI 300-s schedule used in Experiment 1 to arrange the operant food deliveries, and a VT 100-s schedule (programmed as described in Experiment 2) replaced the FT 100-s schedule to arrange the delivery of the alternative food. The condition labels were changed accordingly (i.e., DRL VT 1-source and DRL VT 2 source). All other procedural details were as described during the last four paragraphs of the procedure section of Experiment 1.

\section{Results}

Table 1 shows the average number of alternative-food deliveries in which the photocell was broken (indicating food consumption) by each pigeon during the last six sessions of each condition of Experiment 4. These averages ranged from 35 (Pigeon 791 during each 1-source condition, and Pigeon 960 during the last 1-source condition) to 21.7 (Pigeon 791, during the 2-source condition). The average number of alternative-food deliveries in which the photocell was broken was always smaller in the 2-source than in the 1-source conditions. Table 1 also shows the final distance between the operant and alternative-food sources. This distance was $122 \mathrm{~cm}, 61 \mathrm{~cm}$, and $30.5 \mathrm{~cm}$ for Pigeons 791, 960 , and 545, respectively.

Response rates for each pigeon during the last six sessions of each condition of Experiment 4 are shown in Figure 10. These rates, calculated as in Experiment 1, ranged from $5.8 \mathrm{rpm}$ (Pigeon 545) to $20.3 \mathrm{rpm}$ (Pigeon 960) during the DRL 30-s baseline. During the next condition, superimposing the VT food to the same source delivering the DRL food produced variable effects: an increase, a decrease, and maintenance of these rates were observed for Pigeons 791, 960, and 545, respectively. When the alternativeVT food was delivered from the back hopper, during the following condition, response rates of Pigeons 791 and 545 decreased from the previous conditions, but were not systematically changed for Pigeon 545. When the VT food was returned to the front hopper during the final condition, response rates of Pigeons 791 and 960 increased from the preceding condition, but Pigeon's 545 rates remained unaltered. 
The average number of responses and the average proportion of responses across the tenths of the alternative-food interval are shown in Figures 11 and 12, respectively.
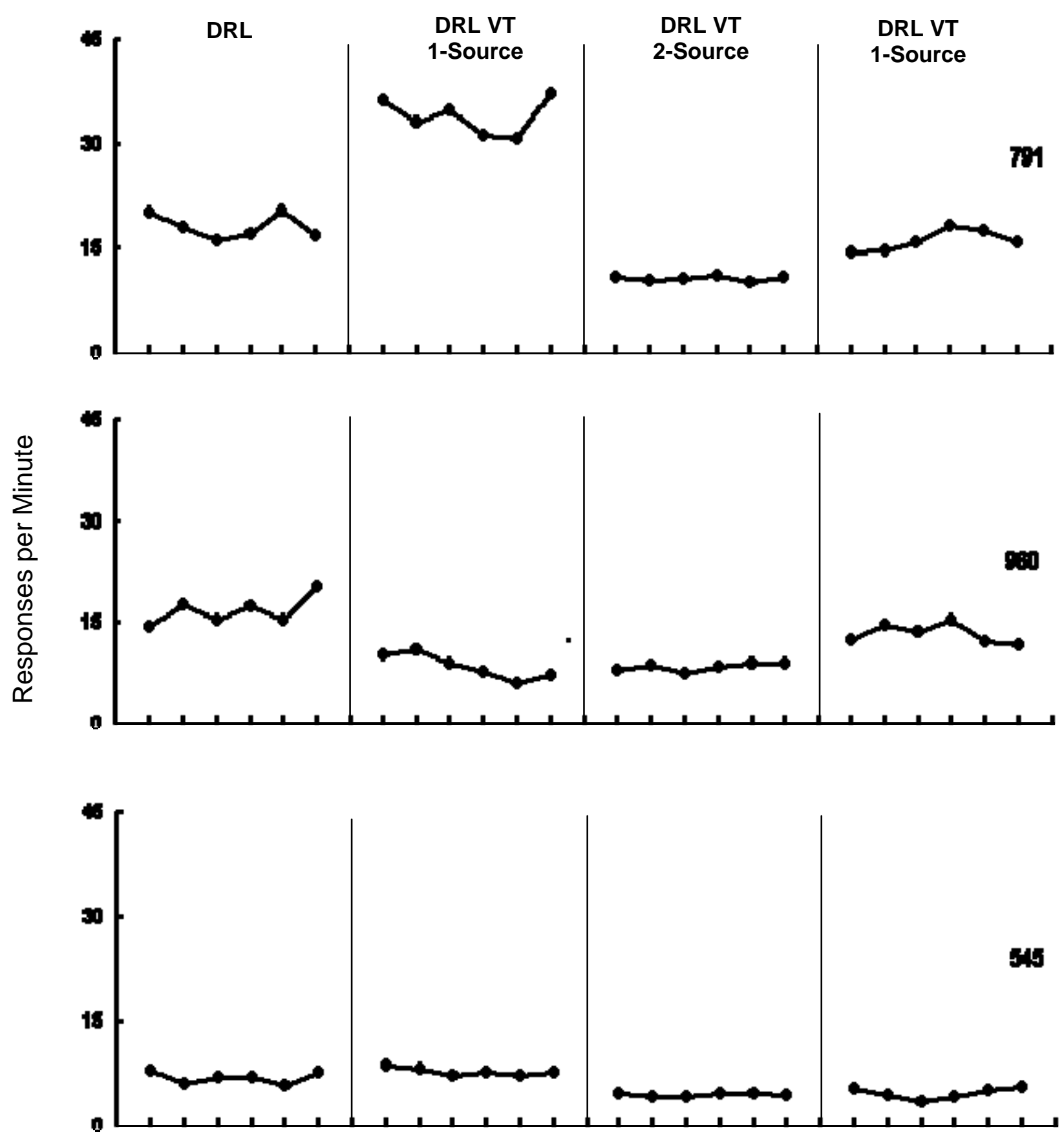

\section{Sessions}

Figure 10. Response rates during the last six sessions of each condition, for each pigeon in Experiment 4. 


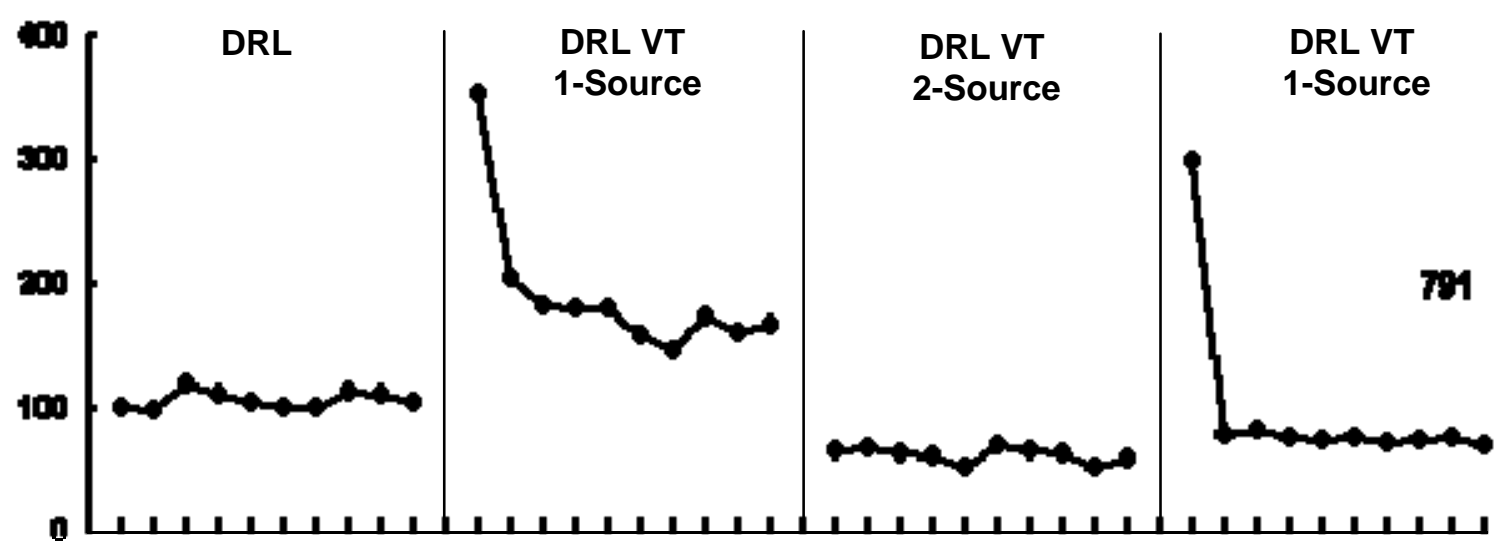

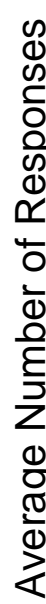
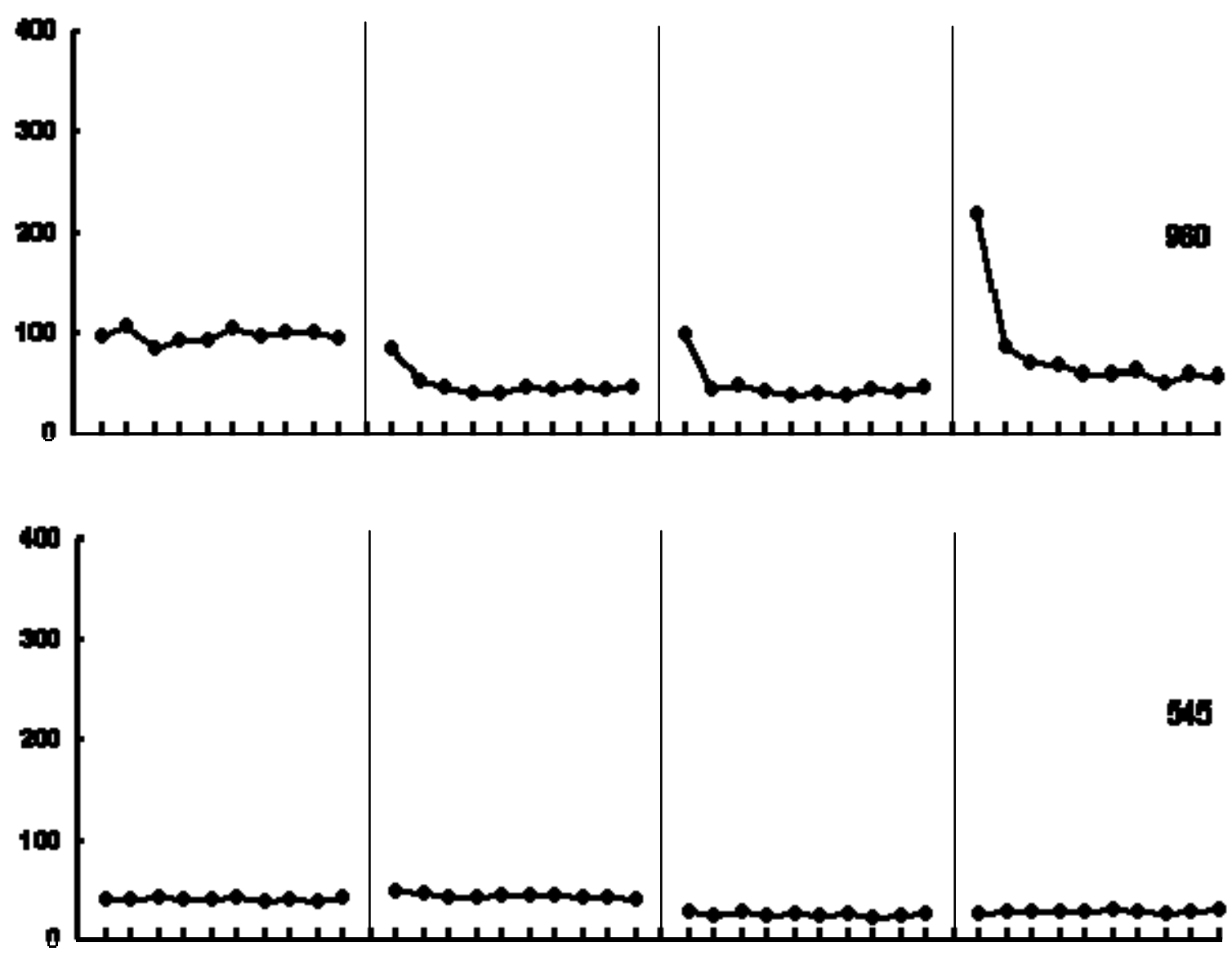

Tenths of the Alternative Interfood Interval

Figure 11. Average number of responses emitted in each tenth of the alternative-food intervals during the last six session of each condition, for each pigeon in Experiment 4. 


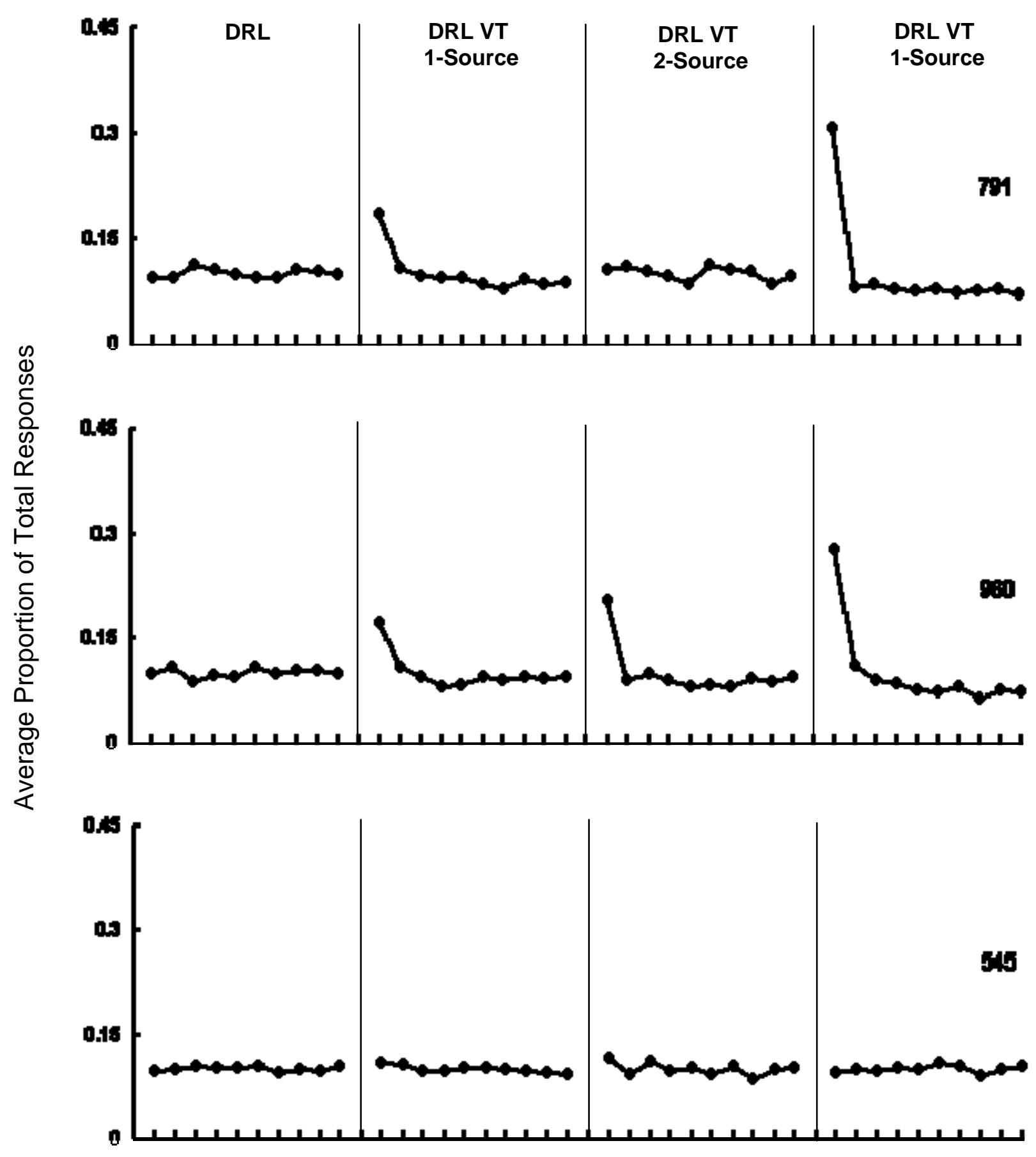

Tenths of the Alternative Interfood Interval

Figure 12. Average Proportion of responses emitted in each tenth of the alternative-food intervals during the last six sessions of each condition, for each pigeon in Experiment 4. 
Average quarter-life values are shown in Table 2. Each of these averages was calculated as in Experiment 2, including all VT-interval values. Responding was linearly distributed across successive tenths of the VT during the DRL baseline for each pigeon. In summary, irrespective of the number of sources delivering the operant and the alternative food, patterns of responding were most commonly characterized by a peak during the first tenth of the VT intervals, followed by more-or-less linear responding. Specifically, this peak occurred for Pigeons 791 and 960 when the alternative food was delivered either from the same or other source than the DRL food, in all but one case (Pigeon 791, during the DRL VT 2-source condition). Responding was linear from the second tenth of the alternative-food interval on, in all but one case (Pigeon 960 during the second exposure to the DRL VT-1 source condition, for which the pattern of responses was slightly negatively accelerated). For Pigeon 545, adding the alternative food from the same source or from a source other than that of the operant food did not produce changes in the linear pattern of responses observed during baseline.

Table 3 shows the average obtained delays between the last response before the alternative-food deliveries and the alternative-food deliveries, calculated as in Experiment 1, during the last six sessions of each concomitant-schedule condition and for each pigeon. These average obtained delays were variable: for Pigeons 960 and 545, a slight decrease and increase in the delays were observed across conditions, respectively. Only for Pigeon 791 a systematic effect of the number of food sources was observed, where greater average delays occurred when there were two sources of food.

\section{Discussion}

During Experiment 4, response rates decreased from the baseline only when the operant and alternative food were delivered from different sources. Patterns of responding were most commonly characterized by a peak during the first tenth of the VT intervals, followed by more-or-less linear responding across the remaining tenths, irrespective of the number of sources delivering the DRL and the VT food. No systematic effects of the number of food sources were observed on the average obtained delays between the last response before the VT food deliveries and these food deliveries.

Both within and across pigeons, there were no exceptions to the finding of lower response rates during the 2-source, as opposed to the 1-source, conditions. This was not true, however, for the patterns of responding. For Pigeon 791, a peak during the first tenth of the alternative-food interval was not observed during the 2-source condition. For Pigeon 960, responding was slightly negatively accelerated from the second tenth of the alternative-food interval on during the last 1-source condition; finally, responding across the VI interreinforcement intervals always was linear for Pigeon 545. Also, although differences between the 1- and 2-source conditions in terms of the average obtained delays between the last response before the alternative-food deliveries and the alternative-food deliveries were not systematic for Pigeons 960 and 545, these delays were longer with two sources of food, for Pigeon 791. 
As in Experiment 2, the final distance between the sources was not the same across pigeons, varying between $30.5 \mathrm{~cm}$ and $122 \mathrm{~cm}$. This seems not to have differentially affected response rates in each condition, however: during Experiment 4, as in the other experiments comprising this study, response rates systematically decreased from the Baseline condition only during the 2-source conditions. Also as in the previous experiments, the absence of decreases in response rates during the 1-source condition may reflect changes in local responding throughout the alternative-food intervals. For example, for Pigeon 791, when the VT food was superimposed on the DRL schedule baseline during the first 1-source condition, a sharp peak occurred during the first tenth of the VT intervals, and from the second tenth on, the average number of responses was still greater than those observed during the same periods in the Baseline condition. As a result, overall response rates were higher during this 1-source condition.

As in Experiment 3, in which a DRL schedule also arranged the operant food, peaks in responding during the first tenth of the alternative-food interval in both 1- and 2source conditions also occurred during the present experiment. That peaks were found during the first tenth of the alternative-food intervals in both Experiments 3 and 4 and in both 1- and 2-source conditions suggests that this finding was not a function of the number of sources or of the variable or fixed scheduling of alternative food. Rather, the peaks seem to be simply a function of adding alternative food to a baseline of DRLmaintained behavior and, as noted in the discussion of Experiment 3, may reflect the discriminative stimulus properties of the alternative-food delivery. For Pigeon 545, the absence of differences between the conditions both in terms of response patterns and the average obtained delays between the last response before the alternative-food delivery and this food delivery may be a result of the short distance $(30.5 \mathrm{~cm})$ between the operant- and alternative-food sources, during the 2-source condition.

The inconsistent differences across pigeons in the average obtained delays between the last response before the VT food delivery and this food delivery was also found in Experiment 2, in which a VT schedule also arranged the delivery of alternative food. As in Experiment 2, when the difference was consistent across conditions (Pigeon 791), average delays were longer with two, rather than one, food sources. In Experiment 4 , as in the previous experiments, there was an inverse relation between the average delays between the last response before the alternative-food deliveries and these food deliveries, and the average number of responses during the last tenth of the alternativefood intervals.

\section{EXPERIMENT 5}

As noted in the literature review, the results of several experiments suggest that whether and how response rates and patterns change when alternative food is superimposed during the schedule arranging the operant food depends, among other variables, on the schedule delivering the alternative food. Indeed, differential responding was found in Experiments 1-4 as a function of whether an FT or VT schedule was in effect. Because each pigeon was exposed to only one alternative-food schedule, however, comparisons of the results found with FT and VT schedules can be made only between 
subjects. Experiment 5 was conducted to allow within-subject comparison of responding when alternative food arranged according to either an FT or a VT schedule is added to a source other than that delivering the VI food.

Method

Subjects

The six pigeons previously used in Experiments 1 and 2 served in this experiment.

Apparatus

The apparatus was the same as described in Experiment 1.

Procedure

Because of the pigeons' prior history, each was exposed from the experiment outset to the first condition of Experiment 5. This condition was the VI FT 2-source for some pigeons, and the VI VT 2-source for other pigeons. As in Experiment 1, during the VI FT 2-source condition, a conct VI 300-s FT 100-s was in effect, in which the operant food was delivered from the front hopper, and the alternative food was delivered from the back hopper. As in Experiment 2, during the VI VT 2-source condition, a conct VI 300-s VT 100-s was in effect, in which the operant food was delivered from the front hopper, and the alternative food was delivered from the back hopper. The VI and the FT schedules were as programmed in Experiment 1, and the VT schedule was programmed as in Experiment 2. During the initial sessions, the distance between the operant and alternative sources of food was increased as described in Experiment 1 until the final distance for each pigeon (defined as the distance used in the previous experiment to which each pigeon was exposed) was reached.

The original experimental design called for the first condition of Experiment 5 to consist of the VI FT 2-source for three pigeons, and of the VI VT 2-source for the other three pigeons. Because of an experimenter error, however, five pigeons (681, 191, 481, 979, and 830) were first exposed to the VI VT 2-source, but Pigeon 536 was first exposed to the VI FT 2-source condition.

Table 4 shows the schedules in effect, the sources of the operant and the alternative food, and the final distance between these sources, for each pigeon and in each condition. During the two (Pigeons 681, 191, 481, and 536) or three (Pigeons 979 and 830) conditions following the initial one, the schedule delivering alternative food was reversed, with the same final distance between the food sources and all other procedural details identical to the previous condition. Pigeons exposed to the VI VT 2-source in one condition thus were exposed to the VI FT 2-source during the next condition, and vice versa. 
Table 4

Schedules in Effect in Each Condition, Number of Sources Delivering These Food Types, the Final Distance Between the Sources, the Number of Sessions per Condition, and the Average Number of Alternative-Food Deliveries in Which the Photocell was Broken ("Alt Food Consumed" - With Ranges in the Parenthesis) During Experiments 5 and 6.

\begin{tabular}{|c|c|c|c|c|c|c|c|c|c|c|}
\hline Exp. 5 & Pigeon & \multicolumn{2}{|c|}{$\begin{array}{cc}\text { Sessions } & \begin{array}{c}\text { Alt food } \\
\text { consumed }\end{array} \\
\text { VI VT } \\
\text { 2-source } \\
\end{array}$} & \multicolumn{2}{|c|}{$\begin{array}{cc}\text { Sessions } & \begin{array}{c}\text { Alt food } \\
\text { consumed }\end{array} \\
& \\
\text { VI FT } \\
\text { 2-source }\end{array}$} & \multicolumn{2}{|c|}{$\begin{array}{c}\text { Sessions } \begin{array}{c}\text { Alt food } \\
\text { consumed }\end{array} \\
\text { VI VT } \\
\text { 2-source } \\
\end{array}$} & \multicolumn{2}{|c|}{$\begin{array}{c}\text { Sessions } \begin{array}{c}\text { Alt food } \\
\text { consumed }\end{array} \\
\text { VI FT } \\
\text { 2-source } \\
\end{array}$} & \multirow[t]{2}{*}{$\begin{array}{c}\text { Final } \\
\text { distance } \\
\text { between } 2 \\
\text { sources }(\mathrm{cm}) \\
122\end{array}$} \\
\hline & 681 & 29 & $28.3(23-34)$ & 15 & $32.7(24-35)$ & 15 & $32.8(32-33)$ & - & - & \\
\hline & 191 & 27 & $24.3(17-28)$ & 26 & 29.7 (27-31) & 41 & 28.7 (20-32) & - & - & 122 \\
\hline & 481 & 38 & $25.3(21-28)$ & 15 & $31.8(30-34)$ & 18 & 26.7 (24-28) & - & & 122 \\
\hline & 536 & - & - & 17 & $34.5(33-35)$ & 16 & 33.7 (32-35) & 18 & 35 (35-35) & 61 \\
\hline & 979 & 16 & 33 (32-35) & 19 & $34.8(34-35)$ & 21 & $32.8(32-34)$ & 15 & 34.5 (33-35) & 30.5 \\
\hline & 830 & 20 & $28.3(27-29)$ & 17 & $34.5(34-35)$ & 17 & $33.2(32-34)$ & 20 & $29(21-32)$ & 30.5 \\
\hline \multirow{8}{*}{ Exp. 6} & & \multirow{2}{*}{\multicolumn{2}{|c|}{$\begin{array}{l}\text { DRL VT } \\
\text { 2-source }\end{array}$}} & \multirow{2}{*}{\multicolumn{2}{|c|}{$\begin{array}{l}\text { DRL FT } \\
\text { 2-source }\end{array}$}} & \multirow{2}{*}{\multicolumn{2}{|c|}{$\begin{array}{l}\text { DRL VT } \\
\text { 2-source }\end{array}$}} & \multirow{2}{*}{\multicolumn{2}{|c|}{$\begin{array}{l}\text { DRL FT } \\
\text { 2-source }\end{array}$}} & \\
\hline & & & & & & & & & & \\
\hline & 946 & 25 & 26.8 (21-29) & 15 & $24.8(21-31)$ & 16 & 22 (17-27) & - & - & 122 \\
\hline & 617 & 15 & $22.7(17-26)$ & 15 & 25.2 (23-27) & 16 & $22.8(15-28)$ & - & - & 122 \\
\hline & 955 & 17 & $32.2(30-34)$ & 34 & 30.7 (29-33) & 15 & $28.2(26-31)$ & - & - & 122 \\
\hline & 791 & - & - & 32 & $23(18-26)$ & 15 & $20.5(11-25)$ & 19 & 22.8 (18-29) & 122 \\
\hline & 960 & - & - & 55 & 34.3 (34-35) & 24 & 34.8 (34-35) & 28 & 34.7 (34-35) & 61 \\
\hline & 545 & - & - & 15 & $19.5(14-24)$ & 17 & $23.3(20-27)$ & 31 & 32 (29-34) & 30.5 \\
\hline
\end{tabular}


In the first condition, stability of responding was assessed after 15 sessions with the final distance between the sources of food. In the remaining conditions, stability was assessed after the $15^{\text {th }}$ session. The stability criteria and all other procedural details were as described in the last three paragraphs of the procedure section of Experiment 1.

\section{Results}

Table 4 shows the average number of alternative-food deliveries in which the photocell was broken (indicating food consumption) by each pigeon during the last six sessions of each condition of Experiment 5. These averages ranged from 35 (Pigeon 536, during the last VI FT 2-source condition) to 24.3 (Pigeon 191, during the first VI VT 2source condition). With the exception of Pigeons 830 and 681, for which there was no systematic difference between the conditions, the average number of alternative-food deliveries in which the photocell was broken was greater when the schedule delivering the alternative food was the FT, as opposed to the VT. Table 4 also shows the final distance between the operant and alternative-food sources. As noted in the methods section above, this distance was the same established as the final one during the previous experiment in which the pigeon served.

Figure 13 shows the response rates of each pigeon during the last six sessions of each condition of Experiment 5. These rates were calculated as described in Experiment 1. Only for Pigeon 191 there was a systematic effect of the alternative-food schedule. For this pigeon, response rates were higher during the VI FT 2-source conditions than on the VI VT 2-source condition. Changing from the VI VT 2-source to the VI FT 2-source condition increased or decreased the response rates observed during the VI VT 2-source condition only in two cases: Pigeon 191 in the first condition change, and Pigeon 830 in the last condition change, respectively. When the conditions changed from the VI FT 2source to the VI VT 2-source, response rates were either maintained (Pigeon 481), increased (Pigeon 830 in the second condition change), or decreased (Pigeons 681, 191 and 979 in the second condition change, and Pigeon 536 in the first condition change). Overall, response rates were not systematically different when the schedule delivering alternative food was FT or VT, and no differential effects were observed as a function of the order of the conditions.

Figures 14 and 15 respectively show the average number of responses and the average proportion of responses across the alternative-food intervals, and Table 5 shows the average quarter-life values during the last six sessions of all conditions of Experiment 5. When the alternative schedule was FT, these averages were calculated as in Experiment 1; when this schedule was VT, averages were calculated as in Experiment 2 (i.e., the analysis included all VT-interval values). In summary, although there were different patterns of responding in different conditions for different pigeons, when the negatively accelerated response pattern occurred it was more pronounced (Pigeon 481) and more consistent (Pigeons 191 and 830) when the alternative-food schedule was FT rather than VT. Moreover, when there was a peak during the first tenth of the alternativefood interval followed by either a slightly positively accelerated or linear responding (Pigeons 536 and 979, respectively), the peak was more pronounced and more consistent 

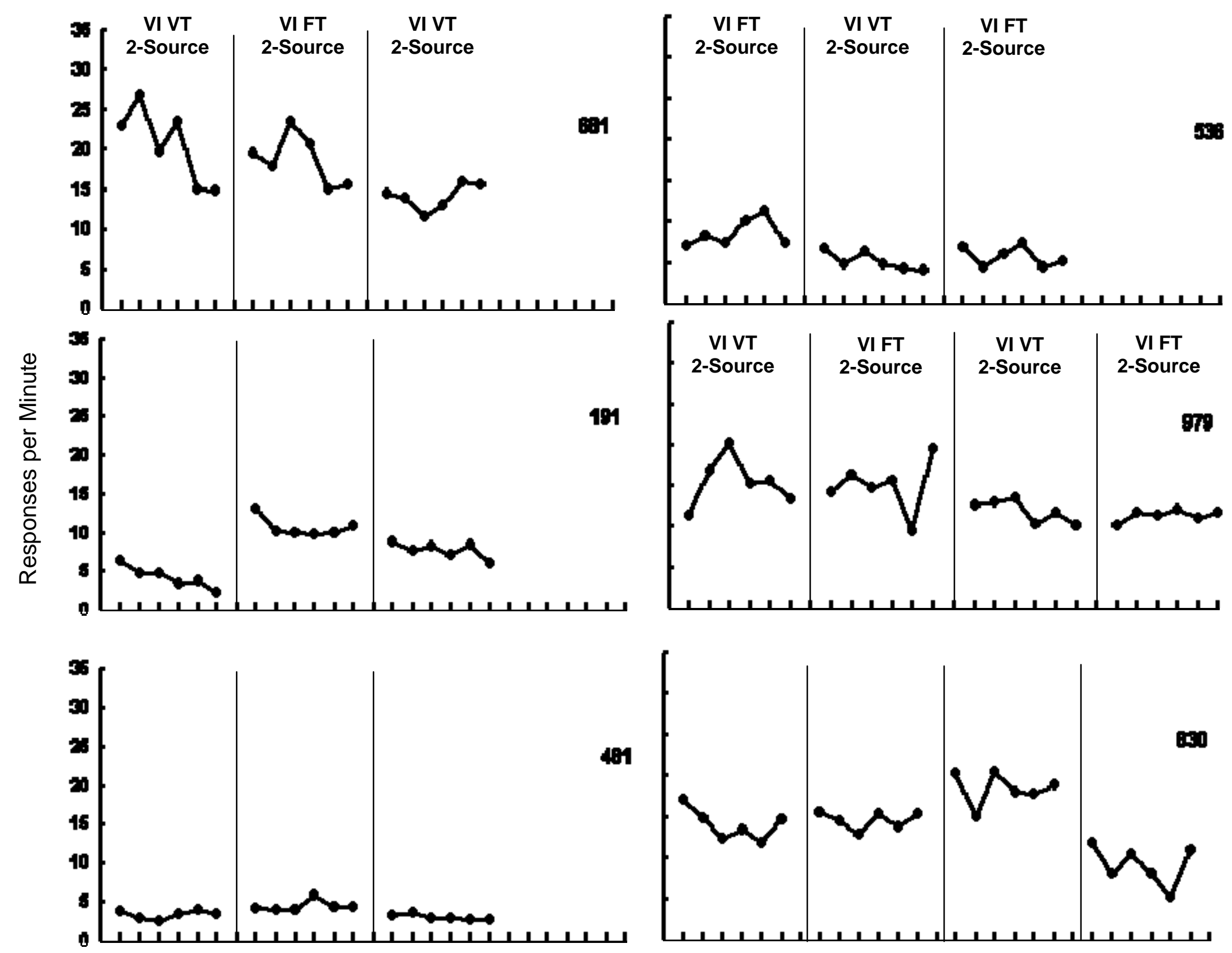

Sessions

Figure 13. Response rates during the last six sessions of each condition, for each pigeon in Experiment 5. 

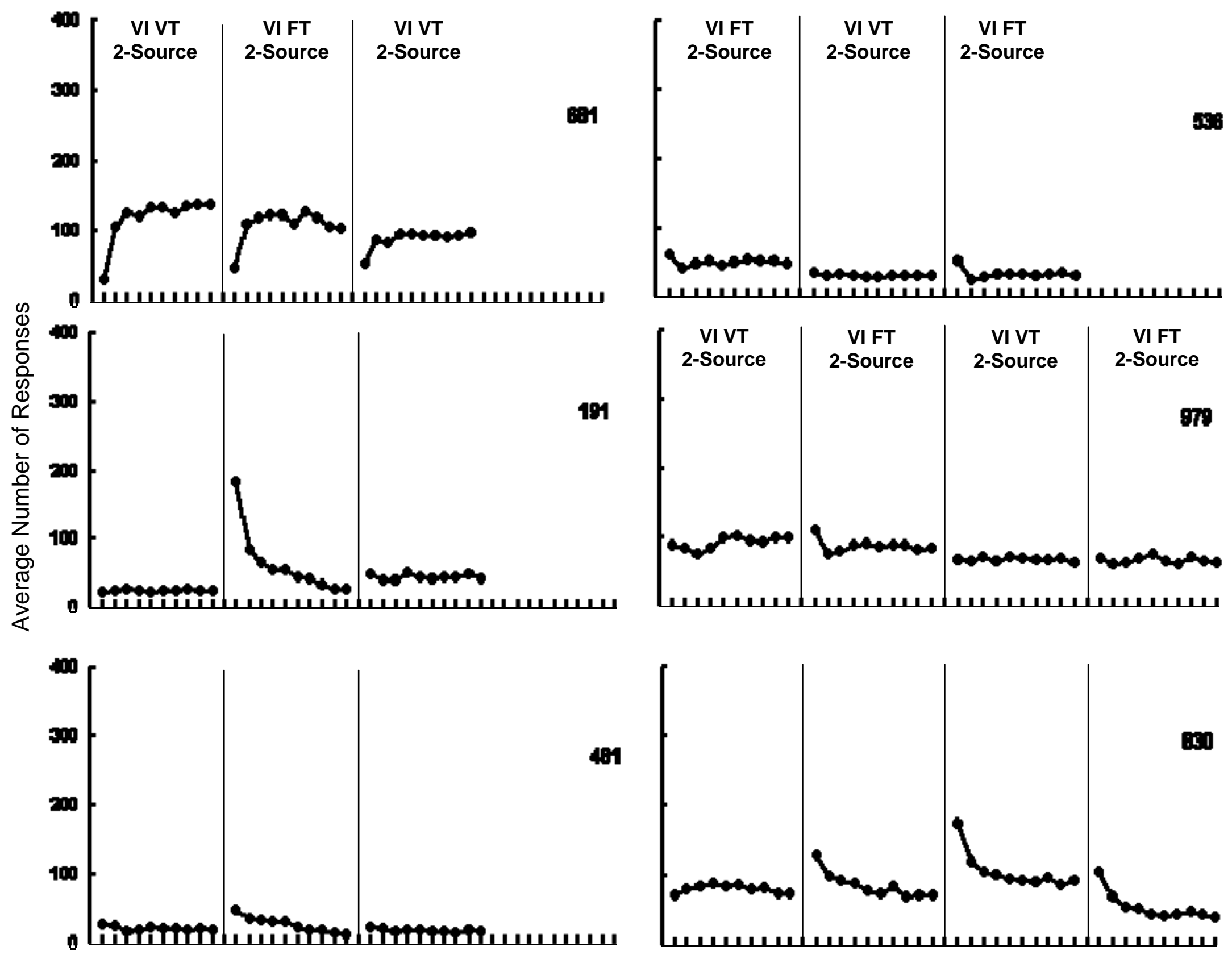

Sessions

Figure 14. Average number of responses emitted in each tenth of the alternative-food intervals during the last six session of each condition, for each pigeon in Experiment 5. 

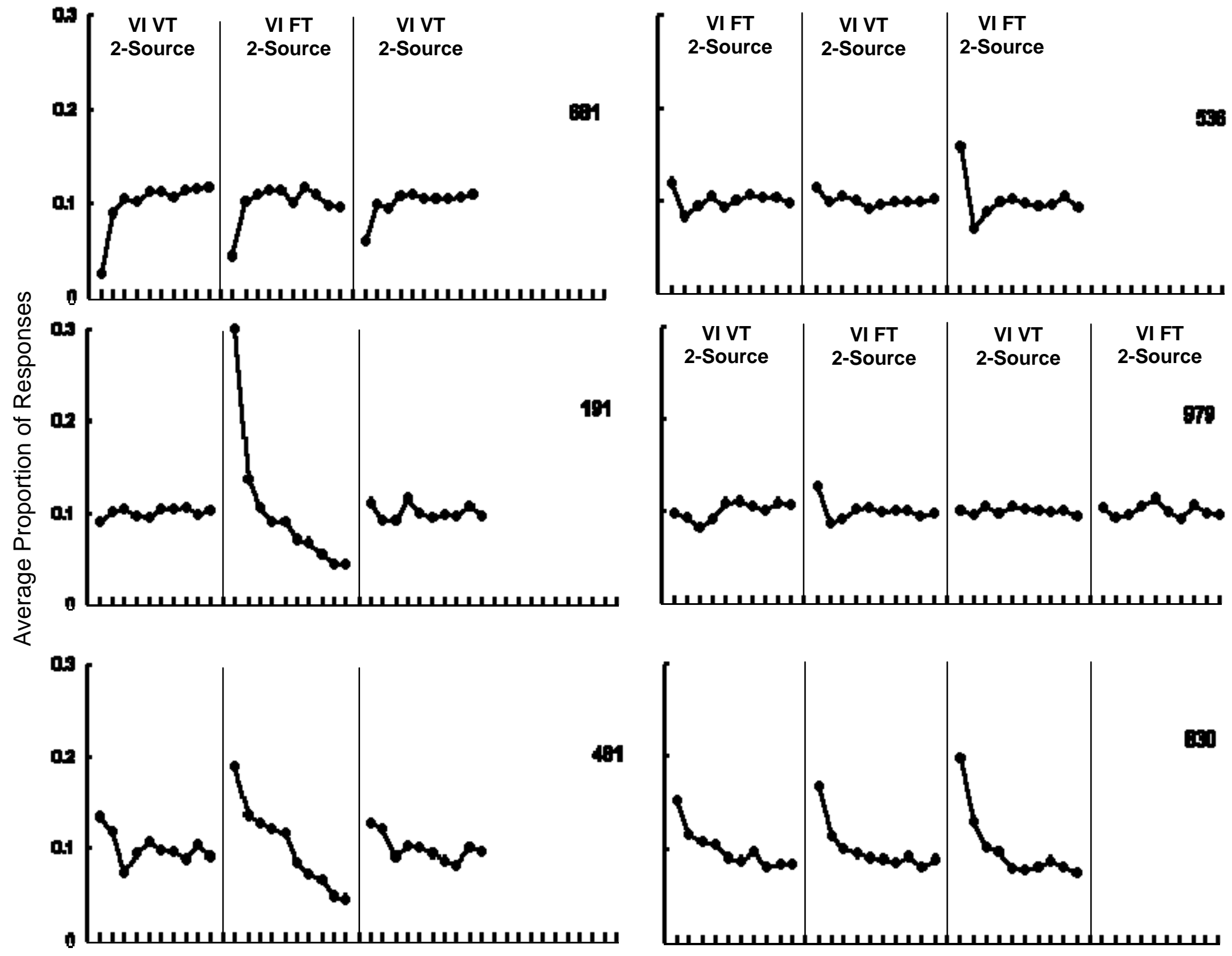

Sessions

Figure 15. Average Proportion of responses emitted in each tenth of the alternative-food intervals during the last six sessions of each condition, for each pigeon in Experiment 5. 
Table 5

Average Quarter-Life of the Last Six Sessions of Each Condition (Ranges in Parenthesis), for Each Pigeon, in Experiments 5 and 6.

\begin{tabular}{|c|c|c|c|c|c|}
\hline \multirow[t]{7}{*}{ Exp. 5} & Condition & $\begin{array}{c}\text { VIVT } \\
\text { 2-Source }\end{array}$ & $\begin{array}{c}\text { VIFT } \\
\text { 2-Source }\end{array}$ & $\begin{array}{c}\text { VIVT } \\
\text { 2-Source }\end{array}$ & $\begin{array}{c}\text { VIFT } \\
\text { 2-Source }\end{array}$ \\
\hline & 681 & 32.8 (29.3-37.4) & $29.6(26.7-30.9)$ & $29.6(28.3-32.1)$ & - \\
\hline & 191 & $25.2(22.6-28.7)$ & $8.4(7.2-9.6)$ & $25.1(22.1-29.3)$ & - \\
\hline & 481 & $20(11.8-27)$ & $14.4(12.2-16.8)$ & $19.5(16.1-20.8)$ & - \\
\hline & 536 & - & $25(21.7-28.7)$ & $23.5(21.1-26.1)$ & $21.4(17.3-26.6)$ \\
\hline & 979 & $27.3(25.1-28.9)$ & $23.7(20.5-28.8)$ & $25.3(23.2-27)$ & 25.7 (23.8-29.3) \\
\hline & 830 & $25.7(23.9-26.5)$ & $18.7(15.8-21.7)$ & $17.2(15.5-19.4)$ & $14.8(11.3-17.6)$ \\
\hline \multirow[t]{8}{*}{ Exp. 6} & & VI & VIVT & VIVT & VIVT \\
\hline & & Baseline & 1-Source & 2-Source & 1-Source \\
\hline & 946 & $21.2(18.4-26.4)$ & $24.1(22.1-26.5)$ & $23.5(22.3-24.4)$ & - \\
\hline & 617 & $20.7(18.1-25)$ & $19(14.7-21.9)$ & $19.8(16.4-22.4)$ & - \\
\hline & 955 & 13.7 (9.8-17.5) & $5.7(5.2-6.2)$ & $11.9(9.2-13.7)$ & - \\
\hline & 791 & - & $18.9(14.1-27.8)$ & 18.8 (17.3-20.7) & $23.6(21-15.5)$ \\
\hline & 960 & - & $11.4(9-15.7)$ & $16.3(15-17.5)$ & $29.3(24.3-32.5)$ \\
\hline & 545 & - & $21.1(18.5-24)$ & $23.2(18-26.3)$ & $22.6(21.6-24.5)$ \\
\hline
\end{tabular}


when the alternative-food schedule was FT. For Pigeon 681, there were no systematic differences in the pattern of responses when the alternative-food schedule was either VT or FT. For this pigeon, with both alternative schedules responding was lower during the first tenth of the alternative-food interval.

The average obtained delays between the last response before alternative-food deliveries and the delivery of that alternative food during the last six sessions of each condition shown in Table 6 were calculated as in Experiment 1. Systematic differences in these delays depending on the schedule arranging the delivery of the alternative food occurred for only two pigeons. Specifically, for Pigeons 191 and 481, average delays were longer when the schedule arranging the alternative-food delivery was FT, as opposed to VT. For the remaining pigeons, there were no systematic differences between the average delays as a function of the schedule delivering the alternative food or the order of exposure to these schedules (with the exception of the slight decrease in the delays across conditions observed for Pigeon 536).

\section{Discussion}

In Experiment 5, response rates were not systematically different between the FT and VT conditions of food delivery. Negatively accelerated responding and peaks during the first tenth of the alternative-food intervals followed by either linear or slightly positively accelerated responding were more common and more pronounced with FT-, as opposed to VT-alternative food delivery. Finally, for most pigeons, average obtained delays between the alternative-food deliveries and these food deliveries did not vary systematically as a function of the schedule arranging the alternative food.

There were exceptions, however, to each of these results. Response rates were higher for Pigeon 191 when the FT schedule delivered the alternative food, as opposed to the VT schedule. Furthermore, a decrease rather than peaks in responding during the first tenth of the alternative-food interval occurred for Pigeon 681, and a negatively accelerated response pattern was found for Pigeons 481 and 830 during some of the conditions involving the VT schedule. Also, there were systematic differences in the obtained delays between the last response before the alternative-food delivery and this food delivery as a function of the schedule arranging this food for Pigeons 191 and 481. For these pigeons, longer delays occurred when the alternative-food schedule was the FT, as compared to the VT.

No studies have conducted within-subject comparisons of responding under VT with responding under FT schedules, when these schedules were in effect concomitantly with other schedules. A few studies, however, have compared responding under single VT and FT schedules. Consistently with the findings in Experiment 5, many of these studies have revealed no systematic differences in response rates as a function of the exposure to these different alternative schedules. For example, Zeiler (1968) found similar decreases in response rates when either a VI or an FI schedule was changed to a VT or an FT schedule. As in Experiments 1-4 comprising this study, during Experiment 5 , response rates in the different conditions reflected the pattern of responding during the 
Table 6

Average Obtained Delays Between the Last Response Before the Alternative-Food Deliveries and Alternative-Food Deliveries During the Last Six Sessions of the Conditions With Alternative Food, for Each Pigeon in Experiments 5 and 6. Numbers in Parenthesis are Standard Deviations.

\begin{tabular}{cccccc}
\hline Exp. 5 & Condition & $\begin{array}{c}\text { VIVT } \\
\text { 2-Source }\end{array}$ & $\begin{array}{c}\text { VIFT } \\
\text { 2-Source }\end{array}$ & $\begin{array}{c}\text { VIVT } \\
\text { 2-Source }\end{array}$ & $\begin{array}{c}\text { VIFT } \\
\text { 2-Source }\end{array}$ \\
& & & & & \\
& & & & & \\
& Pigeon & $10.05(22.44)$ & $9.84(19.18)$ & $3.88(5.87)$ & - \\
& 681 & $12.83(15.57)$ & $19.95(19.50)$ & $8.93(10.30)$ & - \\
& 191 & $20.12(23.22)$ & $36.52(12.30)$ & $13.9(12.30)$ & - \\
& 481 & - & $8.01(9.30)$ & $9.78(10.65)$ & $11.36(11.09)$ \\
& 536 & $5.89(6.98)$ & $5.41(5.93)$ & $6.24(6.62)$ & $6.68(6.44)$ \\
& 979 & $5.47(5.96)$ & $5.87(4.88)$ & $4.74(4.41)$ & $21.47(29.93)$ \\
\hline & 830 & VI & VIVT & VIVT & VIVT \\
& 946 & $10.78(9.54)$ & $9.81(8.71)$ & $9.93(10.12)$ & - \\
& 617 & $11.77(7.75)$ & $11.84(7.38)$ & $15.28(10.64)$ & - \\
& 955 & $13.91(9.44)$ & $17.33(9.35)$ & $14.13(10.97)$ & - \\
& 791 & - & $11.29(9.00)$ & $9.98(7.60)$ & $11.49(7.51)$ \\
& 960 & - & $5.84(7.31)$ & $6.76(6.49)$ & $5.14(5.62)$ \\
& 545 & - & $10.99(13.54)$ & $8.20(6.34)$ & $7.65(5.85)$ \\
\hline
\end{tabular}


alternative-food intervals. For Pigeon 191, for example, the change from the VI VT 2source to the VI FT 2-source schedule changed the pattern of responding from linear to negatively accelerated. This negatively accelerated responding was characterized by a sharp peak during the first tenth of the alternative-food interval followed by decreasing responding across the remainder of the interval. As a result, overall response rates increased during the VI FT 2-source schedule. During the subsequent VI VT 2-source condition, the response pattern became linear again and overall response rates decreased.

The fact that negatively accelerated responding across the time schedule interfood interval was more common when VI schedules were combined with FT as opposed to VT schedules is consistent with the results of both Experiments 1 and 2. Also, consistent with experiments combining VI and FT schedules arranging food from different sources (Experiment 1 of the present study and Lattal \& Abreu-Rodrigues, Experiment 5), this pattern of responding did not always occur. For Pigeon 681, for example, response patterns were similar to those obtained during Experiment 1, and may be explained in the same manner. That is, the decrease in the first tenth of the alternative-food interval may have been a function of pausing and walking back from the back hopper after the delivery of the alternative food. Also as discussed in Experiment 1, it is possible that the negatively accelerated pattern did not emerge because, when the FT hopper was activated, this pigeon was able to reach the hopper and consume the food before it was deactivated. The response of orienting towards the alternative-food source thus probably was controlled by the stimuli that accompanied activation of the back hopper (i.e., the light and the noise), as opposed to the regularity of the alternative-food intervals.

A negatively accelerated pattern during the VT alternative-food delivery schedule is not, however, consistent with the results of Experiment 2. In each of the VI VT 2source conditions where negatively accelerated responding occurred, the immediately preceding condition was a VI FT 2-source in which this pattern was observed (for Pigeon 481, this condition was the last one in effect during Experiment 1). Thus, decreasing responding across the VT food intervals might have been a carryover of the effects produced by combining VI and FT food from different sources. This result is consistent with other experiments reporting that patterns of responding under alternative schedules may be a function of the pattern generated by the history of exposure to another reinforcement schedule (e.g., Lattal, 1972). It also is not surprising that peaks in responding were most common when the alternative schedule was FT. This probably is because, in contrast to the VT food deliveries, a second FT food was never delivered shortly after the previous one. Thus, responses that would allow the consumption of the alternative food (such as orienting towards the back hopper) did not compete with keypecking immediately after the delivery of the alternative food, when this food was delivered by the FT, as opposed to the VT schedule.

In addition to the schedules delivering the alternative food, another variable that may have influenced the results is the distance between the operant- and alternative-food sources for each pigeon. In general, response patterns across the alternative-food intervals were more systematically different during the VI VT 2-source and VI FT 2-source conditions when the distance between the sources was either $122 \mathrm{~cm}$ or $60.5 \mathrm{~cm}$ (Pigeons 
191, 481, and 536; there were no systematic differences for Pigeon 681, possibly because of the reasons described in the discussion of Experiment 1 and mentioned above). When the distance between the sources was shorter (30.5 cm - Pigeons 979 and 830), there were no systematic differences in patterns of responding between the VI VT 2-source and VI FT 2-source conditions.

Finally, while average delays between the last response before the alternativefood deliveries and alternative-food deliveries were largely unsystematic across and within pigeons, for Pigeons 191 and 481 these delays were longer when the FT schedule arranged the delivery of alternative food. For these pigeons, the negatively accelerated response pattern was more pronounced during the VI FT 2-source condition, implying low local response rates during the last tenth of the alternative-food interval and, thus, decreasing the likelihood that a response would be closely followed by an alternativefood delivery.

\section{EXPERIMENT 6}

As Experiment 5, this experiment was designed to compare responding maintained when FT or VT food occurred from either the same or a different source than the reinforcer. In Experiment 6, however, the operant food was arranged by a DRL schedule rather than a VI schedule.

\section{Method}

\section{Subjects}

The six pigeons previously used in Experiments 3 and 4 served in this experiment.

\section{Apparatus}

The apparatus was the same as described in Experiment 3.

\section{Procedure}

Because of the pigeons' prior history, each was exposed from the experiment outset to the first condition of Experiment 6. This condition consisted of the DRL FT 2source for three pigeons, and of the DRL VT 2-source for the other three pigeons. As in Experiment 3, during the DRL FT 2-source condition, a conct DRL 30-s FT 100-s was in effect, in which the operant food was delivered from the front hopper, and the alternative food was delivered from the back hopper. As in Experiment 4, during the DRL VT 2source condition, a conct DRL 30-s VT 100-s was in effect, in which the operant food was delivered from the front hopper, and the alternative food was delivered from the back hopper. The FT schedule was programmed as described in Experiment 1, the VT schedule was programmed as described in Experiment 2, and the DRL schedule was programmed as described in Experiment 3. During the initial sessions, the distance 
between the operant and alternative sources of food was increased as described in Experiment 1 until the final distance for each pigeon (defined as the distance used in the previous experiment to which each pigeon was exposed) was reached.

Table 4 shows the schedules in effect, the sources of the operant and the alternative food, and the final distance between these sources, for each pigeon and in each condition. During the two conditions following the initial one, the schedule delivering alternative food was reversed, with the same final distance between the food sources and all other procedural details identical to the previous condition. Pigeons exposed to the DRL VT 2-source in one condition thus were exposed to the DRL FT 2-source during the next condition, and vice versa.

In the first condition, stability of responding was assessed after 15 sessions at the final distance between the sources of food. In the remaining conditions, stability was assessed after the $15^{\text {th }}$ session. The stability criteria and all other procedural details were as described in the last three paragraphs of the procedure section of Experiment 1.

Results

Table 4 shows the average number of alternative-food deliveries in which the photocell was broken (indicating food consumption) by each pigeon during the last six sessions of each condition of Experiment 6. These averages ranged from 34.8 (Pigeon 960, during the DRL VT 2-source condition) to 19.5 (Pigeon 545, during the first exposure to the DRL FT 2-source condition). With the exception of Pigeons 617 and 791, for which the average number of alternative-food deliveries in which the photocell was broken was greater when the schedule delivering the alternative food was the FT, there were no systematic differences as a function of the schedule delivering the alternative food. Table 4 also shows the final distance between the operant- and alternative-food sources. As observed in the methods section above, this distance was the same established as the final one during the previous experiment to which the pigeon was exposed.

Figure 16 shows the response rates of each pigeon during the last six sessions of each condition of Experiment 6, calculated as described in Experiment 1. Overall response rates were similar across all conditions for each pigeon, with two exceptions: for Pigeon 791, response rates decreased during the last exposure to the DRL FT 2-source condition, and for Pigeon 960 response rates decreased slightly during the DRL VT 2source condition, but did not recover during the next DRL FT 2-source condition. For each pigeon, overall response rates were not systematically different when the schedule delivering alternative food was either FT or VT, and no differential effects were observed as a function of the order of exposure to the conditions.

The average number of responses and the average proportion of responses during the alternative-food intervals of the last six sessions of each condition are shown in Figures 17 and 18, respectively. Average quarter-life values of the last six sessions of each condition are shown in Table 5. Each of these averages was calculated as described 

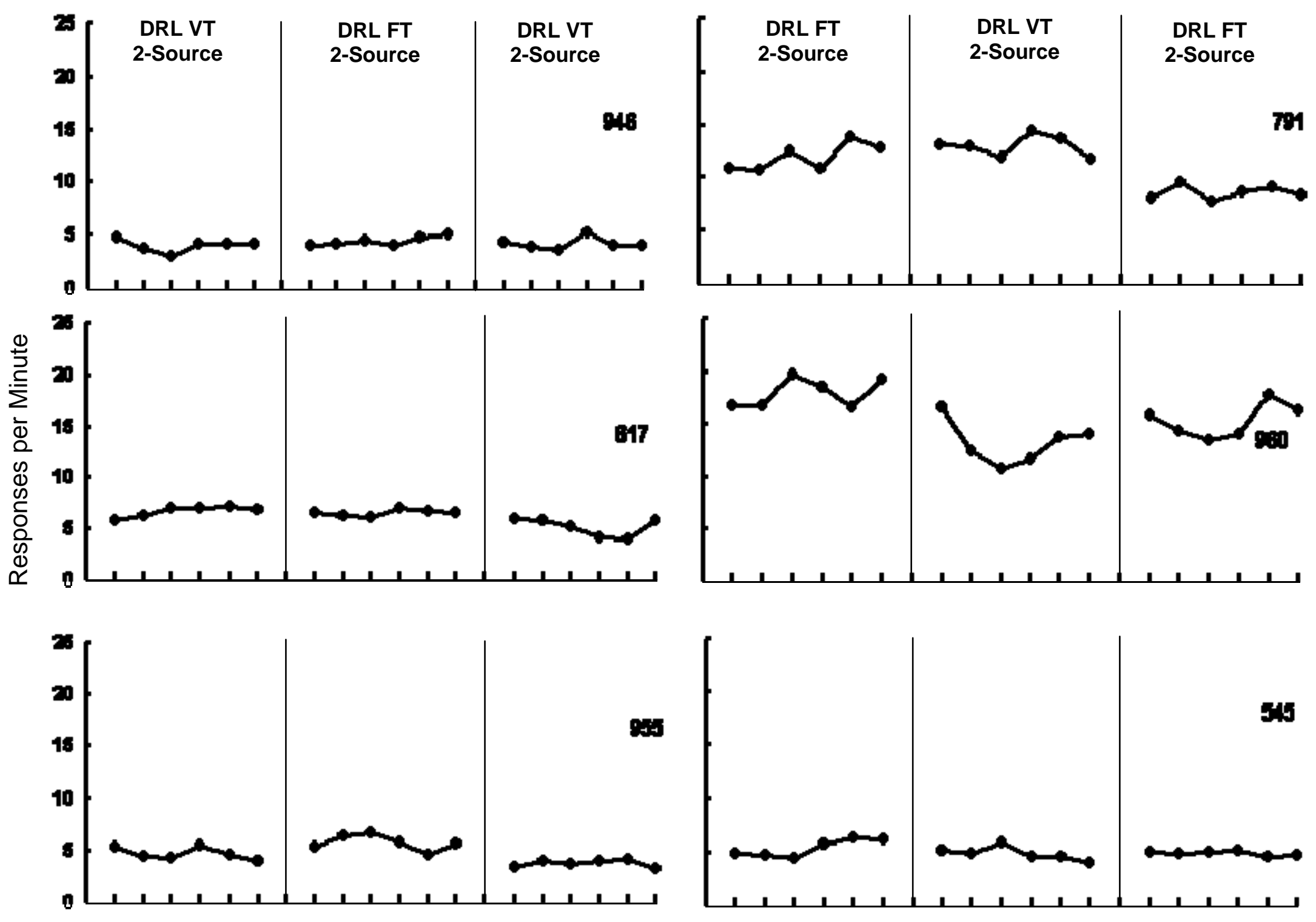

Sessions

Figure 16. Response rates during the last six sessions of each condition, for each pigeon in Experiment 6. 

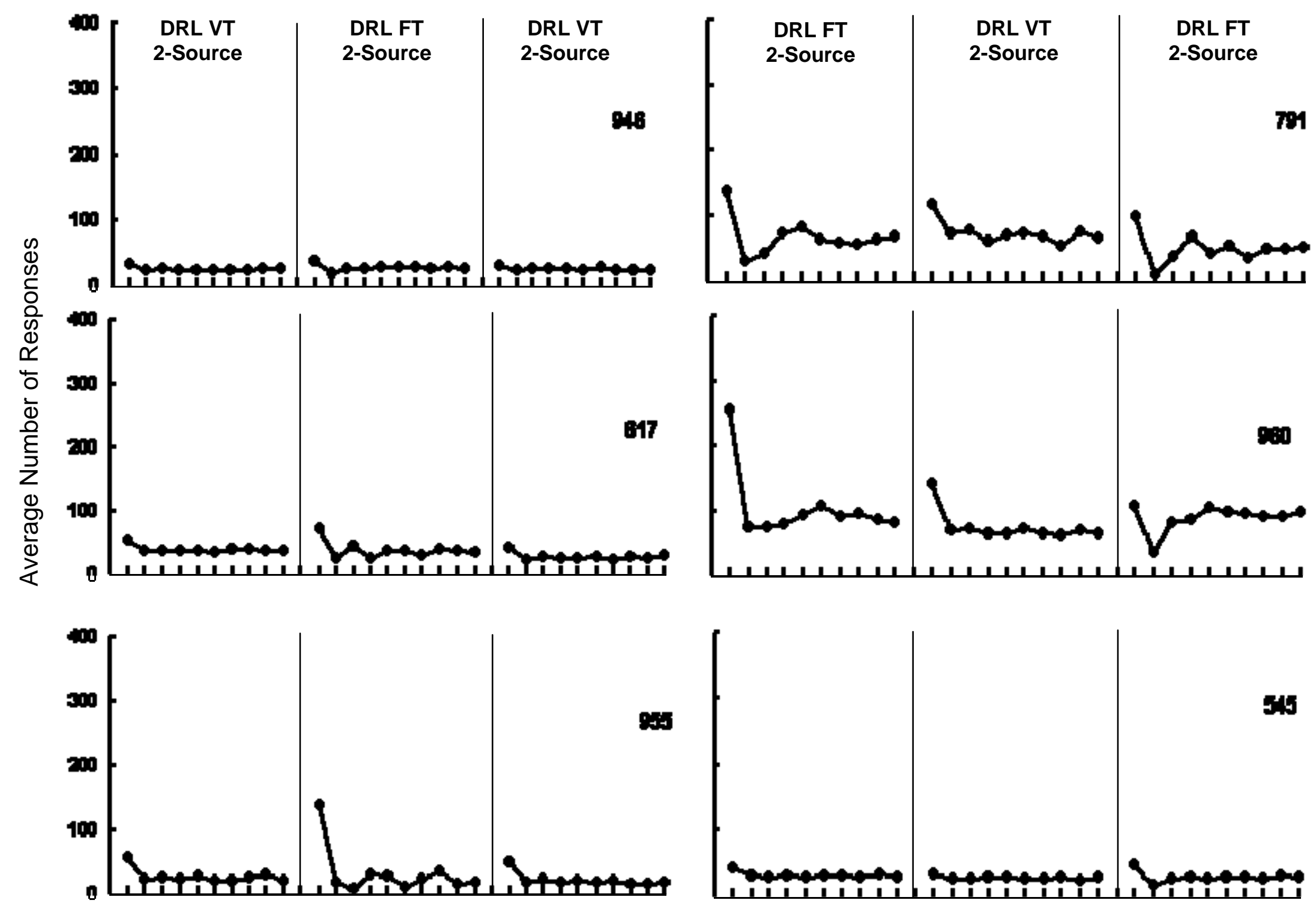

Sessions

Figure 17. Average number of responses emitted in each tenth of the alternative-food intervals during the last six session of each condition, for each pigeon in Experiment 6. 


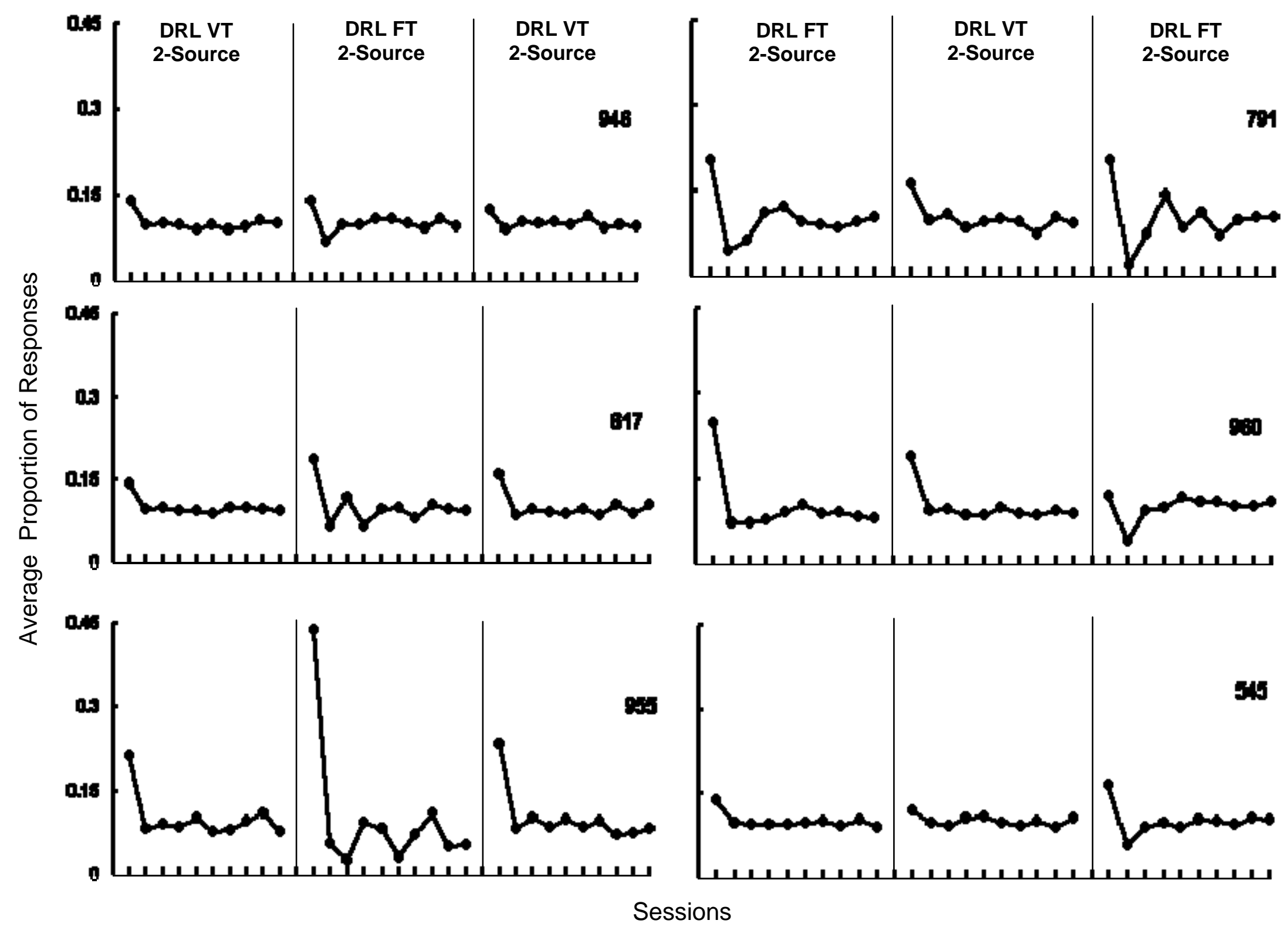

Figure 18. Average proportion of responses emitted in each tenth of the alternative-food intervals during the last six session of each condition, for each pigeon in Experiment 6. 
in Experiments 1 and 2 when the alternative-food schedule consisted, respectively, of the FT and the VT (including all the interval values). In summary, in all conditions and for each pigeon, the pattern of responses peaked during the first tenth of the alternative-food intervals (although such peak was less pronounced for Pigeon 545 under the DRL VT 2source condition). Furthermore, the peak in the pattern during the first tenth of the interval was more pronounced when the alternative-food schedule was FT (with the exception of Pigeon 960, during the second exposure to the DRL FT 2-source condition). The data in Figure 18 show that there were three different local patterns of responding during the VT and FT interfood intervals. The most common pattern was one of linear responding following a peak in responding during the first tenth of the alternative-food interval. This linear pattern was observed for each pigeon under the DRL VT 2-source condition, and in four instances during the DRL FT 2-source conditions (Pigeons 617 and 955, and Pigeons 960 and 545 on the first exposure to the condition). The second- most common pattern was a decrease in the distribution of responses during the second tenth, following the peak during the first tenth, and linear responding from the third tenth of the alternative-food interval onward. This pattern was observed only in the DRL FT 2-source condition, in four conditions (Pigeon 946, Pigeon 791 in the last exposure to the condition, and Pigeons 960 and 545, on the last exposure to this condition). A positively accelerated pattern of responding across the alternative-food interval after the peak at the first tenth of the alternative-food intervals was observed only for Pigeon 791 on the first DRL FT 2-source condition.

The average obtained delays between the last response before the alternative-food deliveries and the alternative-food deliveries across the last six sessions of each condition, calculated as in Experiment 1, are shown in Table 6. Although the effects of the different schedules arranging the alternative food sometimes were systematic, the direction of these effects varied between pigeons. For Pigeons 955 and 791, greater average delays were found when the schedule delivering the alternative food was FT. For Pigeon 960, however, the opposite result was found. That is, average obtained delays were slightly longer when the alternative-food schedule was VT. For the remaining pigeons, no differences in the average obtained delays were observed as a function of the alternative-food schedule.

\section{Discussion}

Response rates did not systematically change across conditions of Experiment 6, as a function of the schedule delivering the alternative food. In addition, a peak in responding after the alternative-food delivery always occurred, regardless of the schedule of alternative food delivery. These peaks were more pronounced, however, when the FT schedule was in effect, as compared to the VT schedule. Average obtained delays between the last response before the alternative-food delivery and this food delivery were not systematically different during the DRL FT 2-source and the DRL VT 2-source conditions.

The results were consistent across all pigeons in terms of the absence of systematic response -rate differences between the conditions delivering FT and VT food. 
Pigeon 960 was the only exception for more pronounced peaks in the proportion of responses during the first portion of the alternative-food interval with the FT schedule than the VT schedule. Specifically, during the last DRL FT 2-source condition, the peak in the first tenth of the alternative-food interval was smaller than that during the previous DRL VT 2-source condition. There also were exceptions to the absence of systematic differences in the average obtained delays between the last response before the alternative-food delivery and this food delivery, between the DRL FT 2-source and DRL VT 2-source conditions. For Pigeons 955 and 791, greater average delays occurred when the FT schedule delivered the alternative food. For Pigeon 960, however, the opposite result was obtained.

The lack of systematic differences in response rates when the alternative schedule was FT or VT is consistent with the results of Experiment 5, in which a VI schedule was used to arrange the operant food. Furthermore, results of studies showing no systematic differences in response rates under single FT and VT schedules are consistent with those of Experiment 6 (e.g., Zeiler, 1968). As in Experiments 1-5 of the present study, changes or maintenance of overall response rates reflected the local responding across the alternative-food intervals under each condition. For example, for Pigeon 791, when the alternative-food schedule was changed from VT to FT, the average number of responses decreased during most tenths of the alternative-food interval, as compared to the average number of responses per tenth during the previous condition. As a result, response rates decreased from the DRL VT 2-source to the DRL FT 2-source condition.

The peak during the first tenth of the alternative-food intervals observed during the DRL FT 2-source and DRL VT 2-source conditions is consistent with the findings of Experiments 3 and 4, respectively, using the same schedules. As in these experiments, the peaks may reflect the discriminative stimulus properties of the alternative-food deliveries. Furthermore, the more pronounced nature of the response peaks when the alternativefood schedule was FT, as opposed to VT, is consistent with the results of Experiment 5. As with those results, these in Experiment 6 may be a function of the fixed or variable temporal arrangement of food deliveries by the FT and VT schedules.

The fact that the most common pattern after the peak was linear indicates that the temporal arrangement of the FT food did not control the DRL responding in these cases. The second most common pattern was a decrease in responding during the second tenth of the alternative-food interval. This decrease during the second tenth is consistent with the results of Experiment 3 and, as in that Experiment, may be a result of the extinction of the high-rate responding after the first tenth, because high response rates are not reinforced under the DRL 30-s schedule. The slightly positively accelerated pattern of responses found for Pigeon 791 under the first DRL FT 2-source condition is consistent with the findings of Lattal (personal communication, October $25^{\text {th }}, 2006$ ) and of Experiment 3, in which similar responding was obtained for Pigeon 955 under identical conditions. As previously discussed, this pattern may be a function of accidental reinforcement of responding by alternative-food deliveries, and of the regular temporal distribution of the FT-food delivery. 
As in Experiments 2, 4, and 5, the final distance between the food sources was not identical across pigeons. It does not seem, however, that this difference in distances affected the results in major ways. For example, for all pigeons, response rates were not different as a function of the schedule arranging the alternative food, independently of the distance between the sources. It is also possible, of course, that increasing the distance further than $122 \mathrm{~cm}$ would have produced more systematic results.

As previously noted, average obtained delays between the last response before the alternative-food deliveries and these food deliveries did not seem to be a function of the alternative-food schedule. For the few cases in which there were systematic differences between the FT and VT conditions, the variability shown in Table 6 as standard deviations was great enough to prevent safe conclusions about these differences. It is possible, however, that further increasing the distance between the sources for each pigeon would produce more systematic effects of the alternative-food schedule on the average delays.

\section{GENERAL DISCUSSION}

The series of experiments presented here further examined the interactions between alternative- and operant-schedules arranged concomitantly, and investigated the effects of separating the food sources on both the response rates and patterns produced by these schedules. To integrate and account for the results obtained, in the first part of this general discussion section the results of Experiments 1-6 are systematized and compared to the literature on the effects of concomitant schedules. During this part of the discussion, accounts are also offered for the results obtained with different schedules arranging the operant and alternative food, depending on whether these food sources were separated or the same. Next, the relation between the procedures and results of the present experiments and those of other operant studies are outlined, in an attempt to integrate different areas of research. Finally, the implications of the present experiments for applied research and practice are discussed, and general conclusions are offered.

\section{Effects of the Schedules And the Number of Sources Delivering the Operant And Alternative Food}

In each experiment that involved the manipulation of the number of sources delivering the operant and the alternative food, overall response rates only decreased systematically from the operant-schedule baseline when these food sources were separated. When the sources were not separated, variable results were observed across experiments: sometimes response rates decreased, sometimes they increased, and sometimes they remained unchanged. These variable results are consistent with those of other studies in which decreases in response rates when an alternative-food schedule was added to a schedule delivering operant food from the same source was not proportional to the proportion of operant food delivered (e.g., Lattal \& Bryan, 1976, Experiment 3).

Taken together, these results with respect to the alternative food source location qualify Zeiler's (1968) observation that, in simple transitions from interval to time 
schedules, response rates and response patterns are independently controlled by the response-reinforcer dependency and by the temporal distribution of food presentations, respectively. That is, if the response-reinforcer dependency is the primary variable determining response rates, such rates would necessarily decrease from the operantschedule baseline when the alternative food is added, because not all "reinforcers" are dependent on responding under a schedule that simultaneously delivers operant and alternative food. It thus seems to be the case that this independent control of response rates and patterns do not apply in situations in which operant and alternative-food schedules are in effect simultaneously. In this case, the response-reinforcer dependency and the temporal distribution of food presentations appear to interact to determine response rates and patterns of responding. For example, it is possible that some level of responding is maintained because the operant schedule dictates response-reinforcer dependency. At the same time, alternative food deliveries may affect overall response rates directly as a result of being accidentally paired with responding, or indirectly as a result of its temporal distribution causing changes in local response rates.

The fact that the temporal distribution of alternative food presentations may affect overall response rates indirectly as a result of the changes they cause in local response rates was previously observed by Lattal and Abreu-Rodrigues (1997). In their Experiment 5 , changes in local response rate were produced by requiring a changeover response to access the food arranged by the VI and the FT schedule, and by associating each schedule with a specific discriminative stimulus - that is, by temporally separating the food delivered by each schedule. In some of the conditions, the animals were reported to orient towards the hopper more frequently as the FT interval elapsed. Arguably, thus, the FT schedule came to control this orienting response, as opposed to key-pecking, and this resulted in the negatively accelerated pattern of keypecking. To the extent that the alternative food comes to control a response other than key peck, albeit adventitiously, this response can come under the control of the temporal distribution of the FT-food deliveries. Thus keypecking and the response controlled by the FT interval become mirrored images of one another: as the FT interval progresses, the specific responses controlled by the interval increase and, if such response is incompatible with keypecking, then keypecking becomes less frequent as the FT interval elapses. As a result of this process, the negatively accelerated pattern of keypecking throughout the FT interfood interval emerges (cf. Nevin, 1971; Lattal \& Abreu-Rodrigues, 1997, Experiment 5). The results of the present experiments replicated the negatively accelerated response pattern found by Lattal and Abreu-Rodrigues when VI schedules were combined with FT schedules, and extended their results by using a DRL schedule to arrange the operant food and by spatially (as opposed to temporally) separating the food sources.

In the present experiments, the negatively accelerated response pattern was more common and more pronounced when FT schedules arranged the alternative-food delivery from a different source than that of the baseline schedule. This finding is consistent with the possibility that the temporal arrangement of the alternative-food delivery came to control a response other than keypecking. When the sources of operant and alternative food are spatially separated, a specific response that allows consumption of the alternative food is actually required. In this case, the consumption of the alternative food 
is dependent on walking to the hopper where this food is delivered, a distinct operant response not unlike pecking a second key or engaging in observing behavior vis à vis the feeder. Thus, the schedule arranging the temporal distribution of the alternative food comes to control the response of walking to the hopper where this food is delivered, while the schedule delivering the operant food controls keypecking. Because keypecking and walking towards the hopper delivering the alternative food are incompatible responses, the specific temporal distribution of the alternative food should affect the distribution of keypecking across the alternative food intervals: the temporal distribution of keypecking thus become negatively accelerated when the alternative-food schedule is an FT, but remains linear when this schedule is VT. Furthermore, because control of a response other than keypecking is more likely when the food sources are separated, and because this response may compete with keypecking, overall response rates are lower with two rather than with one food source.

The negatively accelerated response pattern was more common when the baseline schedule was the VI, as opposed to the DRL. One difference between these two schedules that may explain this result is the response-pacing requirement involved in DRL schedules. That is, DRL schedules require that responding be controlled by the passage of time. This temporal control required by the DRL schedule thus may have competed with control by the temporal arrangement of the FT food, thereby making the negatively accelerated responding less common with DRL schedules than with VI schedules, which do not require temporal control of responding.

The pattern of responding most commonly found when the baseline schedule was a DRL consisted of peaks in responding during the first tenth of the alternative-food interval followed by variable responding, irrespective of the schedule delivering the alternative food. This pattern may be related to the discriminative properties of the alternative food deliveries ( $c f$. Uhl \& Garcia, 1969) discussed previously. Also as discussed previously, the fact that the peaks during the first tenth of the alternative-food interval were more pronounced with DRL than VI schedules may be related to the absolute number of responses generated by these schedules. That is, because less responding occurs under DRL schedules, peaks may seem more pronounced because local increases in responding are proportionally greater with this schedule than with the VI schedule. Peaks were also more pronounced with FT, as opposed to VT schedules, probably because under FT schedules alternative food is never delivered immediately after another FT-food delivery, and thus the responses that may be controlled by the FTfood delivery (such as orienting towards this food source) do not compete with keypecking.

When the baseline schedule was DRL, after the peak in responding during the first tenth of the alternative-food interval, positively accelerated responding occurred in only one case (Pigeon 955, during the conct DRL FT 1-source conditions of Experiment 3 ). This result is consistent with those of Lattal (personal communication, October $25^{\text {th }}$, 2006), who also found this pattern in a few cases, and may be a result of accidental reinforcement of keypecking by alternative-food deliveries. When the positively accelerated pattern occurred, obtained delays between the last response before the 
alternative-food delivery and alternative-food deliveries were shorter in the 1-source, as compared to the 2-source, condition. Perhaps the positively accelerated pattern was not maintained during the 2-source condition because, in this condition, keypecking was not closely followed by alternative-food deliveries, and thus the accidental reinforcement effects were eliminated.

In addition to the schedules arranging the operant and alternative food and the number of sources delivering each food type, the distance between these sources may have influenced the results. Based on a pilot study showing that alternative-food consumption would sharply decrease if the distance between the sources was greater than $122 \mathrm{~cm}$, this distance was set as the one to be used in the present experiments for each pigeon (thereby maintaining the final distance between sources constant across experiments). In several cases, however, consumption of the alternative food decreased to low levels before the final $122 \mathrm{~cm}$ distance was attained, and thus the distance between the food sources could not be further increased. Perhaps differences in responding with one and two food sources would be more systematic if the distance between them was longer. It is possible that in some cases (for example, Pigeon 681 in Experiment 1), this distance was so short that, when the alternative-food hopper was activated, the pigeon could travel to the alternative-food source rapidly enough to consume this food, before the hopper was deactivated. Thus, the temporal arrangement of this alternative food did not come to control responses other than keypecking. It is also interesting that when the final $122 \mathrm{~cm}$ distance between food sources was not attained, it was when the alternative schedule was VT, and never when it was FT. That the temporal arrangement of food is regular under the FT schedule and not under the VT schedule may account for this result. In other words, the delivery of food under the FT schedule is "predictable," in that responses that enable consumption of the alternative food (such as walking towards the alternative-food source) may increase in frequency as the FT interval elapses. In contrast, because VT-food deliveries are irregular and therefore "unpredictable," responses that allow consumption of this food do not necessarily occur before their delivery, and thus this alternative food sometimes was not consumed. This possibility is supported by the fact that, in general, there were fewer photocell breaks (indicating food consumption) when the alternative-food schedule was VT, as opposed to FT.

\section{Combinations of Operant- And Alternative-Food Delivery in the Basic Extant Operant- Behavior Literature}

The results obtained in the present experiments have implications both to research on the effects of the concomitant combination of operant and alternative-food schedules,

and to other basic operant studies that share similarities with the present study in terms of the goal of better understanding the behavioral interactions that develop when more than one food source or schedule of food delivery is in effect at the same time. To this end, this section focuses on four research areas: other experiments in which concomitant schedules have been investigated, contrafreeloading, choice, resistance to change, and temporal control. 
On the Effects of Concomitant Schedules of Reinforcement

In summary, the series of experiments presented herein contribute to the concomitant-schedules literature by providing evidence of how the operant and alternative schedules interact when they consist of VI or DRL and FT or VT, respectively, and how this interaction is modulated by the separation between the sources of food. When VI schedules were combined with VT schedules delivering food from the same source, on the one hand, response rates did not always decrease, and remained linear for most subjects, consistent with the results of Lattal (1974). When VI were combined with FT schedules, on the other hand, responding also did not decrease systematically, and in some cases patterns of responding became negatively accelerated, consistent with the results of Lattal \& Abreu-Rodrigues (1997). When a DRL was the operant schedule and an FT delivered the alternative food from the same source, variable changes in response rates occurred, and, in a few cases, responding became positively accelerated, consistent with the results of Lattal (personal communication, October $25^{\text {th }}$, 2006). The results of the present experiments also extend previous research by determining the effects of combining DRL and VT schedules, and of the spatial separation of the food sources.

The effects of spatially separating the sources of operant and alternative food were similar to those obtained by Lattal and Abreu-Rodrigues, who temporally separated the food arranged by the operant- and alternative-food schedules (1997, Experiment 5). Taken together, the results of both studies indicate that the spatial/temporal separation of these food sources change the nature of the interaction between the schedules in effect. As discussed in the section above, it appears that the separation of the operant- and alternative-food sources increased the likelihood of discrimination between the schedules of operant and alternative food - that is, the likelihood that the schedules will control different responses (specifically, keypecking and walking or orienting towards the alternative-food source).

\section{Contrafreeloading}

Given that the operant schedules arranged food deliveries less often than the alternative-food schedules, it may seem surprising that increasing the distance between food sources resulted in abandonment of the alternative-food, rather than the operantfood schedule. Similar results have been reported in other studies, and have been labeled as “contrafreeloading” (e.g., Osborne, 1977; Inglis, Forkman, \& Lazarus, 1997).

Typically, in these studies, subjects are exposed to a reinforcement schedule during the baseline, followed by a test in which the same schedule is in effect and, additionally, the events used as reinforcers are made continuously available during the sessions.

Contrafreeloading is said to occur when responding is maintained in the presence of the identical and continuously available nominal reinforcers, and the proportion of alternative- to operant-food consumption favors the latter - that is, operant food is "preferred" over the alternative food. Although the alternative food was not continuously available in the present experiments, the procedure and results seem similar to those of contrafreeloading studies, because both operant and alternative food were concomitantly 
available, and pigeons "preferred" the operant over the alternative food when consumption of both food types was made difficult by increasing the distance between the food sources.

Among other variables, the history of reinforcement of the response that produces the operant food may contribute to contrafreeloading. For example, Jensen (1963) and Tarte and Snyder (1973) found a direct relation between the number of responsedependent food deliveries during baseline, and the magnitude of the contrafreeloading effect during the following condition. Similarly, the pigeons used in the present experiments had an extensive history of reinforcement of keypecking, both during the baseline of Experiments 1-4 and during the previous experiments to which they had been exposed. In addition to the reinforcement history, it has been argued that contrafreeloading is originated and maintained because the operant response produces not only food, but also stimulus changes (such as those that accompany the activation of the hopper) that function as conditioned reinforcers for this response (Osborne, 1977). In the present experiments, these stimulus changes accompanied the delivery of both operant and alternative food. Proprioceptive stimuli produced by keypecking, however, did not. By definition, such stimuli accompany only the responses that produce them. It is possible that these proprioceptive stimuli produced by keypecking functioned as conditioned reinforcers for the operant response ( $c f$. Dinsmoor, 2001), further increasing the likelihood of contrafreeloading in the present experiments.

\section{Choice}

In addition to the literature on contrafreeloading, the results of the present experiments also relate to studies on choice behavior that involve concurrent schedules of reinforcement. This is because a situation in which the operant and the alternative food are concurrently available but contingent on incompatible responses - such as keypecking and walking to the source of alternative food, when these sources are separated necessarily involves choice between the alternatives leading to the consumption of each food delivery. The variables that affect choice when the experimental procedure involves a concurrent schedule - i.e., when different responses and discriminative stimuli are correlated with each schedule - have been studied extensively in the operant behavior literature (e.g., Herrnstein, 1970; Madden, Smethells, Ewan, \& Hursh, 2007; Maguire, Hughes, \& Pitts, 2007; Margit Bak \& Pedersen, 2007; McSweeney, Swindell, \& Weatherly, 1996). Similarly to the results of the experiments comprising this study, the results of many studies on choice behavior have shown that the distribution of responses across the alternatives depends on the distribution of food across these alternatives. For example, when exposing pigeons to a concurrent FI VI schedule, Nevin (1971) found that most responding on the VI key occurred early in the FI interval. Lattal and Boyer (1980) also found that the distribution of responses on an FI schedule depended on the distribution of reinforcers delivered from an alternative variable differentialreinforcement-of-other-behavior (DRO) schedule. The DRO schedule was similar to a VI schedule in which reinforcement was contingent on a pause greater or equal to the DRO schedule value. When the FI and the DRO schedules were in effect simultaneously, Lattal 
and Boyer found responding to be more linear within the FI with shorter required DRO pauses.

Studies that use the concurrent schedule procedure to study choice behavior usually involve systematic attempts to decrease the interaction between the components of concurrent schedules, by means of effecting a clear separation of the responses and stimuli correlated with each of the components and using changeover delays. These studies frequently have found approximate matching between the distribution of responses and reinforcers across the alternatives (Herrnstein, 1970; McDowell, 1989). Although a direct comparison between choice studies and the present study should be made with caution, because most choice studies use conc VI VI schedules, the results of the present experiments augment the experimental analysis of choice because they reveal how responding that is exposed to schedules that are in effect simultaneously are affected by parameters of the component schedules, when there is no clear separation between them in terms of responses and discriminative stimuli (during the 1-source conditions), and when different responses are required to consume the food arranged by each schedule, and different stimuli are associated with the delivery of each food type (during the 2-source conditions).

The results of the present experiments also may be discussed in terms of matching between the proportion of responses and reinforcers across alternatives. If the present experiments are conceptualized as a concurrent schedule in which two different responses - keypecking and orienting towards the alternative-food source (see, for example, Lattal \& Boyer, 1980) - produce the same reinforcer, there was no matching between the proportion of responses and reinforcers arranged by each schedule, when the operant and alternative schedules delivered food from a single source. When the baseline schedule was the VI 300-s and the FT 100-s schedule was simultaneously in effect, for example, the FT schedule delivered food three times more frequently than the VI schedule, but response rates did not systematically decrease relative to the baseline with the VI schedule only. As noted before, response rates only decreased systematically when the food sources were separated. It is possible that the separation of the food sources functioned as a variable that decreased the interaction between the schedules in effect and increased the likelihood that they would come to control different responses, making the arrangement more similar to a concurrent schedule and thereby increasing the likelihood of matching between response and reinforcement rates. It seems important to note, however, that even when the food sources were separated strict matching between response and reinforcement rates may not be expected because the responses correlated with each schedule were not equal (cf. Baum, 1974).

\section{Resistance to Change}

In addition to contrafreeloading and choice studies, some resistance-to-change studies share similarities with those like the present ones that investigated the effects of concomitant schedules. Resistance-to-change studies have used the exposure to identical reinforcement schedules, typically arranged as components of a multiple schedule and delivering reinforcers at different rates, delays, or magnitudes (e.g., Bell, 1999; Cohen, 
Riley, \& Wiegle, 1993; Nevin, 1974). After stable responding is achieved, the contingencies in effect are either directly or indirectly disrupted, and the effects of the disruption are analyzed. On the one hand, the direct disruption of responding involves indirectly changing the contingencies in effect during the components by, for example, changing the deprivation of the subjects. This has been done by feeding the animals before the sessions and by adding alternative food, delivered according to VT schedules, during a blackout separating the components. On the other hand, responding is said to be directly disrupted when the contingencies in effect during the components are directly changed by either removing the contingency (i.e., implementing extinction), or by adding another reinforcement schedule concomitantly to the components - usually a VT schedule. This latter procedure is, in fact, the procedure used in studies of the effects of combining operant and alternative food deliveries, because in both cases a schedule delivering alternative food is added to a baseline reinforcement schedule that delivers operant food. Studies of concomitant schedules thus complement the results of resistance to change studies. Specifically, when the resistance-to-change test consists of adding alternative food to the operant baseline schedule, responding is disrupted. The results of the present experiments indicate, in addition, that the specific changes in response rates and patterns are a function not only of the reinforcement-related variables manipulated (such as rate, magnitude, or delay), but also of the schedule parameters and of their separation. For example, Boakes, Halliday, and Poli (1975) found a large increase in response rates in the component of the multiple VI VI schedule to which a VT schedule was superimposed. It is possible that such increases were a function of changes in the local patterns of responding when the alternative-food schedule was added to the operant schedule baseline. Because Boakes et al. did not show measures of response patters, however, it is not possible to determine if this was the case. In fact, many resistance-tochange studies do not analyze changes in response patterns as a function of superimposing the alternative food. The implications of the present experiments to the resistance-to-change literature are that such patterns should be analyzed and the specific schedule parameters should be taken into consideration, to provide a more complete account of the changes produced when operant responding is disrupted by the concomitant alternative-food delivery.

\section{Temporal Control}

A final research area that is related to the present experiments is temporal control, defined as behavioral sensitivity to temporal properties of stimuli (Catania, 1991). Temporal control studies have used a variety of procedures, and have found that patterns of responding are many times a function of temporal aspects of the contingencies in effect, such as the interreinforcer intervals. For example, FI responding is said to be temporally controlled when the break-and-run (i.e., pause after the delivery of a reinforcer followed by an abrupt increase in responding, until the end of the interval) or the scallop pattern (i.e., progressive increase in responding throughout the interreiforcer intervals) emerges. The present experiments relate to temporal control studies because they investigated how the temporal arrangement of the alternative food controlled operant responding. An important difference between the procedures used in temporal control studies and the one of the present experiments, however, is that while in the case of the 
former responding is most frequently examined as a function of the direct manipulation of temporal variables (for example, length of the FI intervals - Higa \& Pierson, 1998), in the latter case responding was examined as a function of the indirect manipulation of the temporal variable. That is, in the present experiments, temporal control was demonstrated when VI or DRL responding changed as a function of the alternative interfood intervals for example, when a negatively accelerated VI pattern of responding was observed when an FT schedule was superimposed. The present experiments thus add to the temporal control literature by showing this indirect temporal control, especially when the sources of food were separated.

\section{Implications for Applied Research}

As noted in the literature review, behavior maintained by reinforcement contingencies is disrupted frequently by events that are not dependent on such behavior. These events frequently are similar in form to the ones that are delivered response dependently. For example, work maintained by access to money may be disrupted by the response-independent delivery of money (e.g., winning the lottery), and attentionmaintained responding may be disrupted by the delivery of response-independent attention. In the applied behavior analysis literature, it has been shown that delivering response-independent reinforcers (incorrectly labeled "noncontingent reinforcement" [Lattal \& Poling, 1981]) is an effective technique for reducing problem behavior. An extrapolation of this degrading of the response-reinforcer dependency has led to assessments of treatment integrity, which refers simply to the degree to which a treatment has been implemented as planned. As noted by St. Peter Pipkin (2007), treatment integrity is reduced when the reinforcers for appropriate behavior are delivered following problem behavior, which this author termed errors of commission. With such errors, problem behavior may not substantially decrease because it is followed by reinforcers, either accidentally or by design. By analogy, in the present experiments, if keypecking is conceptualized as the "problem behavior," errors of commission would consist of alternative-food deliveries following keypecking. In fact, consistent with the results of St. Peter Pipkin, key-peck rates typically were inversely related to the average obtained delays between the alternative-food deliveries and these food deliveries.

Although in most applied alternative-reinforcer studies the previously reinforced response is extinguished, other such studies have concomitantly delivered alternative and operant reinforcers, in a manner similar to the 1-source conditions used in the present experiments. For example, Hagopian et al. (2000) decreased problem behavior to nearzero levels when the same nominal reinforcer that maintained the problem behavior was delivered according to an FT schedule and superimposed on the FR-1 schedule that maintained the behavior during baseline. The authors argued that the reductions in problem behavior may have been a function of the availability of alternative sources of reinforcement. Specifically, engagement with the alternative tangible reinforcer remained high during the conditions with alternative reinforcers, and competed with the problem behavior that produced the same reinforcer. This interpretation is similar to the one offered herein, that is, keypecking was more likely to decrease when the operant and alternative schedules were likely to control different responses that compete with each 
other (the 2-source conditions). This interpretation, however, is limited by the fact that no applied studies have superimposed alternative reinforcers to a source other than that delivering the operant reinforcers, but suggest applied experiments to investigate the effects of the separation of reinforcement sources. In any case, together with Hagopian et al. and St. Peter Pipkin (2007), the present experiments suggest that whether responding will decrease when an alternative source of reinforcement is added depends on the manner in which the alternative and operant schedules interact. Specifically, changes in response rates seem to depend on the extent to which alternative reinforcers follow the operant or other response, and perhaps as one consequence of that, whether the operant and alternative schedules control different responses that are incompatible with one another (that is, responses that cannot be emitted at the same time). Methodologically, the results suggest that the most common index of behavior change in applied studies, the overall response rates, often are a function of patterns of responding. This suggests that applied research involving alternative reinforcers would be wise to consider that response patterns may be the wellspring of overall response rates, and thereby the more basic measure.

\section{Conclusions}

As Lattal and Abreu-Rodrigues observed, "[a]s living organisms move through time and space, they encounter a mixture of events, some that occur as a result of their actions and others that occur independently of those actions" (1997, p. 375). Behavior is thus considered as a stream that is a function of this mixture of events. The experiments comprising this study contribute to understanding some of the variables that determine the behavior stream - specifically, the degree to which reinforcing events are dependent on behavior, their temporal distribution, their interaction, and their separation. The effects of intruded events into a stream of behavior maintained by different contingencies of reinforcement have, as has been shown in the present experiments, broad implications for understanding operant behavior and its amelioration in applied settings. 


\section{References}

Baum, W. M. (1974). On two types of deviation from the matching law: Bias and Undermatching. Journal of the Experimental Analysis of Behavior, 22, 231-242.

Bell, M. C. (1999). Pavlovian contingencies and resistance to change in a multiple schedule. Journal of the Experimental Analysis of Behavior, 72, 81-96.

Boakes, R. A., Halliday, M. S., \& Poli, M. (1975). Response additivity: Effects of superimposing free reinforcement on a variable-interval baseline. Journal of the Experimental Analysis of Behavior, 23, 177-191.

Catania, A. C. (1991). Time as a variable in behavior analysis. In I. H. Iversen \& K. A. Lattal (Ed.), Experimental analysis of behavior, Part 1 (pp.1-19). New York: Elsevier Science.

Cohen, S. L., Riley, D. S., \& Weigle, P. A. (1993). Tests of behavior momentum in simple and multiple schedules with rats and pigeons. Journal of the Experimental Analysis of Behavior, 60, 255-291.

Deluty, M. Z. (1976). Excitatory and inhibitory effects of free reinforcers. Animal Learning and Behavior, 4, 436 - 440.

Dinsmoor, J. A. (2001). Stimuli inevitably generated by behavior that avoids electric shock are inherently reinforcing. Journal of the Experimental Analysis of Behavior, 75, 311-333.

Findley, J. D. (1958). Preference and switching under concurrent scheduling. Journal of the Experimental Analysis of Behavior, 1, 123-144.

Fleshler, M., \& Hoffman, H. S. (1962). A progression for generating variable-interval schedules. Journal of the Experimental Analysis of Behavior, 5, 529-530.

Hagopian, L. P., Crockett, J. L., van Stone, M., DeLeon, I. G., \& Bowman, L. G. (2000). Effects of noncontingent reinforcement on problem behavior and stimulus engagement: The role of satiation, extinction, and alternative reinforcement. Journal of Applied Behavior Analysis, 33, 433-449.

Herrnstein, R. J. (1970). On the law of effect. Journal of the Experimental Analysis of Behavior, 13, 143-266.

Higa, J., \& Pierson, D. (1998). Temporal control in rats: Analysis of nonlocalized effects from short interfood intervals. Journal of the Experimental Analysis of Behavior, 70, 35-43.

Imam, A. A., \& Lattal, K. A. (1992). A suggestion for describing combinations of response-dependent and response-independent events. The Behavior Analyst, 15, 179-182.

Inglis, I. R., Forkman, B., \& Lazarus, J. (1997). Free food or earned food? A review and fuzzy model of contrafreeloading. Animal Behaviour, 53, 1171-1191.

Jensen, G. D. (1963). Preference for bar pressing over "freeloading” as a function of number of rewarded presses. Journal of Experimental Psychology, 65, 451-454.

Lattal, K. A. (1972). Response-reinforcer independence and conventional extinction after fixed-interval and variable-interval schedules. Journal of the Experimental Analysis of Behavior, 18, 133-140.

Lattal, K. A. (1974). Combinations of response-reinforcer dependence and independence. Journal of the Experimental Analysis of Behavior, 22, 357-362. 
Lattal, K., A., \& Abreu-Rodrigues, J. (1997). Response-independent events in the behavior stream. Journal of the Experimental Analysis of Behavior, 68, 375-398.

Lattal, K. A., \& Boyer, S. S. (1980). Alternative reinforcement effects on fixed-interval performance. Journal of the Experimental Analysis of Behavior, 34, 285-296.

Lattal, K. A., \& Bryan, A. J. (1976). Effects of concurrent response-independent reinforcement on fixed-interval schedule performance. Journal of the Experimental Analysis of Behavior, 26, 495-504.

Lattal, K. A., \& Maxey, G. C. (1971). Reductions in DRL responding following removal of the response-reinforcer dependency. Psychological Reports, 29, 1095-1099.D.

Lattal, K. A., \& Poling, A. D. (1981). Describing response-independent events: Babel revisited. The Behavior Analyst, 4, 143-152.

Lund, C. A (1976). Effects of variations in the temporal distribution of reinforcement on interval schedule performance. Journal of the Experimental Analysis of Behavior, 26, 155-164.

Madden, G. J., Smethells, J. R., Ewan, E. E., \& Hursh, S. R. (2007). Tests of behavioraleconomic assessments of relative reinforcer efficacy II: Economic complements. Journal of the Experimental Analysis of Behavior, 88, 355-367.

Maguire, D. R., Hughes, C. E., \& Pitts, R. C. (2007). Rapid acquisition of preference in concurrent schedules. Behavioural Processes, 75, 213-219.

Margit Bak, J., \& Pedersen, L. J. (2007). The value assigned to six different rooting materials by growing pigs. Applied Animal Behaviour Science, 108, 31-44.

McDowell, J. J. (1989). Two modern developments in matching theory. The Behavior Analyst, 12, 153-166

McSweeney, F. K., Swindell, S., \& Weatherly, J. N. (1996). Within-session changes in responding during concurrent schedules with different reinforcers in the components. Journal of the Experimental Analysis of Behavior, 66, 369-390.

Nevin, J. A. (1971). Rates and patterns of responding with concurrent fixed-interval and variable-interval reinforcement. Journal of the Experimental Analysis of Behavior, 16, 241-247.

Nevin, J. A. (1974). Response strength in multiple schedules. Journal of the Experimental Analysis of Behavior, 21, 389-408.

Nevin, J. A. (1984). Pavlovian determiners of behavioral momentum. Animal Learning and Behavior, 12, 363-370.

Nevin, J. A., Tota, M. E., Torquato, R. D., \& Shull, R. L. (1990). Alternative reinforcement increases resistance to change: Pavlovian or operant contingencies? Journal of the Experimental Analysis of Behavior, 53, 359-379.

Osborne, S. R. (1977). The free food (contrafreeloading) phenomenon: A review and Analysis. Animal Learning and Behavior, 5, 221-235.

Shull, R. L., Gaynor, S. T., \& Grimes, J. A. (2002). Response rates viewed as engagement bouts: Resistance to Extinction. Journal of the Experimental Analysis of Behavior, 77, 211-231.

St. Peter Pipkin, C. C. (2007). A laboratory investigation of the effects of treatment integrity failures on differential reinforcement procedures (Doctoral dissertation, University of Florida, 2007). Dissertation Abstracts International, 67, 4696. 
Tarte, R. D., \& Snyder, R. L. (1973). Some sources of variation in the bar pressing versus freeloading phenomenon in rats. Journal of Comparative and Physiological Psychology, 84, 128-133.

Uhl, C. N., \& Garcia, E. E. (1969). Comparison of omission with extinction in response elimination in rats. Journal of Comparative and Physiological Psychology, 69, 551-562.

Williams, B. A. (1989). The effects of response contingency and reinforcement identity on response suppression by alternative reinforcement. Learning and Motivation, 20, 204-224.

Zeiler, M. D. (1968). Fixed and variable schedules of response independent reinforcement. Journal of the Experimental Analysis of Behavior, 11, 405-414.

Zeiler, M. D. (1977). Elimination of reinforced behavior: Intermittent schedules of notresponding. Journal of the Experimental Analysis of Behavior, 25, 23-32. 